\title{
Reframing development?
}

Human trafficking prevention in Thailand and Cambodia

by

Jennifer Margaret Cameron, B.A. (Hons.)

A thesis submitted to

The Faculty of Graduate Studies and Research in partial fulfilment of the requirements for the degree of

Master of Arts

The Norman Paterson School of International Affairs

Carleton University

Ottawa, Ontario

December, 2004

@2004, JMC 


$\begin{array}{ll}\begin{array}{l}\text { Library and } \\ \text { Archives Canada }\end{array} & \begin{array}{l}\text { Bibliothèque et } \\ \text { Archives Canada }\end{array} \\ \begin{array}{l}\text { Published Heritage } \\ \text { Branch }\end{array} & \begin{array}{l}\text { Direction du } \\ \text { Patrimoine de l'édition }\end{array} \\ \begin{array}{l}\text { 395 Wellington Street } \\ \text { Ottawa ON K1A ON4 } \\ \text { Canada }\end{array} & \begin{array}{l}\text { 395, rue Wellington } \\ \text { Ottawa ON K1A ON4 } \\ \text { Canada }\end{array}\end{array}$

Your file Votre référence ISBN: 0-494-00716-8

Our file Notre référence

ISBN: 0-494-00716-8

NOTICE:

The author has granted a nonexclusive license allowing Library and Archives Canada to reproduce, publish, archive, preserve, conserve, communicate to the public by telecommunication or on the Internet, loan, distribute and sell theses worldwide, for commercial or noncommercial purposes, in microform, paper, electronic and/or any other formats.

The author retains copyright ownership and moral rights in this thesis. Neither the thesis nor substantial extracts from it may be printed or otherwise reproduced without the author's permission.
AVIS:

L'auteur a accordé une licence non exclusive permettant à la Bibliothèque et Archives Canada de reproduire, publier, archiver, sauvegarder, conserver, transmettre au public par télécommunication ou par l'Internet, prêter, distribuer et vendre des thèses partout dans le monde, à des fins commerciales ou autres, sur support microforme, papier, électronique et/ou autres formats.

L'auteur conserve la propriété du droit d'auteur et des droits moraux qui protège cette thèse. $\mathrm{Ni}$ la thèse ni des extraits substantiels de celle-ci ne doivent être imprimés ou autrement reproduits sans son autorisation.
In compliance with the Canadian

Privacy Act some supporting forms may have been removed from this thesis.

While these forms may be included in the document page count, their removal does not represent any loss of content from the thesis.
Conformément à la loi canadienne sur la protection de la vie privée, quelques formulaires secondaires ont été enlevés de cette thèse.

Bien que ces formulaires aient inclus dans la pagination, il n'y aura aucun contenu manquant. 


\begin{abstract}
Human trafficking has great potential to raise concerns, funds and border control measures. Using interview-based primary research, I examine seven Cambodian and Thai NGOs' and international organisations' (IOs) human trafficking prevention work, asking whether these projects fit with criticisms of co-option through donor funding or an anti-migration framework. Theory suggests substantial opportunity for both. However, my analysis of the seven NGOs and IOs shows that these organisations "frame" their agendas in ways that are likely to mobilise donor resources, rather than changing their agendas to match those of the donor community. These organisations are aligning new anti-trafficking language and objectives (including those set out in the 2000 UN Protocol to Prevent, Suppress and Punish Trafficking in Persons) with their previous and on-going work, target groups and priorities. Furthermore, both NGOs and IOs were critical of donor and/or national policy, including migration policy and the UN Trafficking Protocol.
\end{abstract}




\section{Acknowledgements}

I would like to thank CIDA and those associated with the Bill McWhinney Memorial Scholarship and Travel Grant, which allowed me to conduct primary research and pursue this thesis project. I am also grateful to Franc R. Joubin and the family of Marion Selig as well as the Ontario Graduate Scholars Fund, whose support enabled my return to school.

Thanks also to the twenty-two development professionals in Thailand and Cambodia who agreed to be interviewed and included in my study. Nwe-Nwe Aye of Save the Children United Kingdom (SC UK); Hang Vannak and Phil Marshall of the United Nations Inter-Agency Project to Combat Human Trafficking (UN-IAP); Sompop Jakantra of the Development and Education Project for Daughters and Communities (DEPDC); Prungchit Phanawathanawong, Khleang Rim and Hans van de Glind of the International Labour Organisation Mekong Subregional Project to Combat Trafficking in Children and Women (ILO-TICW); Nopsarin Sreyroth of the Cambodian Women's Crisis Centre (CWCC); Ros Sokham of the Cambodian Migration and Development Committee (CMDC); Parisuda (Moo) Sudhamongkala of Mirror Art Group (MAG); Kannika (Jeng) Angsuthanasombat of Asian Research Centre for Migration (ARCM), Institute of Asian Studies, Chulongkorn University; Janet Ashby of Asia Regional Cooperation to Prevent People Trafficking (ARCPPT); Alec Bamford of CUSO Thailand; Thongkorn Hironraks and Nipa Banerjee of the Canadian International Development Agency (CIDA); Tom Beloe of the Department for International Development United Kingdom (DFID); Varaporn Intharat and Kelly O'Brien of Empower Chiang Mai; Bundit Panwaviseth of Friends of Women Foundation (FOW); Naly Pillorge of Ligue de defense cambodgienne aux droits des homme (LICADHO); Sary Moni of International Organisation for Migration (IOM); Siriporn Skrobanek of Foundation for Women (FFW); and Tassanee Srimongkol of Planned Parenthood Association of Thailand (PPAT) Nortbern Project. They gave me access to an extraordinary breadth of insights, information and resources about their organisations and anti-trafficking work in the sub-region.

I would also like to thank the advisory committee, Professors Daiva Stasiulis and Dane Rowlands and the external examiner, Prof. Doris Buss, as well as Prof. Jean Daudelin, Vivian Cummins, Cindy Halden and Brenda Sutherland for their guidance and assistance.

Finally, I would like to thank my mentors, friends and family who have supported, challenged and assisted me throughout. 


\section{Table of Contents}

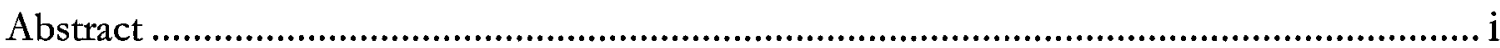

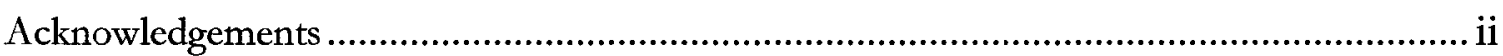

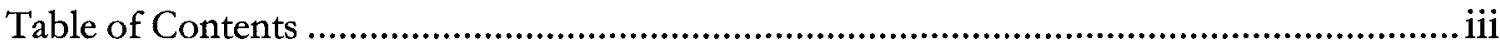

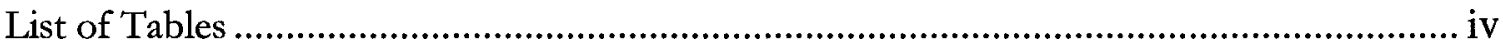

CHAPTER 1: Introduction: Preventing harms, accessing funds ................................... 1

CHAPTER 2: Trafficking definitions and destinations ............................................. 9

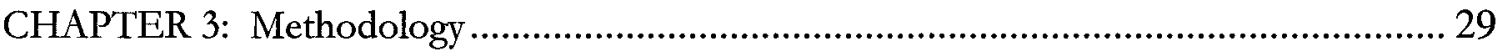

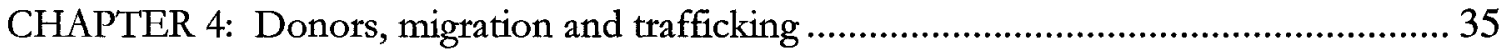

CHAPTER 5: NGOs and donors: Co-optation or framing? .......................................... 44

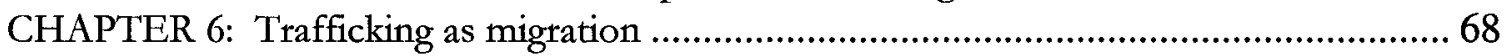

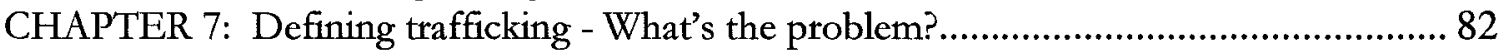

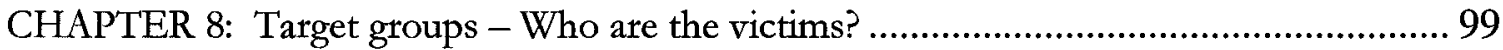

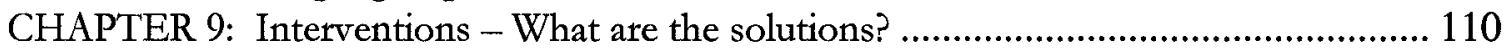

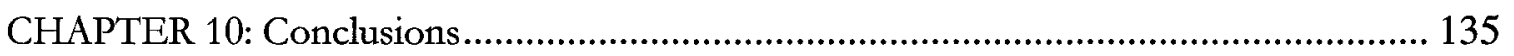

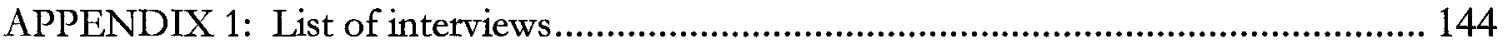

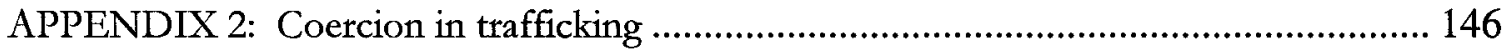

APPENDIX 3: Application to Research Ethics Board .............................................. 147

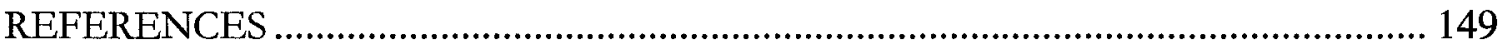




\section{List of Tables}

Table 1: UN Trafficking Protocol Definition (Article 3) (2000)............................................10

Table 2: Trafficking in Cambodia (as cited in Global March 2000) ........................................23

Table 3: Trafficking in Thailand (as cited in Global March 2000) ...........................................26

Table 4: Trafficking Prevention Projects of NGOs and IOs .................................................30

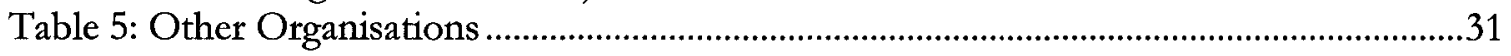

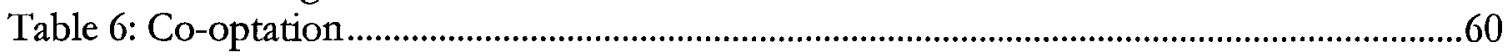

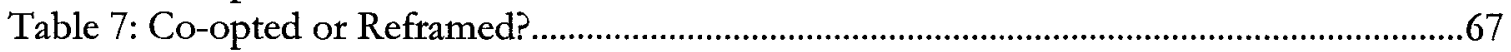

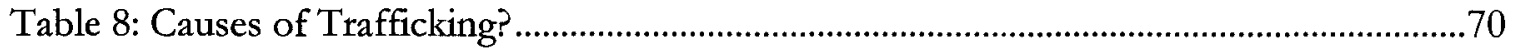

Table 9: Typology of trafficking prevention interventions ............................................................73

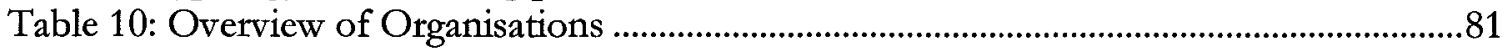

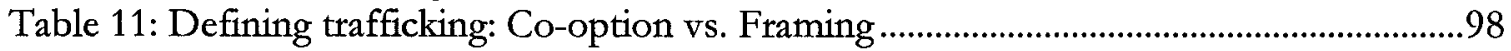

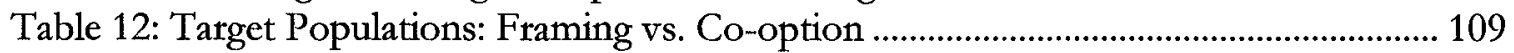

Table 13: Prevention, cooperation and other measures (Article 9 UN Protocol) ................ 110

Table 14: Expanding Local Opportunities ................................................................................ 128

Table 15: Interventions: Framing vs. Co-option ................................................................. 134 
The issue of female labour migration, of which trafficking is a significant sub-issue, has to be seen as a product of existing power relations between genders, between classes and between states at different ends of the bierarchically organized global system. Restrictive migration policies in an otherwise fairly deregulated world in which advanced and less advanced countries are closely tied together by political and economic links exacerbate migrant workers' opposition in general and women's specifically

(Piper and Ublin 2002, 189). 


\section{CHAPTER 1: Introduction: Preventing harms, accessing funds}

I observe since September 2003 international organization specialized in agriculture coming to trafficking issues. We know that the subject is very "sexy" and can earn billions of dollars. But please do not denature trafficking to a marketing object, because victims will suffer much more (Legros 2004).

People migrate to gain economic opportunities, escape social or political strife and environmental devastation, hoping for something better for themselves or their families. Nobody hopes to be trafficked. Perversely, it is often those with the greatest need and desire to migrate that have the fewest legitimate means, and so are most vulnerable to being trafficked. In recent years, human trafficking has received growing attention from the media, governments and community development projects. Yet, alongside the accolades and approval for these responses, there have also been criticisms and concern: first, that antitrafficking agendas may reflect restrictive migration policies; and second, where implemented by non-governmental organisations (NGOs), that they may be examples of opportunism, reflecting donor-country agendas in order to access funding.

I examine these concerns by comparing and analysing interview-based information from donor-funded trafficking prevention projects of international organisations (IOs) and NGOs in Thailand and Cambodia. From June to August 2003, I interviewed representatives of 17 organisations doing anti-trafficking work in Thailand and Cambodia, and I focus my analysis on the seven of them that work specifically on trafficking prevention in sending areas. These include two Cambodian NGOs: the Cambodian Women's Crisis Centre (CWCC) and the Cambodian Migration and Development Committee (CMDC); two Thai NGOs: the Mirror Art Group (MAG) and the Development and Education Project for Daughters and Communities (DEPDC); one international NGO: Save the Children UK (SC UK); and two IOs: the International Labour Organisation (ILO) and the United Nations (UN). My analysis suggests that despite economic reliance on donors, these organisations' 
potential congruence with donor policy is not profound. Though sensitive to donor preferences, organisations are not co-opting themselves to gain donor funds. Rather they are strategically framing projects that are consistent with their organisational identities and broader work agendas as trafficking prevention projects that are congruent with funding availability. Though I initially considered IO projects a suitable baseline indicating donor policy, both NGOs and IOs proved critical of donor approaches to trafficking prevention, demonstrating significant independence from and criticism of donor positions. Surprisingly, it was an IO that produced and encouraged the most extreme criticisms of mainstream responses to trafficking.

Trafficking as a development issue, the field in which I work, first came to my attention in 2000. I was in Laos, neighbour of Thailand and Cambodia, doing a child labour research project. Some of the girls I interviewed described situations and fears that I later was able to label as trafficking, which the United Nations Protocol to Prevent, Suppress and Punish Trafficking in Persons, Especially Women and Children defines as the movement, receipt or holding of a person by force, deception or abuse of power for the purposes of exploitation, including but not limited to sexual servitude, bonded labour, and the extraction of organs (2000). From that time, I observed a steady increase in awareness of human trafficking as a development issue, and of development projects dedicated to its combat and suppression. Even a sustainable agriculture NGO started an anti-trafficking project! Trafficking includes a collection of heinous abuses of human rights, some of which I heard from the mouths of young victims themselves, yet I was reluctant to see these new projects as a great step forward.

This reluctance was at least in part due to my knowledge that many of these projects were both new and donor-funded. As such they were potentially driven by an interest in 
harnessing donor resources rather than by the needs of the communities they serve. NGOs working in development are frequently understood in terms of their "close proximity to poor and vulnerable target groups" and their responsiveness to the communities with which they work (UNDP 1988, art. 7). Donor funding causes concerns about "the potential cost to NGOs of implementing official donor agendas" (Pearce 2000), and the risk that "NGOs feel more accountable to their official donors than to their intended beneficiaries" (Edwards and Hulme in Pearce 2000). Both in general and in the case of trafficking, one might reasonably expect donor policy to be consistent with donor country interests and priorities, and projects funded under their auspices to be furthering them. Donor agendas and funding priorities are not necessarily inconsistent with particular NGO or community priorities. However, there is scope for conflicts of interest in matters of trafficking and migration. Donor countries tend to be migrant-receiving, currently favouring restrictive migration policies (Pedersen, Pytlikova and Smith 2004, 22), while the majority of organisations in my study understand trafficking as in part due to a lack of safe, accessible, legal migration opportunities (Marshall 2003, Jakantra 2003, Rim 2003, van de Glind 2003, Aye 2003, Ros 2003).

Trafficking, even in definition, is a very contentious issue. Chapter two, focuses on trafficking first conceptually, looking at definitions and debates, then in the concrete, describing what is known about trafficking routes and destinations in Cambodia and Thailand. I begin by discussing the UN Trafficking Protocol definition and some points of conceptual disagreement and suggest that trafficking can be understood as at least in part a result of restrictive migration regimes. It also provides evidence that in Cambodia and Thailand, where my study focuses, trafficking is generally understood as beginning with migration. This chapter highlights my concerns about overlap between trafficking and 
migration. Chapter three discusses my methodology and further introduces the organisations that I focus on in my analysis.

In chapter four I present evidence suggesting that donor policy on trafficking in part reflects donor-country preferences and efforts to restrict migration. In particular, donor policies and positions do not favour the expansion of migration regimes (or migrant rights, particularly for undocumented migrants) in general or as a way to reducing trafficking and the harms associated with trafficking. These policies and preferences of donor countries represent a political opportunity structure for organisations like NGOs who rely on them for funding. As Atmar and Goodhand suggest, "Aid cannot be viewed in isolation from the wider foreign policy objectives of donor governments" (2001).

Theorists and activists raise concerns about donor funding, suggesting that with donor dollars come donor agendas. In chapter five, I summarise some of these concerns, highlighting six particular points as raised by Korten and Quizon (1995). The influence of donors on the organisations they fund can be understood as ranging from negligible to profound. For my analysis, I narrow this range to two possibilities. First, following “...numerous references in the nonprofit and NGO literature (e.g., Grombjerg, 1993; Smillie, 1995; Smith and Lipsky, 1993) to the dangers of state funding in bringing about cooption, distortion and even corruption of the NGO..." (Themudo, 2002), that the influence can be described as co-opting. ${ }^{1}$ On a scale ranging from complete autonomy to a complete lack thereof, co-optation signifies an influence that is more profound, where organisations both

\footnotetext{
1 Themudo also suggests that, "NGOs receiving state funding are often less able to pursue their mission because of attached demands and conditions" and that "co-optation and loss of independence" are concerns. Igoe suggests that through official funding "NGO leaders have become less accountable to their constituent communities" and "energies have been diverted into activities that can be justified in donor funding reports" $(2203,863)$. This has also been raised at the UN Non-Governenmental Liaison Service's 20th Anniversary Conference on The UN, where participants brought forward the criticism that "Official aid can severely distort the work of the NGO community and several examples of NGO co-option were described" (UN NGLS 1995; also see Pearce 1997; Korten and Quizon 1995; Hulme and Edwards 1997; Bebbington and Riddell, 1997).
} 
discursively and substantively reflect donor positions in their projects. Second, following insights about frame alignment from social movement theory, the influence is deemed to be more superficial whereby organisations discursively frame their work in terms that appeal to donors. Both provide an explanation of how organisations access donor resources and have different interpretations of the degree to which they accommodate or adopt donor positions in order to do so. I conclude chapter five by ascribing indicators for "co-optation" and "framing" to each of Korten and Quizon's six concerns. These indicators and points form the basis for my analysis and conclusions about the projects and organisations in my study (chapters seven through nine).

Chapter six returns to the issue of trafficking itself, this time as a subset of migration, presenting different theoretical ideas about migration and their insights for the design of anti-trafficking projects and interventions. This chapter includes general ideas about migration, how trafficking fits in with migration, and what sorts of areas for intervention might be conceptualised a priori to change and improve outcomes for migrants and trafficking victims.

Chapter seven is the first of three chapters applying these concepts and indicators to the organisations included in my study. In chapter seven, I compare how the seven organisations I focus on define trafficking. I find that though they all officially accept the Trafficking Protocol definition, each does so in ways that link aspects of it to their particular development priorities, bridging their organisational agendas to trafficking. I also find that all engage in some form of criticism or advocacy, either internationally or nationally, that challenges dominant approaches (either donor or national policy) to trafficking or migration. Neither tendency is well accounted for by co-optation's more profound understanding of donor influence, assuming that organisations distort and change their agendas to access 
donor funds, depoliticising or silencing dissenting opinions. Chapter eight focuses on the target groups and intended beneficiaries of the trafficking prevention projects. I find a nearuniversal focus on women and children that is consistent with the Trafficking Protocol, donor policies as well as with the broader organisational focus of the NGOs and IOs in my study. As such, both co-optation and framing can reasonably account for this tendency. Chapter nine examines the sorts of interventions and activities that organisations engage in to "prevent" trafficking, finding that beyond some lobbying and certain human-capital building activities, these are largely not trafficking-specific activities. Rather, they are development interventions that are framed, presented and understood in terms of antitrafficking goals or potential outcomes. Despite donor funding, each project is consistent with the organisational frame, priorities and other work of the NGO or IO implementing it. Furthermore, both NGOs and IOs engage in advocacy and take positions that challenge mainstream positions associated with donors. This suggests that donor funding does not preclude independence from, or criticisms of, donor positions and that framing rather than cooptation better explains how organisations engage with donors. I conclude with a summary of my findings and some indications for policy and future research.

\section{Definitions}

Throughout, I deal with three sets of interests, those of donors, IOs and NGOs. By donor I mean countries, such as those in the Organisation for Economic Co-operation and Development's Development Co-operation Directorate (OECD-DAC), that are the wealthier nations of the world. They are the major sources of development assistance funding, which they distribute either bilaterally, through the official development assistance agencies of government (e.g. donor agencies like DFID, AusAID, USAID and CIDA) or through contributions to multilateral organisations (e.g. the World Bank, the UN). In terms 
of migration, these same countries tend to be receiving (or destination) rather than sending (or origin) nations of poorer, lower skilled or undocumented migrants including trafficking victims. As chapter four details, they tend to have restrictive migration policies and regimes that limit the official entry and stay of these and other potential migrants, and are reluctant to extend rights to or otherwise "reward" undocumented migrants (see, for example, Downer 2004). Donor policy represents a political opportunity structure for organisations, as donor countries are the main source of funding and resources for the organisations in my study.

By international organisations (IOS) I mean organisations whose members are states. IOs may be assumed to be closely aligned with donor policy, representing a baseline of donor policy in action. Their projects are expected to implement and be developed from that policy: "International institutions are created by states, supported by states, and beyond a certain level of tolerance - serve the interests of states" (Tarrow n.d., 21). They are expected to be relatively vertical and rigid in structure and ways of working; funded by, directed by, and reporting to donors as part of their mandate and identity.

Non-governmental organisations (NGOs) are distinct from government organisations (GOs) because they are formed by and part of civil society. ${ }^{2}$ They are distinct from private sector organisations (i.e. businesses, corporations) because they do not share the goal of profit-making. For my work, I focus only on those NGOs that have goals and work agendas related to development in general, and sending area trafficking prevention in particular. International NGOs (INGOs) are organisations which have origins and a base in one

${ }^{2}$ The "non-governmental organisation" was recognised in Article 71 of the UN Charter (1947). UN Economic and Social Council (ECOSOC) Resolution 288(X) (1950) defines international NGOs (INGOs) as "Any International Organization which is not established by International Governmental Agreements shall be considered an International Non-Governmental Organization." By extension, NGOs at the national level are not established by national government agreements. This establishes the NGOs as a priori distinct from intergovernmental international organisations (IOs) such as the UN organisations on the basis of their membership while recognising them as both domestic and international actors. 
country (e.g. the UK) but work in other countries (e.g. Thailand and Cambodia). Save the Children UK is the only international NGO included in my study. The other four NGOs in my study are national, meaning that they are based in and work in the same country. In general, I expect NGOs to be closely aligned with their intended beneficiaries and motivated by a desire to empower and assist these communities. As such, they may take positions or work in ways that are not consistent with or do not reflect donor policy and practices. By definition, NGOs are distinct from IOs in terms of membership, and by expectation in terms of norms and structure.

I classify areas or countries as sending when they are where migrants and/or trafficking victims are from or leaving from; transit for those through which migrants and/or trafficking victims pass en route to a third, fourth, or other destination; and receiving when they are recipients of or a destination for flows of migrants and trafficking victims. None of these categories is mutually exclusive. For example, in addition to ongoing internal trafficking and migration, Cambodia and Thailand are sending, receiving and transit countries for migration and trafficking in the sub-region, and Thailand is a significant transit and sending country to countries beyond the sub-region.

Trafficked men, women and children are amongst the most marginalised and disenfranchised populations in the world today. Frequently classified as "criminal" due to their lack of legitimate migration status in the eyes of the law, they have little, if any, way to escape these conditions or to demand compensation for their work, let alone the violations against their bodies, minds and rights. In the next chapter, I focus on trafficking itself, first looking at the UN Trafficking Protocol (2000), examining how trafficking has been defined by the international community, then describing trafficking routes and victims in Thailand and Cambodia. 


\section{CHAPTER 2: Trafficking definitions and destinations}

The UN Trafficking Protocol, which came into force on December 25, 2003, answered repeated calls from activists, policy makers and others for a common definition. It did not, however, please them all. In the first section of this chapter, I present some perspectives on trafficking both in definition and in terms of how it is related to migration. In the final section, I look at trafficking in the concrete, reviewing what is known about trafficking in Cambodia and Thailand, where my study focuses.

\section{Defining Trafficking}

The UN Trafficking Protocol provides a three-part definition of trafficking (see table one, below), which Matthew Friedman of the US Agency for International Development (USAID) summarises as involving the movement and trade or sale of persons, a technique of doing so (i.e. deception, fraud, violence), and a purpose for that movement (labour, servitude) (Population Council 2001, 14). Like previous international instruments addressing trafficking, ${ }^{3}$ the protocol emphasises the sex trade as a destination sector ${ }^{4}$ and women and children as its victims.

\footnotetext{
3 Precedent legal instruments include: the 1904 International Agreement for the Suppression of the White Slave Trade; the 1910 International Convention for the Suppression of the White Slave Traffic; the League of Nation's Mandate; the 1921 Convention for the Suppression of the Traffic in Women and Children; the 1933 International Convention for the Suppression of the Traffic in Women of Full Age; the 1949 UN Convention for the Suppression of the Traffic in Persons and the Exploitation of the Prostitution of Others. The UN Special Rapporteur on Violence Against Women suggests that these instruments share concerns about the sex trade mixed with concerns about female migration and independence $(2000,10)$

${ }^{4}$ There are two strongly opposing interpretations of the nexus of the sex trade (particularly migrant sex workers) with trafficking. Organisations such as the Coalitions Against the Traffic of Women (CATW) see all sex work as non-consensual and therefore trafficking, while others like the Global Alliance Against Trafficking of Women (GAATW) favour responding to the abuses currently associated with the sex trade by decriminalising, regulating and extending the protective and responsive mechanisms of the law, such as labour codes, to those working in the sex trade. This is similar to the argument that the abuses migrant domestic workers face, for example, could be at least in part mitigated by extension of regulation and workers' rights to private households as places of employment (see, for example, Stasiulis and Bakan 2003, 107). While many women and children are subject to the means set out in subparagraph 3(a) of the trafficking protocol for commercial sexual exploitation, it is the method and means, not the sector of employment, that defines this as trafficking (Sanghera, 1998; Jordan 2002, 8). Even so, the role of the sex trade in trafficking remains prominent and is recognised in the protocol as a sector of particular concern.
} 


\section{Table 1: UN Trafficking Protocol Definition (Article 3) (2000)}

(a) "Trafficking in persons" shall mean the recruitment, transportation, transfer, harbouring or receipt of persons, by means of threat or use of force or other forms of coercion, of abduction, of fraud of deception, of the abuse of power or of a position of vulnerability or of the giving or receiving of payments or benefits to achieve the consent of a person having control over another person, for the purpose of exploitation. Exploitation shall include, at a minimum, the exploitation of the prostitution of others or other forms of sexual exploitation, forced labour or services, slavery or practices similar to slavery, servitude or the removal of organs;

(b) The consent of a victim of trafficking in persons to the intended exploitation set forth in subparagraph (a) of this article shall be irrelevant where any of the means set forth in subparagraph (a) have been used;

(c) The rectuitment, transportation, transfer, harbouring or receipt of a child for the purpose of exploitation shall be considered "trafficking in persons" even if this does not involve any of the means set forth in subparagraph (a) of this article'

(d) "Child" shall mean any person under eighteen years of age.

The Trafficking Protocol grew out of the UN Office on Drugs and Crime and is attached to the Convention on Transnational Organized Crime. It primarily focuses on trafficking as it relates to organised crime. The definition provides criteria for identifying those who have engaged in the criminal activity of trafficking (i.e. "recruitment, transportation, transfer, harbouring or receipt of persons") and is intended to facilitate the identification and prosecution of these traffickers. As Sullivan points out, these definitions of crimes and criminals also define their victims $(2003,68)$.

I understand trafficking across international borders as involving two key sets of violations (by definition, internal trafficking only involves the second, as follows): first, the possible violation of state sovereignty and/or laws, particularly by the unsanctioned entry of individuals (i.e. trafficking victims); second, the violation of the human rights of victims by their traffickers, employers (or owners) and customers (or consumers) ${ }^{5}$ (Piper and Iredale 2002). These violations are not unique to trafficking. State sovereignty is also violated by irregular, unsanctioned or illegal migrants; and these same irregular migrants may be subject to violations. The 'Trafficking Protocol's organised crime approach can be consistent with responses to both, and neither is necessarily inconsistent with donor (i.e. donor states) or

\footnotetext{
5 "Employer" and "customer" do not seem appropriate terms for such exploitative relations.
} 
NGO positions. However, it would be inconsistent for states to be indifferent to violations of state sovereignty and/or laws. As Saskia Sassen suggests, "Immigration policy is deeply embedded in the question of state sovereignty" $(1999,178)$. It would also be inconsistent for NGOs, understood to "share the common goal of helping people and benefiting society" (ADB 1995, 2), to be indifferent to abuses or violations suffered by these populations.

In the following paragraphs I present some perspectives on the Trafficking Protocol that suggest a tension between responses to violations of state sovereignty and violations of human rights. First, I suggest that the human rights provisions in trafficking protocol are weak. 'This is indicated, for example, by the discretionary language around protection and assistance for trafficking victims. Second, I consider what some theorists consider a "focus on movement," and the possibility that "protecting from trafficking" may include protecting vulnerable populations from their right to move (Jordan 2002, 31). Finally, I consider the inclusion of consent in the definition, suggesting that it plays an ambiguous role in distinguishing trafficking victims from smuggled or other illegal migrants.

Human rights and migrant rights advocates along with organisations such as UNICEF, the International Organisation for Migration (IOM) and the Office of the High Commissioner on Human Rights (OHCHR) resisted what they saw as a subversion of human rights considerations during the negotiations of the UN Trafficking Protocol. ${ }^{6}$ Their advocacy, formally presented in an inter-agency statement and an informal note by the UN High Commissioner on Human Rights (HCHR) had some influence on the final text:

\footnotetext{
${ }^{6}$ In 1998, following recommendations of the Commission on Crime Prevention and Criminal Justice and the Economic and Social Council (ECOSOC), the UN General Assembly (UNGA) established an ad hoc committee to elaborate a convention against transnational organised crime. From January 1999 through October 2000, 11 sessions were held. Participants included over 120 countries and a number of international non-governmental organizations (NGOs) and humanitarian organisations. These organisations played a key role in deliberations on the Trafficking Protocol (Raymond, 2002: 491-2).
} 
The inter-agency statement contained specific recommendations for strengthening the draft text of the two instruments by enhancing protection provisions and ensuring adequate and appropriate links to existing international human rights instruments and standards. Recommendations made by OHCHR and other international agencies are reflected to some extent in the final text of the instruments. (UN OHCHR 2001, 3)

Recommendations regarding the upholding of the human rights of migrants, particularly irregular migrants, as established by international human rights conventions and treaties, were not fully addressed by the final draft. There is some human rights language in the protocol. But, as Lin Chew points out, the protocol's emphasis on criminal prosecution still detracts from the rights of victims, protecting only those who serve as witnesses in criminal prosecution of their traffickers (in Population Council 2001, 14). Furthermore, the protocol contains language for mandatory enforcement for matters of trafficking-related offences, but only discretionary provision of protection assistance for victims (Reale 2003, 2). For example, article three of the protocol, "Criminalization", begins as follows: "Each State Party shall adopt such legislative and other measures as may be necessary to establish as criminal offences the conduct set forth in article three of this Protocol..." (UN ODC 2000). In section two, addressing the protection of victims, article six reads, "In appropriate cases and to the extent possible under its domestic law, each State Party shall protect the privacy and identity of victims of trafficking in persons..." and "Each State Party shall consider implementing measures to provide for the physical, psychological and social recovery of victims of trafficking in persons" (UN ODC 2000, emphasis added). This suggests that the protocol is more concerned with those who violate state sovereignty and human rights than with the provision or guarantee of these human rights. This is further supported by evidence that during negotiations, NGOs and activists along with governments of poorer migrant-sending countries lobbied for greater extension of rights to victims of both trafficking and smuggling, governments of wealthier migrant-receiving countries resisted: 
Generally, developed countries to which persons are often trafficked have taken the position that there should not be a right to remain in their countries as this would provide an incentive both for trafficking and illegal migration. Countries whose nationals were more likely to be trafficked wanted as much protection and legal status for trafficked persons as possible. (UNODC n.d.)

Some advocates and activists are also concerned with the protocol's emphasis on movement. For Friedman, emphasis on movement, coupled with ideas of prevention and rescue in transit, result in attempts to stop irregular migration rather than focus on human rights violations in receiving countries and work places (Population Council 2001, 14). Muireann O'Briain from ECPAT ${ }^{7}$ Bangkok states this criticism in stronger terms: there is a "hidden agenda of anti-trafficking," namely, the prevention of irregular migration (ibid., 16). A focus on movement may encourage further restrictions to the mobility of populations in sending areas, particularly those considered vulnerable to trafficking (i.e. women, children, the poor). This is a key concern for two reasons. First, these populations already have limited opportunities, particularly given the restrictive migration regimes favoured by many migrant-receiving states (see chapter four). Second, such restrictions may increase vulnerability to trafficking and reliance on criminal organisations:

Illegal migration takes place when there is a demand for migrant labour in host societies, a supply of willing migrants in home societies, and a lack of legal channels to link these demands and supplies. Oxfam - citing research by the Home Office - told us that there is strong circumstantial evidence that measures aimed at preventing access to the EU had "led to growing trafficking and illegal entry of both bona fide asylum seekers and economic migrants". (House of Commons International Development Committee 2004, 34)

For women in particular, these restrictions diminish their autonomy:

The Protocol should distinguish between adults, especially women, and children. It should also avoid adopting a patronizing stance that reduces women to the level of children, in the name of 'protecting' women. Such a

\footnotetext{
${ }^{7}$ End Child Prostitution, Child Pornography and Trafficking of Children for Sexual Purposes.
} 
stance historically has 'protected' women from the ability to exercise their rights. (Lem in Human Rights Caucus, 1999)

Over-reliance on legal mechanisms serves to compound the restrictions on movement and employment, particularly of younger women. An equation of women with children justifies this (ibid., 10-3), attempting to "protect" women from the decision to migrate, rather than empowering them to make informed migration decisions or access safer migration opportunities. Ann Jordan, Director of the Initiative Against Trafficking in Persons of the International Human Rights Law Group, also finds these problems:

Governments must not adopt any laws or measures that would prevent anyone, particularly women, from leaving the country for the purpose of 'protecting' them from being trafficked. Unfortunately, some governments have adopted policies or measures that, in effect, 'protect' young women out of their right to travel. $(2002,31)$

As the Human Rights Caucus lobbied during the drafting of the Trafficking Protocol, women must be respected as adults and encouraged to claim their rights, including their right to mobility. Not only would such "protection" infringe on rights, but it also predictably adds to reliance of potential migrants on underground, hidden, agent-assisted movement. As controls on movement are tighter and borders are made less porous, people rely more on migration experts, increasing risk and profits for smugglers and traffickers:

Detailed knowledge of the various immigration policies is the most valuable capital of 'travel' agencies aiding (legally or illegally) the migration process. Every decision by industrialized countries to make immigration more restrictive increases the profit margin for these agencies. (Harzig, 23)

Human trafficking is "the fastest growing source of profits for organized criminal enterprises worldwide" (US Department of Health and Human Services 2004). Estimates suggest transnational human trafficking and smuggling generate 10 billion US dollars annually (Dall'Oglio 2004). Higher profits attract more organised and professional (rather than cottage-industry) criminal involvement, while increased risk may drive away smaller-scale 
agents and preclude unassisted border crossings. Movement and border control efforts are both intended to decrease violations of state sovereignty and human rights. However, unless coupled with an opening of safer, legal migration opportunities for these same populations, these efforts may increase reliance on traffickers and smugglers and the potential incidence of human rights violations.

The final item I look at is the inclusion of consent in the protocol definition. When identifying those criminals engaged in trafficking and, by extension, their victims, the Trafficking Protocol does not just look at the crimes or harms that have been committed (and suffered). It also looks at the age or consent of the victim. According to the protocol, consent is irrelevant when the victim is a child. ${ }^{8}$ This implies that it is relevant for adults. ${ }^{9}$ So, crimes and abuses visited upon migrant workers are not considered trafficking if victims are over a certain age (i.e. 18) and have, in some way, consented. There is confusion about the role of consent in distinguishing trafficking from smuggling. For example, the US Department of Health and Human Services suggests, "Victims are coerced into trafficking. If victims do consent, that consent is rendered meaningless by the actions of the traffickers" (2004). Do conditions or consent distinguish trafficking from other forms of movement or abuses suffered by migrants? In July 2000, the Working Group on Contemporary Forms of Slavery stated that they were:

Deeply concerned at reports that the definition of "trafficking" contained in the present version of the draft protocol limits coverage of "trafficking" to those cases in which such activity is carried out through coercion without the "consent" of those who were trafficked, thus shifting the focus of the inquiry and the burden of proof from the actions of the accused to the state of mind of the complainant. (2000)

\footnotetext{
${ }^{8}$ Tumlin warns against classifying all child migration or labour as trafficking as it forms only part of the child migrant labour on construction sites, in small shops, factories or homes, and begging gangs (2000, 6-9). Even with children, trafficking may be considered to comprise only part of the larger phenomena of migrant labour, and trying to identify numbers of "trafficking victims" from within these broader migration patterns is difficult. ${ }^{9}$ Sub-paragraph (b) states that consent is irrelevant where the means set forth is sub-paragraph (a) are employed. Those means preclude or diminish the agency of the victim in choice-making.
} 
International law states that "no individual can consent to debt bondage or to being sold as chattel" (Human Rights Watch 2002, 43). Yet, consent remains in the Trafficking Protocol definition, and demonstrating or denying consent has become a significant issue. For example, advocates may carefully make the distinction that while individuals may have consented to migrate for work, they did not consent to the type of work, the working conditions or the terms (Intharat 2003; SC UK 2002, 7; Marshall 2003, van de Glind 2003; Jakantra 2003).

Applied solely to the movement of people, consent may be useful in distinguishing trafficking victims who are transported and held against their will from those who have in some way consented to move. Consent also plays a role when the sex trade is the destination sector for victims or migrants: "the Protocol makes an implicit distinction between 'coerced' and 'non-coerced' migration for prostitution" and this "leaves states free to recognise sex work as labour and regulate it under according to labour standards" (Doezema, 2002). As such, the inclusion of consent may be considered a victory for those fighting for sex workers rights. Yet the Trafficking Protocol "offers very little in terms of human rights protections for trafficking victims, and nothing at all for (migrant) sex workers who were not coerced" (ibid.). Ishrat Shamim suggests that this focus on consent is erroneous:

The defining variable of trafficking in persons is the violation of the migrant's human rights... Victims of trafficking are exposed to physical and psychological violence and abuse, denied labor rights, are illegal before the law and are often found in forced and unwanted relationships of dependency with their traffickers.... Trafficking with consent is a contradiction in terms, because no one ever consents to slavery, servitude or forced labor conditions. (2003)

Applied to the exploitation or abuse of people, the inclusion of consent suggests that beneath a certain level of exploitation, consent is the distinguishing factor. As the Canadian Council for Refugees points out, what a person will consent to is relative, "Deplorable 
conditions may be better than what one left behind (or that one faces if returned to one's home country)" $(2003,3)$.

I agree that the question of consent is problematic, potentially shifting the emphasis from "the actions of the accused" to "the state of mind of the complainant" (UN Working Group on Contemporary Forms of Slavery 2000). Beyond distinguishing those who have chosen to migrate from those who have been forced or coerced, the inclusion of consent limits which migrants who are working and living in exploitative conditions qualify as trafficking victims, not on the basis of the conditions or abuses that they are enduring, but rather on the basis of their consent to these conditions.

Unless preserving state sovereignty endangers the well-being of migrants or preserving the rights of migrants increases violations of state sovereignty, responses to violations of state sovereignty and of human rights can be compatible. However, it seems that in the Trafficking Protocol, provisions for human rights are weak:

While the Trafficking Protocol represents a tremendous step forward, it does not fully incorporate international human rights standards guaranteeing all persons, even undocumented victims of trafficking, access to justice and basic services such as temporary shelter, medical care, and food. It contains provisions ensuring some physical safety for trafficked persons who assist in prosecuting their traffickers, but it leaves provision of services and protections to the discretion of governments, even if the government has adequate financial resources or has confiscated the assets of the traffickers. The protocol does not require governments to grant temporary visas or permanent residency to victims when traffickers in the home country pose a serious threat to their safety. (Jordan 2001, 16)

I consider trafficking to be partially an outcome of restrictive migration regimes and a failure of will amongst governments to respond to violations committed against migrants. Neither of these conditions is challenged or remedied by the protocol. Though I find certain aspects of the Trafficking Protocol definition problematic, particularly the 
ambiguities around consent and the discretionary and limited nature of its human rights provisions, I use it as a starting point for my work.

\section{Quantifying trafficking: The problem of numbers}

There is a lack of knowledge and agreement on the scope and nature of trafficking, but no lack of estimates, guesses or opinions offered by stakeholders. The UN Office on Drugs and Crime (UNODC) estimates that 700,000 people are trafficked each year (2004), while the US State Department reports that per year "at least 700,000 and possibly as many as 4 million people" are trafficked around the world (US Department of State 2003). This is a variation of over 470 per cent! Such confusion is endemic to discussions of trafficking, and it complicates the design, targeting and evaluation of responses. It also means that I cannot give clear and correct information about the number of trafficked persons in Cambodia and Thailand. As UNESCO explains, "When it comes to statistics, trafficking of girls and women is one of several highly emotive issues which seem to overwhelm critical faculties. Numbers take on a life of their own, gaining acceptance through repetition, often with little inquiry into their derivations" (UNESCO n.d.). In this section, I address some of the challenges complicating data-gathering, intending to explain rather than add to this variation.

First, sources and methods are complicated by the illegal and profitable nature of trafficking (Ralph 2000, 1; IOM 2001, 1). Those involved in trafficking have the resources and incentives to conduct their business in a concealed manner, hiding it from law enforcement and other officials, and victims are unlikely to report their experience to authorities (IOM 2001, 1; Laczko 2002, 4). Secondly, whether directly involved in trafficking activities or not, government officials have also been reluctant to draw attention to criminal 
trafficking activities. ${ }^{10}$ This is a barrier to debating and improving legislation, making trafficking a government priority, or even improving data collection and research (IOM 2001, 1; Laczko 2002, 5). Trafficking is largely unseen, unreported, and quantified only with difficulty by those working to gather information.

There are further methodological problems. Jyoti Sanghera, current Advisor on Trafficking to the Office of the High Commissioner for Human Rights, explains:

Figures on the scale of trafficking are often derived from small-scale surveys based upon disparate methodologies or sources such as police records, local information, or media reports which cannot be scientifically representative... calculations are based on many untested assumptions. Most data on the number of trafficked persons are based on anecdotal evidence, speculation and projection. (Sanghera 2002, 17-8)

In addition, trafficking frequently occurs across borders and administrative zones, while projects and governments focus on particular geographic areas, and data-sharing and research collaboration can be limited by a lack of cooperation (Laczko 2002, 4).

With governments not necessarily looking for data, and those benefiting from trafficking actively hiding their activities, it may be assumed that figures under-represent the incidence of trafficking. However, there are cases when organisations "enthusiastically" put forward numbers that over-state and mischaracterize trafficking. Possibly this is done out of recognition that each known case of trafficking likely indicates many more unknown cases, or as a strategy to reinforce the importance of anti-trafficking work. These over-estimates may use data gathered about the larger phenomena of irregular migration or sex work to quantify trafficking, numerically conflating the issues. In this chapter, there are places where I want to describe trafficking, but am only able to provide information on sex worker or immigrant populations, or their migration patterns. Statistics on migration, irregular

\footnotetext{
${ }^{10}$ No country wishes to draw attention to such negative aspects, particularly given the US punitive responses (see US State Department 2003 and US State Department 2004).
} 
migration or sex worker populations may be more available and accessible (thought certainly not easily attained or verified); however, to consider them representative of trafficking either involves an erroneous equation of trafficking with, for example, sex work, or an expression of the very contentious belief that all sex workers (or all irregular migrants) are or should be considered to be trafficked. This complicates the interpretation of data.

In response to these problems, UNESCO and others have begun compiling largescale databases of data on trafficking. These are at present a raw collection of frequently contradictory evidence from different sources. They are a "first step" towards positive change in terms of accounting for, justifying and establishing reliable numbers, enabling open discussion of numbers, their sources, and the assumptions and methods behind them. I use information from the organisations and individuals I interviewed for my primaryresearch, the Global March Against Child Labour data-base, and other sources to describe what is known about trafficking in Thailand and Cambodia. Moving from quantitative towards qualitative descriptions, limitations of the data remain. Descriptions tend to portray the larger phenomena of migration, irregular migration patterns or the incidence of sex work. Though trafficking is linked to each of these, as defined by the Trafficking Protocol, it is only one sub-set of each of them. I begin with a discussion of dominant techniques of trafficking in the sub-region and then give an overview of identified trends in terms of movements, sectors and demographics.

\section{Trafficking in Thailand and Cambodia}

Currently in the Greater Mekong Sub-region (Thailand, Cambodia, Laos, Vietnam, Myanmar and Yunnan province of China), population movements including trafficking are largely intra-Asian (Uhlin and Piper 2002, 172). Echoing global trends, there is a "feminisation" of migration, and a slow but growing recognition of gender difference and 
roles of woman migrants beyond followers and dependents of male migrants (ibid., 175;

Castles and Miller 2003, 9). Lim suggests this growing component of female migrants may

be due to the growth of the service sector, particularly domestic labour and sex work (1998).

Trafficking is associated with different Map: Trafficking Routes ${ }^{11}$

degrees of force and a great variety of

techniques (see Appendix 2) and in the

sub-region is typically less associated with

kidnapping and abduction than with

migration (including but not limited to

smuggling). Elements or evidence of

trafficking emerge or occur partway

through the process or in the final

destination. Hans van de Glind, Deputy

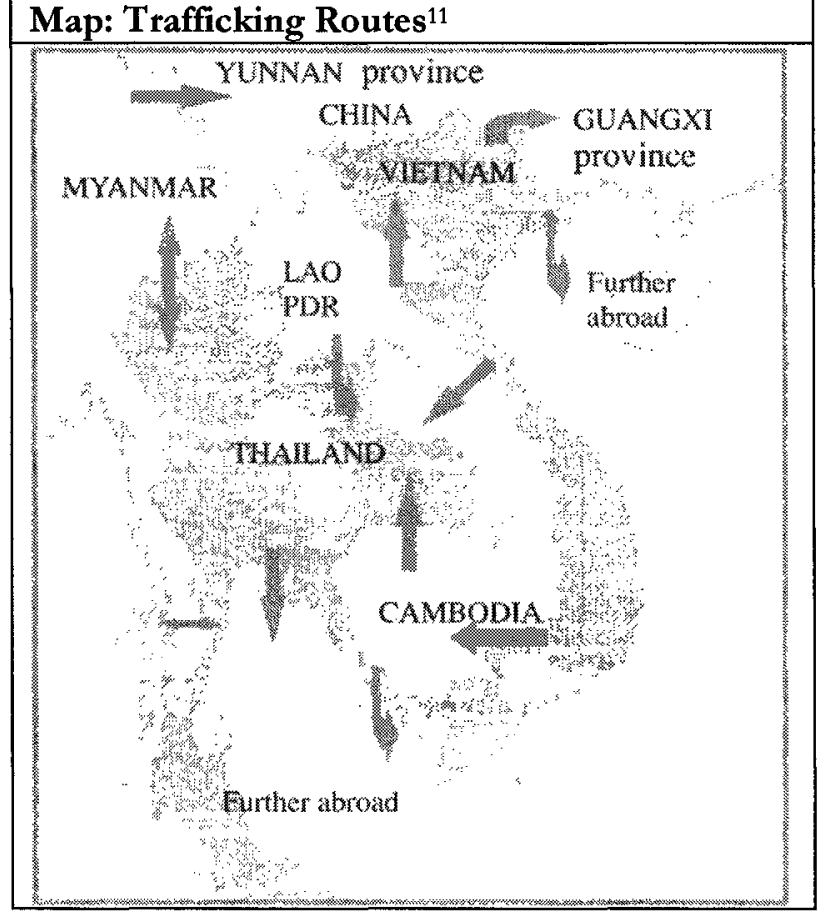

Manager of the ILO Mekong Sub-regional Project to Combat Trafficking in Children and

Women at the time of the interviews, characterised trafficking in the region as follows:

Research by Dr. Kritaya in Thailand in $1997-98^{12}$ points out that quite a few of those ending up in an exploitative situation that are effectively in a situation of trafficking left their place of origin voluntarily and became trafficked in the process. And research in recent years in our project target sites and direct information that we receive from various missions reconfirms that the majority of the cases are not really kidnapping and use of force in the place of origin... many people for lack of better alternatives simply want to leave their villages and through networks of friends and acquaintances often leave the place of origin, and while they're on the move they end up in a situation of being trafficked. (2003)

Though there are substantial forced internal migrations associated with government-initiated political and industrial agendas, as well as cases of abduction and kidnapping which some

\footnotetext{
11 Taken from UN Inter-Agency Project website http://www.un.or.th/traffickingproject .

${ }^{12}$ See Archavanitkul, 1998.
} 
believe to be increasing (i.e. for adoption, the sex or the bride trade, or military service) (Tumlin 2001, 16), organisations mostly characterise trafficking in the Mekong Sub-region in the same terms as van de Glind and Archavanitkul.

Phil Marshall, project manager of the UN Inter-Agency Project at the time of the interviews reported, "In fact we find that a lot of people that end up being trafficked left home voluntarily in the sense of not being forced - they might not have had enough information, they might not have been overtly tricked or they may have just wanted to take their chances" (2003). He suggests elsewhere that the majority of trafficking in the subregion is best described as irregular migration plus labour exploitation (2001, 4). This voluntarism does not imply that individuals have full or complete information with which to make decisions, nor a variety of options from which to choose. "Voluntary" blind and risky migration signals a lack of options: it is a choice made in the absence of opportunities.

Siriporn Skrobanek, co-founder of the Foundation for Women, a Thai NGO engaged in anti-trafficking advocacy and education, takes a similar position:

We see trafficking in the context of migration. I think that migration is a kind of basic right of people. They think that migration can improve their situation, so people migrate... but due to the restrictive nature, particularly of the cross-border migration, then the consensual migration turns out to be smuggling or trafficking. (2003)

Khleang Rim, Cambodian coordinator for the ILO trafficking project as well as Hang Vannack, coordinator for the UN Inter-Agency Project in Cambodia both agree with this migration-focused characterisation (2003). Janet Ashby, who has worked on trafficking with the UN, IOM and AusAID in Cambodia finds, "very little documented kidnapping. Most people agreed to something at the time they left their home... they thought they were going to was a restaurant, or they were coming for factory work... it's not clear at what point that becomes trafficking" (2003). 


\section{Cambodia}

In Cambodia, there are known patterns of internal, international (receiving) and international (sending) trafficking. Internally, rural and poorer areas are sending areas, and urban centres, principally Phnom Penh, receiving areas. Both children and adults are victims, and destination sectors include the sex trade (particularly for women and children), fisheries (particularly for men) and factory work, especially the garment sector. Subregionally, Cambodian children are begging in Vietnamese and Thai cities; children and women are in Thailand in the sex trade, women are in China in domestic service, and men, women and children are in a variety of sectors in Thailand. Khleang, head of the ILO's Cambodian national project, explained:

For the sexual exploitation, it's mostly women and girls, but some boys for paedophiles... For the garment or other sectors may be both men and women, because trafficking is not just focused on sexual exploitation... Some go to Vietnam for begging in Ho Chi Minh City. In Cambodia for garment sector, sexual exploitation, and some for the fishing, fish or brick making factories, rubber plantations.... In Thailand, begging - some reports say for the sexual exploitation, fishing. (2003)

\begin{tabular}{l}
\hline Table 2: Trafficking in Cambodia (as cited in Global March 2000) \\
\hline - Cambodian men, women, and children are trafficked internationally, principally to Thailand for sexual \\
exploitation and bonded labour, including street begging (US Dept. of State, Trafficking in Persons Report, 2001) \\
- Children and adults from poorer rural areas are trafficked to Phnom Penh and other commercial areas \\
(ibid.) \\
3,000 women and children are trafficked to Cambodia for prostitution, and to China for domestic work \\
(ILO-IPEC, Trafficking in Children and Women, 1999) \\
Up to 35\% of the estimated 15,000 prostituted persons in Phnom Penh have been smuggled into Cambodia \\
from China or Vietnam ("The Street of Little Flowers", Bangkok Post, 23 February 1997 in CATW Fact Book) \\
Many of the estimated 15,000 to 20,000 prostitutes in Phnom Penh are believed to be Vietnamese girls and \\
women (UNICEF, Children on the Edge, citing United Nations ESCAP (2000), UNICEF East Asia and Pacific) \\
At least 3,000 girls from Vietnam have been trafficked to Cambodia for prostitution, more than 15\% are \\
below 15 years (ILO-IPEC, Combating Trafficking in Children for Labour Exploitation in the Mekong Sub-region, 1998) \\
Of the 1,060 child beggars in Thailand in 1997, 95\% were Cambodians (Kyodo News Service)
\end{tabular}

The national head of the UN Inter-Agency Project in Cambodia also described Phnom Penh as the major internal destination and Thailand as the main international 
destination. He drew attention to the flow of Vietnamese into Cambodia for the sex trade (also see Tumlin 2001, 7) and of Cambodian children from border areas to cities in Vietnam for begging, and the gender and age differences that characterise these flows:

Majority of men are trafficked to other countries, but majority of women and children trafficked inside Cambodia. Majority of men trafficked for construction workers, for working for like in the seas - fishing - for the farm worker. And majority of women trafficked into Thailand for sex workers, begging on the streets - we have children especially for begging and boys for begging on the streets, sell flowers. (Hang 2003)

According to Ashby, there are large numbers of young Vietnamese women and girls entering Cambodia for prostitution, and relatively small numbers of Cambodians going to Vietnam, mostly to Ho Chi Minh City for begging. She stressed that only some of this latter movement can be classified as trafficking:

It's really difficult to say how much of that is trafficking because there's a traditional pattern that people from the border area - particularly Prey Veng ${ }^{13}$ - regularly go on begging trips, particularly in the dry season. In some villages it's even seen as their traditional way of life, so there doesn't seem to be too much exploitative trafficking in that, but there may be some.

She also mentioned domestic labour:

There's probably quite a bit of forced domestic labour - I won't say forced domestic labour that is to some degree involuntary or not what people bargained for when they first got into the decision... a lot of people come from the country and work as domestic servants and we don't really know much about the conditions. (2003)

These statements characterise migratory flows, but they do not indicate the numbers of people involved, nor do they indicate the proportion of these migratory or labour flows that are trafficking victims.

In Cambodia trafficking is associated with the sex trade, and particularly with children in the sex trade. Though adults and children are trafficked into other sectors, recognition of this may be complicated by the Cambodian trafficking law's particular focus

\footnotetext{
${ }^{13}$ Prey Veng province lies between Phnom Penh and Vietnam in the South of Cambodia.
} 
on sex trafficking. Though beyond the focus of my work, Cambodia is also a key area of concern in the highly-profitable international trafficking of infants for adoptions (Pilorge 2003). It is a regional sending-country for men, women and children in a variety of sectors, and Thailand is the major destination for Cambodians.

\section{Thailand}

Thailand is involved in the majority of cross-border migration and trafficking in South East Asia. Likely due to its relative economic wealth and political stability, it is the primary receiving area for sub-regional movements, particularly from the bordering countries of Myanmar (Burma), Laos and Cambodia. It is also a major transit and sending area for movements to countries further abroad to countries like Taiwan, Malaysia, Hong Kong and Singapore (UNIFEM n.d., Sheet 3; Uhlin and Piper 2002, 173). But this has not always been the case.

Migration dynamics have changed significantly in Thailand since the early 1980s, responding to economic change and growth in Thailand. ${ }^{14}$ Thailand has grown wealthy relative to other countries in the sub-region but remains less affluent than other countries in the region, such as Singapore and Malaysia. In the mid-1990s it became a destination for low-wage labourers including sex workers from poorer areas and countries in the region (particularly Myanmar (Burma), Cambodia, Laos and China), and a source of workers including sex workers for places like Japan and Taiwan (Phongpaichit 1999). This was not without the encouragement of the Thai government: “Thai government policies support export of labour in general... [this] implicitly includes women for sex services" (ibid., 97). There are large movements of Thai men and women to Japan, where men work in factories,

\footnotetext{
${ }^{14}$ In the 1970 s, movements were primarily from Asia to the Middle East, with a focus on legal male workers for construction and infrastructure, and illegal or trafficked female workers for domestic and sex work. Through the 1980s the economic boom was accompanied by an expansion of employment in East and South East Asia, with a lot of short-contract migration (Uhlin and Piper, 2002: 174).
} 
grocery stores, in hotels or restaurants or as manual labourers; women as sex workers,

hostesses or waitresses (both associated with the sex- or pseudo-sex trade) (ibid., 81).

\section{Table 3: Trafficking in Thailand (as cited in Global March 2000)}

- Trafficking is international and domestic. Most cross border trafficking in South East Asia involves Thailand, a substantial receiver, transit and sender country (ECPAT, CSEC Database; US Dept. of State, Trafficking in Persons Report, July 12, 2001)

- NGOs and government departments cite 200,000 persons trafficked, which is considered a credible estimate (US Dept of State, Country Reports on Human Rights Practices - 1999, 25 February 2000)

- Victims are primarily young women and girls trafficked for sexual exploitation, although a significant number of men and women are trafficked for farm, industrial and domestic labour (US Dept. of State, Trafficking in Persons Report, July 12, 2001)

- Women are trafficked internationally to Japan, Taiwan, Australia, Europe, and the United States, chiefly for sexual exploitation and, to a lesser degree, sweatshop labour (US Dept. of State, Trafficking in Persons Report, July 12, 2001)

- Of 1,062 child beggars in 1999, 80 were Thai and 982 were foreign (ILO-IPEC, Children in Prostitution, Pornograply and Illicit Activities, September 1999)

- Internal traffic of Thai females consists mostly of 12-16-year-olds from hill tribes of the north/northeast. Most are sent to closed brothels, which operate under prison-like conditions (CATW-Asia Pacific, Trafficking in Women and Prostitution in the Asia Pacific, 1996)

Thai women are also domestic and sex workers in other areas, such as Hong Kong and the Middle East (Angsuthanasombat 2003). Phongpaichit draws attention to the supply of labour from poorer and politically troubled neighbouring countries, the increased demand for all labour in Thailand in the 1990s, and the paradoxically increased migration restrictions $(1999,89)$. The director of the Development and Education Program for Daughters and Communities (DEPDC) suggested that changes in trafficking reflect changes in economic and migration policy. For adult and child workers alike, there is a high demand for cheap labour to fuel production that is new to the past decade:

At that time [ten years ago] trafficking meant that when someone pushes, takes or buys someone into prostitution... Labour is - no need to traffic. There was no condition to traffic anyone because the border control or the law of Mekong Region... it was just free. If you want to cross the border and you can get a cheap job if you can work... So there is no one smuggling or trafficking for labour. But now, right now, with the countries changing and economics changing, poor countries, rich countries, labour is a big problem -factories, industry, new industries - not just everyone cross border and get a job. (2003) 
Child trafficking victims are forced into prostitution, bonded labour, domestic work, forced marriages, adoptions and begging. As in all countries of the sub-region, children are trafficked internally and internationally for sexual exploitation, usually from rural to urban areas. Thai women, girls and sometimes boys are trafficked internally from the northern and north-eastern provinces of Phayao, Chiang Mai and Chiang Rai to red light districts in Bangkok, Pattaya, Hat Yai and other southern cities (Jakantra 2003). ${ }^{15}$ Though explicable in terms of the relative economic poverty of the north, there is also the myth of the "beautiful and fair" northern girls, "If you go to Hat Yai or to the border close to Malaysia all the prostitutes came from the north, and some from the northeast. But mostly from the north because the northern girls look prettier" (Hiranraks 2003).

Migratory flows from Laos to Thailand are thought to be the most substantial in the region, and the cultural and linguistic similarities facilitate integration. While oppression, drought, war and civil strife have in the past sent huge refugee movements to Thailand from Cambodia, Laos and Vietnam, Thailand is now a major recipient people fleeing Myanmar. ${ }^{16}$ Faced with daily risks and realities of rape, forced labour, beatings, deprivation of livelihood and other horrors at the hands of the military junta, large flows of men, women and children cross into the north of Thailand, many reliant on smugglers for passage. Governments of both countries attempt to tightly control movement between their borders. The Burmese are

\footnotetext{
${ }^{15}$ There is also a flow of girls and young women from Vietnam and other countries into China, particularly for forced marriages. This is linked to the serious lack of women of marriageable age in China, itself a result of the one-child policy that originated in the late 1970 s and the so-called "cultural preference" for male children. This creates a demand for marriageable women from neighbouring countries, some of which is met through trafficking.

${ }^{16}$ During and after the years of war in Vietnam, Laos and Cambodia border controls were stepped up in response to the numbers of people fleeing the strife and oppression of their home countries and heading for Thailand to seek asylum or passage further abroad. Thailand has never signed the UN Convention on Refugees, and so technically does not recognise refugee status. Even so, the UN High Commissioner on Refugees (UNHCR) operates from the UN building in Bangkok, offering unrecognised UNHCR cards to those who qualify as convention refugees. There are still large refugee camps in border areas (see US Embassy in Thailand, 2004).
} 
portrayed and perceived as "enemies" of the Thai. In Thailand, they are unwelcome as immigrants or refugees and ethnic minority groups with Burmese heritage have long been denied legally established citizenship rights (Human Rights Watch 2004). Groups like the UN Inter-Agency Project on Human Trafficking are working to change this, "what we're doing is to look at the 400,000 ethnic minority people who are technically Thai, who have the technical rights to Thai citizenship, but they haven't been awarded it" (Marshall 2003).

Though currently more likely fleeing economic hardship, Cambodians lack legal labour migration opportunities and many rely on smugglers. Varaporn Intharat of Empower Chiang Mai sees reliance on smugglers as the only option for many Cambodians and Burmese trying to enter Thailand. But not all smuggling is trafficking, even where the sex trade is involved: women may know that they will be working in the sex trade and pay smugglers to help them cross the border or pay agents to help them find employers. Trafficking is defined by the conditions of work, where women and other victims are beaten, deceived, forced to work or unable to leave, not by their status as irregular or smuggled migrants or as sex workers (Intharat 2003).

In the sub-region, trafficking victims include those who have made blind or risky migration choices, been lured by false promises, or who upon arrival or in transit come under the control of those who use force, coercion, or their vulnerability as migrants to exploit them. This study, like that of the organisations it focuses on, is primarily concerned with trafficking in this broader context of migration and recognises that there are compelling reasons that may lead people to choose to migrate. From this understanding, the goal of trying to target interventions to prevent trafficking in sending communities where distinguishing trafficking victims from other migrants is largely impossible seems difficult, and there is a tangible risk of confounding migration prevention and trafficking prevention. 


\section{CHAPTER 3: Methodology}

This thesis is based on interviews that I conducted in Thailand and Cambodia in the summer of 2003, funded by the Bill McWhinney Memorial Scholarship and Research Travel Grant through CIDA.17 Data gathering was remarkably straightforward: every organisation I contacted to request interviews was very accommodating. Finding organisations that fit my criteria, however, was rather difficult. The approval I received from the Carleton Research Ethics Board precluded identifying suitable projects by word-of mouth. This was a very large constraint. By design, I focus on organisations that self-identify as working in human trafficking prevention in sending areas, the reasons for which are discussed in the next section of this chapter. I found organisations through internet searches and national NGO directories. Unfortunately, directories were not necessarily comprehensive or up to date and only certain organisations have web sites. I interviewed representatives of 17 organisations, seven of which fit my criteria. These seven (see table four, below) are the focus of my analysis. Evidence from the other organisations (table five) is used to supplement information about trafficking issues and responses.

Interviews were semi-structured and based around three themes: the organisations' understanding of trafficking, their interventions and their relations with other organisations. Each lasted approximately one hour and was recorded where participants consented. ${ }^{18}$ Every participant provided measured, reflective responses. I remain thankful for having had the opportunity to learn from them.

17 Though funded through CIDA, this views and positions expressed in this paper are not those of CIDA. 18 Participants read and signed letters of informed consent in accordance with the requirements of the Research Ethics Board at Carleton University (see Appendix 3). Interviews were conducted in English with two exceptions: the Cambodian Women's Crisis Centre interview was conducted with the assistance of a translator; and the Friends of Women Foundation interview in a combination of English, Thai and Lao. 


\begin{tabular}{|c|c|c|c|c|}
\hline Project name & Organisation & Type & Area of work & Donors (past and present) ${ }^{19}$ \\
\hline \multirow{2}{*}{$\begin{array}{l}\text { Project to } \\
\text { Combat } \\
\text { Trafficking of } \\
\text { Children and } \\
\text { Women } \\
\end{array}$} & $\begin{array}{l}\text { Mirror Art Group } \\
\text { (also known as } \\
\text { Bannok) }\end{array}$ & $\mathrm{NGO}$ & Thailand & $\begin{array}{l}\text { ILO (Sudhamongkala 2003; van de } \\
\text { Glind 2003) }\end{array}$ \\
\hline & $\begin{array}{l}\text { Development and } \\
\text { Education Project } \\
\text { for Daughters and } \\
\text { Communities } \\
\text { (DEPDC) }\end{array}$ & NGO & Thailand & $\begin{array}{l}\text { Asian Children's Fund (ACF) Japan; } \\
\text { UNICEF; ILO-IPEC; Canada Fund; } \\
\text { AusAID; ANZ Women's Groups; } \\
\text { Global Fund for Women (US); } \\
\text { Siroptimists (British Embassy); } \\
\text { Cooperaid (Switzerland); Finland } \\
\text { Embassy; Japanese Embassy; USAID } \\
\text { Asia Foundation; VSO (NGO funded } \\
\text { by DFID) and AVI (NGO funded by } \\
\text { Australian government) (DEPDC } \\
\text { 1999) }\end{array}$ \\
\hline \multirow[t]{2}{*}{$\begin{array}{l}\text { Trafficking } \\
\text { Project }\end{array}$} & $\begin{array}{l}\text { Cambodian } \\
\text { Women's Crisis } \\
\text { Centre (CWCC) }\end{array}$ & NGO & Cambodia & $\begin{array}{l}\text { Terre des Hommes (TDH) Germany, } \\
\text { TDH Netherlands (mostly TDH), } \\
\text { BMZ, Oxfam Hong Kong, Danish } \\
\text { Church Aid, World Food Program, } \\
\text { ILO, IOM The Asia Foundation } \\
\text { (CWCC 2002, 1; Nopsarin 2002) }\end{array}$ \\
\hline & $\begin{array}{l}\text { Cambodian } \\
\text { Migration and } \\
\text { Development } \\
\text { Committee } \\
\text { (CMDC) }\end{array}$ & $\mathrm{NGO}$ & Cambodia & $\begin{array}{l}\text { UNICEF, CIDA, US Embassy Asia } \\
\text { Fund, Danish Church Aid, Asia } \\
\text { Foundation (US AID); ICMC; } \\
\text { proposals in with the Canada fund, } \\
\text { AusAID and the EU (Ros 2002) }\end{array}$ \\
\hline $\begin{array}{l}1999 \text { title "PAR } \\
\text { with children" } \\
\text { (in border areas) }\end{array}$ & $\begin{array}{l}\text { Save the Children } \\
\text { UK (SC UK) }\end{array}$ & INGO & $\begin{array}{l}\text { Sub-regional } \\
\text { National offices } \\
\text { in: Thailand, } \\
\text { Cambodia, Laos, } \\
\text { Yunnan, } \\
\text { Myanmar }\end{array}$ & DFID (Aye 2003; Beloe 2003) \\
\hline $\begin{array}{l}\text { Inter-Agency } \\
\text { Project to } \\
\text { Combat Human } \\
\text { Trafficking } \\
\text { (formerly } \\
\text { Women and } \\
\text { Children) (UN- } \\
\text { IAP) }\end{array}$ & $\mathrm{UN}$ & 10 & $\begin{array}{l}\text { Sub-regional } \\
\text { project with } \\
\text { head office in } \\
\text { Thailand and } \\
\text { national offices } \\
\text { in: Cambodia, } \\
\text { Laos, Yunnan, } \\
\text { Myanmar }\end{array}$ & $\begin{array}{l}\text { AusAID, UN (Turner) Foundation; } \\
\text { NZ ODA (for phase two); Norway } \\
\text { thought the Ministry of Foreign Affairs } \\
\text { (not NorAD); UNDP; Netherlands } \\
\text { Embassy (Hang 2003; Marshall 2003) }\end{array}$ \\
\hline $\begin{array}{l}\text { Mekong Sub- } \\
\text { Regional Project } \\
\text { to Combat } \\
\text { Trafficking in } \\
\text { Children and } \\
\text { Women (ILO- } \\
\text { TICW) }\end{array}$ & ILO & IO & $\begin{array}{l}\text { Sub-regional } \\
\text { project, with } \\
\text { national offices } \\
\text { in Thailand, } \\
\text { Cambodia, Laos } \\
\text { and Yunnan }\end{array}$ & $\begin{array}{l}\text { DFID; Japanese government; plus } \\
\text { some other smaller donations (van de } \\
\text { Glind 2003; Beloe 2003) }\end{array}$ \\
\hline
\end{tabular}

${ }^{19}$ Aside from identifying who these donors are, I do not delve into specificities. For example, I lack information on the volume of funding. My primariy research did not systematically include donors, and my focus is on the NGOs and IOs themselves. It is possible that there are other donors of whom I am not aware. 


\begin{tabular}{|l|l|l|l|}
\hline \multicolumn{1}{|c|}{ Table 5: Other Organisations } & \multicolumn{1}{c|}{ Type } & \multicolumn{1}{c|}{ Focus } & \multicolumn{1}{|c|}{ Location } \\
\hline Friends of Women Foundation (FOW) & NGO & $\begin{array}{l}\text { Labour rights, Primarily } \\
\text { advocacy }\end{array}$ & Thailand \\
\hline Foundation for Women (FFW) & NGO & $\begin{array}{l}\text { Women's rights, } \\
\text { Primarily advocacy }\end{array}$ & Thailand \\
\hline $\begin{array}{l}\text { Asian Research Centre for Migration } \\
\text { (ARCM) }\end{array}$ & Academic & $\begin{array}{l}\text { Contemporary Asian } \\
\text { migration }\end{array}$ & $\begin{array}{l}\text { Regional, work out } \\
\text { of Thailand }\end{array}$ \\
\hline Empower Chiang Mai & NGO/MO 0 & Sex worker rights & Thailand \\
\hline Family Planning Northern Project & NGO & Health education' ${ }^{21}$ & Thailand \\
\hline $\begin{array}{l}\text { Ligue de defense cambodgienne aux droits } \\
\text { des homme (LICADHO) }\end{array}$ & NGO & Human rights advocacy & Cambodia \\
\hline $\begin{array}{l}\text { Asia Regional Cooperation to Prevent } \\
\text { People Trafficking (ARCPPT) }\end{array}$ & IO & $\begin{array}{l}\text { Trafficking (crime- } \\
\text { focused) }\end{array}$ & Sub-regional \\
\hline $\begin{array}{l}\text { International Organisation for Migration } \\
\text { (IOM) }\end{array}$ & IO & $\begin{array}{l}\text { Migration and } \\
\text { Trafficking2 }\end{array}$ & Sub-regional \\
\hline $\begin{array}{l}\text { UK Department for International } \\
\text { Development (DFID) }\end{array}$ & Government & Bilateral funding agency & $\begin{array}{l}\text { Sub-regional, office } \\
\text { in Thailand }\end{array}$ \\
\hline $\begin{array}{l}\text { Canadian International Development } \\
\text { Agency (CIDA) }\end{array}$ & Government & Bilateral funding agency & $\begin{array}{l}\text { Sub-regional, office } \\
\text { in Thailand }\end{array}$ \\
\hline
\end{tabular}

Information from my interviews is rich and detailed and assumed to be highly representative of organisations' perspectives. All participants were country or sub-regional directors of their organisations' trafficking prevention projects and were asked specifically to respond from an organisational, not personal, perspective. Where available, I supplement interviews with project and other documents.

\section{Selection of Organisations}

Anti-trafficking work takes place on many fronts, and may encompass law enforcement, rescue, return and reintegration of victims, organised crime suppression, and demand reduction. Trafficking prevention can be focused on sending, receiving or transit areas; on supply, demand, or on the agents and facilitators in the middle. There is overlap and complementarities between efforts, but I focus on sending-area trafficking prevention.

\footnotetext{
20 Membership Organisation.

21 The Northern project is not part of the main analysis because the information gathered about the organizations anti-trafficking activities was insufficient for evaluation.

22 IOM anti-trafficking work includes return and reintegration, advocacy, information gathering and sending area prevention work. Unfortunately, my interview was with the Cambodian director of the retum and reintegration project, and $\mathrm{my}$ information about the organization is limited to this aspect.
} 
Sending-area prevention has close ties to traditional community development projects. In a region where, as discussed in chapter two, trafficking is generally characterised as beginning with migration, this is also where concerns about overlap between trafficking responses and migration prevention are expected to be concentrated. What is trafficking prevention in a sending community where those who may become trafficking victims cannot be distinguished from other potential migrants? Sending-community prevention represents a "most likely" case for seeing implementation of policies discouraging migration.

Selecting organisations that share this narrow focus makes for an easier comparison and enables diverse organisations (i.e. NGOs and IOs) to be classified as similar. Theorizing about development organisations, Anna Vakil finds that investigators tend either to assume NGOs are monolithic, failing to recognise the great internal variability, or over-emphasise difference and rely on complex taxonomies that are not widely applicable. Both tendencies, she argues, result in findings whose broader applicability is compromised (1997, 2057). Shared goals also make comparisons of inter-governmental organisations (i.e. IOs such as UN organizations) and international NGOs possible:

The rough similarity of goals, or at least of stated goals, the fact that any goal implies a variety of sub-activities, and the fact that all organizations can usually draw on a common stock of technology (including professional personnel) provides an excellent opportunity to assess performance in a reasonable manner. (Ness and Brechin 1988, 271)

Certainly, NGOs differ from IOs and from each other on many fronts, including how they approach development, analyse and assess problems and solutions. They differ in institutional structures and processes (Heyzer 1995, 6), the countries they work in, and by the type of actor that established them (i.e. donor-organised, government organised, locally established, see Kothari 1986; Heyzer 1995, 6; Riker 1995b, 117-8; Pearce 1997, 259). This complicates, but does not preclude, comparisons. 
Vakil lays out a simple four-point classification scheme for NGOs that includes orientation, level of operation, sectoral focus and other evaluative factors (i.e. gender equality, participation, accountability) (1997, 2062-66). Applying this taxonomy, the organizations I focus on are similar in orientation (i.e. development and welfare work, all are service organisations), they are similar in sectoral focus (i.e. trafficking prevention, though from different perspectives i.e. child-rights, violence against women, etc.). They differ in level of operation (all work in sending communities, but some work locally, others nationally or internationally) and potentially in terms of their evaluative factors (criteria are likely similar).

Throughout this thesis, I try to openly state limitations as well as the assumptions underlying my analysis so that my findings can be understood in their context. I do not compare or analyse how projects change over time. ${ }^{23}$ Rather than looking for evidence of change or consistency over time, I look for indicators of change vs. consistency relative to the organisations' priorities and other projects. Consistency, independence from and criticisms of donor positions are consistent with framing. Change and an absence criticism are consistent with co-optation (chapter five presents the criteria and indicators I use).

The anti-trafficking projects of the IOs and the international NGO are on scale with the entire country-operations of many NGOs and there is a tendency through my analysis to focus exclusively on the anti-trafficking work of the IOs but to reference projects beyond the trafficking-specific work of the NGOs. Though not ideal, this does reflect the way that in practice, many NGOs do not implement discreet, separate projects, but rather approach their work in a more complementary and holistic way, encouraging synergy between their

\footnotetext{
${ }^{23} \mathrm{My}$ research only covers one specific period of time. Even with a time-series, there is no point in time where these projects were being implemented without donor funding. The inital phases and evolution of projects generally involves the design and submission of project proposals to potential funding agencies, and the successful receipt of funding and approval enables project activities to begin (or continue).
} 
projects. Also related to size and scale, there is a relative abundance of documented sources by and about the IOs that usefully supplement my interviews.

As information from my interviews is self-reported, it may more accurately represent what organisations report themselves to be doing rather than what they are doing. Other stakeholders' perceptions of these projects are not part of my data as neither the intended beneficiaries nor the donors have been systematically included. I cannot evaluate the impacts of their interventions. I do not include national differences between Thailand and Cambodia as variables in my analysis. Amongst other factors, politics, history, culture, laws and history of NGO engagement are all expected to exert an influence (Heyzer 1995, 1). ${ }^{24}$

My analysis of interventions only makes generalisations about types of interventions rather than delving into their specifics. Different organisations have different degrees of innovation and ways of suiting activities to the needs and contexts of their target areas and my work, in not systematically visiting intervention sites, is not able to draw out these nuances. I establish only that the organisations engage in these interventions and that they ascribe to them the end of trafficking prevention. Future research including the communities where these projects work would be able to provide these details.

Overall my selection is highly appropriate relative to my questions about migration agendas in anti-trafficking work, organisations taking on their donors' agendas. The narrow focus on sending area prevention projects is suitable for considering the overlap between trafficking prevention and migration prevention and for testing framing and co-optation as potential explanations of NGO-donor relations and donor-funded projects.

\footnotetext{
${ }^{24}$ Thailand is wealthier, culturally and linguistically of different roots, has a different colonial history, form of governance and political history. The country has been at peace for much longer. Cambodia is still recovering from years of war and is facing difficulties that Thailand is not, including peace-building and reconciliation along with other war-related development issues and concerns including, but not limited to, loss of infrastructure, persistent difficulties with landmines (i.c. preventing farming and killing and maiming people), etc.
} 


\section{CHAPTER 4: Donors, migration and trafficking}

In this chapter, I show how donor policy on trafficking in part reflects donorcountry preferences and efforts to both control and restrict migration. Donor countries, generally wealthy and migrant-receiving, do not tend to favour the expansion of migration regimes (or migrant rights) in general, as a path to development or as a way of reducing trafficking and the harms associated with it. In chapter two, I indicated that trafficking violates and exploits victims, trans-national trafficking violates state sovereignty and that the trafficking protocol has not been strong in its responses to human rights violations. I also suggested that trafficking, at least in part, is an outcome of restrictive migration regimes. I characterised trafficking in Thailand and Cambodia as primarily consistent with voluntary migration, rather than abduction, kidnapping or forced migration. This chapter builds on these concerns.

Though it is a simplification to suggest that all government departments (or all persons within a given department) share the same position, this is precisely the assumption that I make for the purposes of this analysis. I assume that government policies and biases directly influence the official development assistance (ODA) departments which fund both NGOs and IOs working in international development. There is evidence that this influence and resistance to it are both part of inter-departmental relations. For example, the UK's Department for International Development (DFID) has come into conflict with their government on using aid to change migration outcomes:

The Department's stated objective was to help developing countries manage migration flows as beneficially as possible, through conflict prevention, humanitarian assistance, and broad-based economic growth, but not through using resources to reduce voluntary migration. This position has brought the department in collision with the government plan, in the run-up to the Seville Council, to make aid to third countries dependent on co-operation on immigration. (Baldaccini 2003, 13) 
Development assistance, or aid, is one of the economic policy tools available to

governments, and donors' funding priorities and choices reflect their policies and objectives, including migration control: “Aid, intervention, and remittances can help to reduce unwanted migration" (Widgren and Martin 2002, 6). This in turn differs from comments made by Tom Beloe, a DFID representative:

Trafficking is an entry point to a much larger discourse around vulnerability and migration. I'm not sure I completely agree with your statement from the British DFID perspective... I think for DFID, trafficking is part of a much larger issue, which is the movement of people - which is certainly not a new phenomenon but is certainly increasing with what is an increasing process of globalisation... there are people who are vulnerable and are susceptible to exploitation. (2003)

However, development policies, including DFID's 1997 White Paper, tend to favour reducing migration, both rural-urban and international (de Haan 2000,1). This is not unique to the UK. For example, the ILO and UNHCR formally investigated official development assistance (ODA, i.e. donor funding) as a tool for reducing migration:

The ILO and UNHCR in 1992 undertook a major project to investigate whether more ODA, or ODA delivered in a different way, could reduce unwanted emigration... Since donor nations already make ODA conditional, meaning that they require recipient countries to respect human rights etc, experts were asked how ODA should be provided if its goal is to reduce emigration pressures. (Widgren and Martin 2002, 6)

The Organisation for Economic Co-operation and Development (OECD) has also published papers looking into aid as a tool for migration control, “Against a background of rising concern over migration pressures from developing countries to the OECD area, Official Development Assistance (ODA) is often cited as a relevant policy instrument for influencing migration flows" (OECD 1993, 3). The report continues to explain that it is difficult to manage or predict the potential impact of different interventions on migration outcomes, discouraging the search for "magic bullet" projects and encouraging the pursuit of policies that are "desirable in their own right": 
DAC members are directly and indirectly addressing the root causes of migration pressures through their ODA programmes...Migration considerations tend to strengthen the case for these programmes, but do not significantly modify their present directions - notwithstanding the need to improve their efficiency and effectiveness... (ibid., 4)

Some of this is related to concerns about the impact of out-migration on developing countries. However, as suggested later in this chapter, there are compelling reasons to acknowledge the positive role of remittances from migrants. I consider concerns about reducing "unwanted emigration" to be consistent with a generalised preference for restrictive migration regimes in donor countries: “One of the migration objectives of the EU's external policy is to address the root causes of migration" (Niessen 2004, 2). The European Council has three times focused on migration and illegal migration as "a top priority" counter irregular migratory flows into its territory, the European Union promotes and supports actions in countries of origin and transit to strengthen border control" (ibid., 7).

A culture of restrictive migration policy has blossomed amongst receiving states alongside increased migration both in the developed and the developing world (van Impe 2000, 113; UN SG 2001, 7). Donor communities (i.e. tich country governments and the international organisations funded by them) currently espouse highly restrictive immigration policies:

... analyses of the regulation of refugee flows, migrant domestics and undocumented workers in Europe and North America almost invariably point out the increasing preoccupation of states with immigration restrictions, border fortifications and reduction in non-citizenship rights. (Stasiulis 1997, 199)

Though donor countries, primarily countries in the EU plus Canada, the US Australia and New Zealand, are migrant-receiving countries, I have suggested that trafficking and migration in Thailand and Cambodia are primarily sub-regional or regional. However,

25 The European Councils in question were 2001 (Laeken), 2002 (Seville) and 2003 (Thessaloniki). 
Thailand is a sending country to "further abroad", and I consider regional out-migration to be linked to longer distance trans-national migration. Furthermore, as global processes, including trafficking and smuggling networks, continue to develop, longer-distance migration will likely becomes increasingly viable. There are indications that countries are systematically increasing sanctions for irregular migration while decreasing opportunities for legal migration, except for the most skilled and wealthy: ${ }^{26}$

The trend means that migration laws at this point in time reflect one of the paradoxes at the centre of globalisation: for those with more, globalisation makes more available, for those with less, there is less. Inequalities are increased, exclusions are underscored... (Dauvergne 2004, 603)

The "countries of immigration" 27 are increasingly selective and restrictive, and Europe has been dubbed "Fortress Europe" due to its restrictive migration policies (Geddes 2000). Though the US tries to manage and limit migration to maximise benefits, "European states do not consider immigration as a matter of national interest" (Niessen and Schibel 2003, 1):

Migration management and prevention came to mean migration restriction, border control and combating clandestine migration, trafficking in and smuggling of human beings. Migration became associated with organised crime and terrorism (especially after the $11^{\text {th }}$ of September) (ibid., 5).

Governments of sending, receiving and transit areas determine sets of political constraints and regulations that may encourage or discourage migration, defining what is admissible and what is legitimate. Van Impe, who locates trafficking within the nexus of migration, points to a worldwide increase in migration at the same time as a decrease of the legal means to do so. The World Bank also acknowledges this:

Developed countries remain wary of relaxing immigration policies, however, as it is feared that immigration would increase competition in local job markets and pose a fiscal burden on local tax payers. Developed countries also fear that large scale immigration may erode cultural values and undermine national security... (Ratha 2003, 158)

\footnotetext{
${ }^{26}$ Dauvergne emphasis that this preference for the skilled and wealthy includes refugees.

${ }^{27}$ Australia, Canada, New Zealand and the US.
} 
Processes linked to globalisation have resulted in policies favouring decreased official restrictions on the movement of many things - but not of people:

The increased propensity to regard free trade and unrestricted capital flows as generally positive developments, however, is not often extended to the area of migration. Indeed, as concerns about domestic unemployment, smuggling, domestic security and potential xenophobic reactions increase, greater restrictions on immigration will emerge in the key recipient states. (Rowlands 1998, 1)

Restrictive migration regimes are coupled with concerns about illegal migration regimes, border control measures and crackdowns on irregular migrants: "In response to the perceived or real growth of illegal migration, and to the evident increase in smuggling and trafficking that is intertwined with it, the nations of the prosperous world are cracking down" (Dauvergne 2004, 599-600). Crackdowns and migration control exacerbate potential migrants' lack of access, making them further reliant on agents (van Impe 2000, 113). Niessen and Schibel suggest that restrictions on migration, including those on low-skilled workers, do not reflect demand for migrants $(2003,18) \cdot{ }^{28}$ Boswell and Crisp state,

The increased scale of international migration has been profoundly troubling to many receiving countries. While the industrialised states derive many benefits from immigration, there remains considerable public and political resistance to any liberalization of migration and asylum policy. $(2004,1)$

From a development perspective, de Haan criticises such approaches, suggesting they "pay too little attention to the contribution of migration to poverty reduction: policies tend to ignore migration or have the implicit or explicit aim to reduce migration" (ibid.). Countries, particularly developing ones, rely on remittances from overseas workers to fuel their economies and help compensate for balance of payment deficits and foreign exchange

\footnotetext{
${ }^{28}$ For example, rapid economic growth in Thailand has resulted in higher working standards, decreased fertility rate and as a result, a deficit of cheap labour. Unmet demand for the importation of labour (particularly unskilled labour) has not led Thailand to an opening of the borders, even for temporary economic migrants (Marshall 2001,3). Marshall estimates that there are 6.6million labour migrants in East and South East Asia, half of whom are irregular $(2001,3)$.
} 
shortages. The World Bank reports, "Remittance flows are the second largest source, behind FDI, of external funding for developing countries. In 2001 workers' remittance receipts of developing countries stood at $\$ 72.3$ billion, much higher than total official flows and private non-FDI flows" (Ratha 2003, 157). This is equal to $260 \%$ of their ODA receipts (World Bank in GTZ 2004). This is almost certainly an understatement, given the volume of unregistered and unofficial transfers that are, for example, carried across borders by hand or post. In some sending areas, like the Philippines, transnational migration has come to be associated with travel, money, social mobility and economic power (van Impe 2000,117), fuelling further migration. None of this necessarily results in a generalised concern about protecting migrant rights or expanding migration opportunities by receiving states, in general or as a development strategy.

The world's wealthy migrant-receiving countries have also refrained from adopting measures that would strengthen and protect the rights of migrants. For example, the Convention on the Protection of the Rights of Migrant Workers and Members of their Families (which finally entered into force in July of 2003 after 13 years of failing to gather sufficient signatories and ratifications) has not been acceded to or ratified by any major migrant receiving states. ${ }^{29}$ This is not the only tool that could be used to protect migrant workers, including those who become trafficking victims. As the UN Special Rapporteur on Violence Against Women affirms, there are other international conventions and treaties that have come into force that received greater support and include provisions that protect the human rights of trafficked persons. These include the Universal Declaration of Human

\footnotetext{
${ }^{29}$ As of March 2004, it was ratified or acceded to by Azerbaijan, Bangladesh, Belize, Bolivia, Bosnia and Herzegovina, Burkina Faso, Cape Verde, Chile, Colombia, Comoros, Ecuador, Egypt, El Salvador, Ghana, Guatemala, Guinea, Guinea-Bissau, Kyrgyzstan, Mali, Mexico, Morocco, Paraguay, Philippines, San Tome and Principe, Senegal, Seychelles, Sierre Leone, Sri Lanka, Tajikistan, Timor-Leste, Togo, Turkey Uganda and Uruguay. These are primarily migrant sending states.
} 
Rights, the International Covenant on Civil and Political Rights, the Convention against the Torture and Other Cruel, Inhuman or Degrading Treatment or Punishment, the Slavery Convention and the Supplementary Convention on the Abolition of Slavery, the Slave Trade and Institutions and Practices Similar to Slavery, and ILO Conventions 29 and 105 concerning Forced Labour and the Abolition of Forced Labour, respectively (2000, 9). With so many influential, established and respected instruments, additional and specific instruments protecting migrants and their families, or addressing the harms associated with human trafficking, seem superfluous. Unfortunately, they are not.

From one perspective, the new trafficking-specific instruments might add to the profile of the anti-human trafficking efforts, and the particular formulation aligns with an anti-organised crime perspective. From another, subsequent international instruments are required because national and international regulations and guidelines prohibiting forced labour, violations in the work place and slavery are not enforced when the victims are migrants or particular types of migrants. Gallagher finds attempts to conceptually and legally separate trafficking from labour migration common, leaving the rights of the trafficked as workers unprotected (Population Council 2001, 6). The Trafficking Protocol can define and respond to abuses faced by trafficking victims without expanding migrants' access to rights beyond the right not to have been trafficked.

Just as there are other international mechanisms, pre-existing laws at the national level define, prohibit and detail responses for most if not all of the abuses and infractions included in trafficking. The Save the Children Alliance's regional review of legal systems in the Mekong Sub-region highlights this. When considering the case of Myanmar, the report notes that at the time of publication there were no laws specific to trafficking in the country, but noted that this was not necessarily problematic: there was no component covered by 
anti-trafficking laws in the other countries that were not covered by other laws in Myanmar, including those establishing minimum labour standards and prohibiting kidnapping and confinement (2001). This does not, of course, imply universal application or respect of these legal instruments.

Looking at trafficking-specific instruments and actions, efforts tend to focus on sending areas, movement and facilitators rather than receiving areas. This is the approach taken by the annual US State Department Trafficking in Persons (TIP) Report, one of the highest-profile, most comprehensive annual comparative assessments of anti-trafficking policy and performance. It cites seven causes of trafficking: the first four of which are root causes associated with sending areas. The first is Poverty and Desire for a Better Liff; Ignorance of Trafficking's Consequences (on the part of families and victims). ${ }^{30}$ Though increasing vulnerability, it is not clear to me how poverty or a desire for a better life cause trafficking. The TIP Report also ranks countries into three tiers corresponding to their efforts to prevent, reduce and respond to trafficking, penalising those who do not adequately respond. ${ }^{31}$ In the 2003 ranking, all of tier three (i.e. not meeting even the minimum standards) and over $80 \%$ of tier two were poor, migrant-sending countries. Yet, many of the abuses and harms suffered by trafficking victims occur in receiving areas. This raises the question of the role of the countries like the US, Germany and Japan who are major receivers and exploiters of

\footnotetext{
${ }^{30}$ Causes two through seven, in the order they are presented, are: Dismption of Societal Values (of poor countries by media images from rich countries); Political and Economic Instability (again, in sending areas); Demand for Cheap Labour (rural-urban in developing country focus, with no attention paid to individuals and companies in rich countries profiting from cheap/slave labour); High Profits (for traffickers, again, individuals and companies in rich countries profiting from cheap/slave labour are not included); and Low Risk (because of the lack of rule of law in sending areas only; no mention of lack of will in receiving countries to apply criminal and legal codes to those exploiting irregular migrants) (US Department of State 2003, 7)

31 The tiers are based on countries' compliance with US government's Trafficking Victims Protection Reauthorization Act of 2003 (TVPRA) (ammending the Trafficking Victims Protection Act of 2000). Tier one countries "fully comply" with the Act's minimum standards; tier two "do not fully comply with the Act's minimum standards but are making significant efforts" to do so; and tier three "do not fully comply with the minimum standards and are not making significant efforts to do so" (US Department of State 2004, 28).
} 
trafficked persons. ${ }^{32}$

Restrictive migration policies and practices espoused by donor countries potentially increase both the profits from and incidence of assisted illegal migration, including trafficking. Restrictive migration regimes and crackdowns do not necessarily stop irregular migration, but they increase profits, risks and, potentially, the incidence of trafficking: Illegal migration takes place when there is a demand for migrant labour in host societies, a supply of willing migrants in home societies, and a lack of legal channels to link these demands and supplies. Oxfam-citing research by the Home Office-told us that there is strong circumstantial evidence that measures aimed at preventing access to the EU had "led to growing trafficking and illegal entry of both bona fide asylum seekers and economic migrants"... (House of Commons International Development Committee 2004, 34)

I suggest that the 2000 UN Trafficking Protocol, along with government initiatives like the US State Department annual report on trafficking, are consistent with efforts to prevent or reduce unwanted migration without expanding opportunities or rights for migrants. This is also the case with funding NGOs and IOs to implement trafficking prevention projects, particularly in migrant-sending areas.

${ }^{32}$ The US acknowledges receiving 18-20,000 trafficking victims per year, yet does not "rank" itself (2003, 22). 


\section{CHAPTER 5: NGOs and donors: Co-optation or framing?}

Under the current level of state attention and support to civil society organisations, many NGOs must understand and manage the state funding paradox if they are to make the best of state funding opportunities while remaining independent and accountable to both members and funders (Themudo 2002).

This chapter describes problems associated with NGO-donor relations and introduces co-optation and framing, the two alternate concepts that I use to analyse the seven NGOs and IOs in my study. I begin with a review of general concerns about donor funding, focusing on the six specific concerns raised by David Korten and Antonio Quizon in Government, NGO and International Agency Cooperation: Whose Agenda? (1995). I interpret these six concerns as "symptoms" of donor influence, assumed to come with donor dollars. Then I present and define how I use and what I mean by the concepts of co-optation and framing, ascribing indicators to each. By co-optation, I mean that projects embody donor agendas, priorities and ways of working in ways that are both more profound and inconsistent with the other work or stated priorities of the NGO or IO implementing them. By framing, I mean that organisations present and rhetorically align the projects and work that is on their own agendas in terms that appeal to donors. Framing involves a less profound reflection of donor priorities, a greater degree of independence and implies that NGOs and IOs continue to set their own agendas. Critical positions with respect to donor positions, though not part of framing, counter-indicate co-optation. Korten and Quizon's concerns and these two theories are the basis of my analysis of the seven projects included in my research. In chapters seven through nine, I look for evidence of these symptoms in the projects, asking whether they are exhibited by the organisations and, using the indicators developed in this chapter, whether they are better explained in terms of co-optation or framing.

Overwhelmingly, theorists identify the availability of funding as a key causal factor in the growth of NGOs, yet many cast it in a negative light. This is precisely where my 
examination starts when I look towards donor-funded trafficking prevention projects of IOs and NGOs in Thailand and Cambodia. As confirmed during my interview with a representative from DFID, there is a lot of funding available for anti-trafficking work and NGOs and IOs are aware of this, "Organisations in Bangkok and in the region are very aware that there's a lot of money to be made by saying that they work with trafficking" (Beloe 2003). If funding is a key determinant of the existence of a project, is it also a key determinant of the agenda of organisations? In the latter section of this chapter, I outline two possible responses to this question. First, the framework of co-optation suggests that it is. Second, in contrast, framing suggests that while donor priorities may influence or change how organisations align, present or rhetorically frame the work that is on their agendas, it does not necessarily profoundly change those agendas.

\section{NGOs, IOs and Donors}

Donor funding is sometimes seen as co-opting NGOs from their original ways of working, including their emphasis on downstream accountability and their ability to serve and carry out their development agendas and empower grassroots communities. At its worst, donor funding is seen to make NGOs the "hand servant" of donor country policy overseas (Smillie in Hulme and Edwards 1997, 7). Najam's initial conclusions about NGO accountability are rather pessimistic: in terms of functional accountability, NGOs rank "high" with respect to patrons (i.e. donors); "low-nil" with respect to clients (i.e. intended beneficiaries and target groups); and "low" with respect to themselves. In terms of strategic accountability, they rank "medium" (patrons) “nil" (clients) and "low" (themselves) (1996, 341). ${ }^{33}$ Maslyukivska writes, "NGOs like most other institutional entities tend to focus

\footnotetext{
${ }^{33}$ Functional accountability ("accounting for resources, resource use, and immediate impacts") and strategic accountability ("accounting for impacts that an NGOs actions have on the actions of other organisations and
} 
principally on their responsibilities to their patrons, very often at the cost of their responsibility to their clients and to their own goals and vision" (1999, 23-4).

In development, the context for my study, IOs are characterised as centrally controlled and working towards growth-oriented development while NGOs are seen as broad-based participatory organisations with goals of empowerment and transformatory people-centred development (Heyzer 1995, 2; Hulme and Edwards 1997, 8; Pearce 1997, 258). Korten and Quizon take this distinction further, addressing the different development paradigms associated with different actors. They ascribe to NGOs the role of criticising the growth-centred approach of international assistance agencies, which they consider responsible for contributing to national debt through international assistance and funding projects that displace the poor and destroy the environment $(1995,131)$. Ness and Brechin approach the distinction structurally using Weber's distinction between tall, hierarchic and flat, collegial bureaucracies, expecting NGOs to reflect the latter and to draw their comparative advantage from this. By their analysis, though practices may be increasingly informed by ideas of participatory approaches, UN organizations and other IOs remain very hierarchical in nature $(1988,266)$. All this points to an expectation that NGOs are different from IOs in terms of their goals, structure, ways of working, accountability and definition of development. In particular, NGOs are linked with transformatory projects that politicise and challenge mainstream (i.e. IO) development approaches. The idealised NGO is a grass-roots participatory organisation with a relatively flat (rather than hierarchical) organisation structure, offering an understanding of development that prioritises people rather than economics and aims to empower marginalized groups, particularly the poor. Juxtaposed to this is the co-opted NGO, which, according to critics, mirrors rather than challenges IOs in 
all of these aspects as a result of donor funding. ${ }^{34}$ Though qualitative changes are less straightforward, the increase in numbers of and funding for NGOs is easily confirmed.

The NGO population has grown both in size and legitimacy. International development NGOs registered with the Organisation for Economic Co-operation and Development (OECD) increased in number from 176 in 1909 to 28,900 in 1993 (OECD in Hulme and Edwards 1997, 4). The volume of OECD-Development Assistance Committee (DAC) members' aid distributed through NGOs grew from $0.7 \%$ in 1975 to $5 \%$ in 1993 , and the World Bank estimates that development NGOs' total income from donors grew from $1.5 \%$ in the early 1970 s to $30 \%$ in the mid-1990s (Hulme and Edwards 1997,6 ). ${ }^{35}$ The increase in numbers of NGOs is linked directly to these increases in resources, both financial and in terms of access to official forums (Meyer 1995, 1277; de Fonseka 1995, 63). ${ }^{36}$

Initially, this sounds promising. With developing country government failures, particularly in terms of assisting the poor and conducting effective rural development (Heyzer 1995, 6; Riker 1995, 14; Bebbington and Riddell 1997, 111) and the neo-liberal imperative of state minimalism (Hulme and Edwards 1997, 3; Cooley and Ron 2002, 10), NGOs with their proximity to the poor emerge as an ideal service provider. Through donor-NGO relations, ODA gains legitimacy and NGOs gain resources to pursue development programmes and goals. Maslyukivska points out that donors find NGOs attractive for many reasons, including "poor performance of official donor programs...

\footnotetext{
34 As mentioned, I initially (and erroneously) assumed that IOs directly reflected donor policy.

35 Funding to NGOs (national and interantional) as a percentage of OECD Development Assistance Community (DAC) official and private flows has steadily increased: $0.16 \%(1980) ; 1.45 \%(1985) ; 1.88 \%(1990)$; $2.11 \%(1985) ; 2.72$ (OECD-DAC).

${ }^{36}$ At the Southern African Universities Social Science Conference (SAUSSC) 22nd Biannual Conference in 2001, Chrispin Radoka Matenga summarised the increase in official funding to NGOs as follows, "The rate of growth of official aid to NGOs has far outstripped the rate of growth of the official development assistance (ODA) itself (Fowler: 1992, op.cit : 15). From 1975 - 85, official aid of member countries of the OECD's DAC to NGOs is said to have increased by 1400 percent (Fowler: 1991a: op.cit: 55). It is also indicated in the Human Development Report 1993 that from 1970-1990 government funds channelled through Northern NGOs increased from $\$ 200$ million to $\$ 2.2$ billion (UNDP)."
} 
married with the clear popularity of NGOs for their work" $(1999,16$; also see Hulme and Edwards 1997, 5; Korten and Quizon 1995, 148). This may not be positive: NGOs receive funding that governments are not trusted with and step in to provide services no longer the legitimate realm of the government, reinforcing state minimalism cum absenteeism. This has negative implications for NGOs as well: "many NGO personnel and analysts have major concerns about the contribution that NGOs are making to development and about the ways in which 'success' has changed and is changing them" (Edwards and Hulme 1997, 3).

There are implications associated with IOs and donor agencies using NGOs to legitimise community-level action, as well as for NGOs working alongside donors or using donor resources. Riker brings up two: the nature of the NGO and the ultimate impact on the communities NGOs serve (1995). This latter component is an area that has been neglected by the literature, a trend that I unfortunately continue in this paper as a result of the focus on NGOs themselves rather than their intended beneficiaries. For Bebbington and Riddell channelling donor funds through NGOs encourages the emergence of opportunistic organisations with no popular base, and a focus on NGOs as service delivery vehicles rather than political movements. This results in a weakening of civil society and a disempowerment of popular organisations (1997, 110-11). Hulme and Edwards see increases in donor funding as increasing the likelihood of NGOs becoming implementers of donor policies $(1997,7)$. Pearce considers donor funding to be responsible for transforming NGOs in service of the people into NGOs in service of the donors. She argues that NGOs have been drawn specifically into projects of capitalist modernisation and political liberalisation, part of a larger neo-liberal agenda, through official bilateral and multilateral funding agencies and governments, "Serving the state and big external donors can and often does contradict with social transformatory projects involving the empowerment of the poor" 
(1997, 258; also see Maslyukivska 1999, 4). Despite a relatively optimistic evaluation of NGOs as providers of international public goods, Meyer comes to a similar conclusion: NGOs that are reliant on external donors are best understood as "independent entrepreneurial economic entities - not as advocates of grassroots justice" (Pearce 1995, 1287). The underlying assumption of these criticisms is that NGOs, like rational actors in mainstream economic theories, respond to "market signals" from donors and change to accommodate them in order to access or maximise their resources.

Aside from national governments, NGOs and IOs are the major actors in development. Initially expectations, like those in this chapter (Korten and Quizon 1995; Ness and Brechin 1988), characterise IOs as more closely aligned with donor positions. Though IO projects may obtain core funding internally, from their parent organisations, they also obtain funding the same way the NGOs do: by submitting project proposals to donors. ${ }^{37}$ Furthermore, my research and analysis suggest that IOs have substantial independence and may use it to express views and opinions that are highly critical of the donor community. Though the literature focuses on NGOs, my research includes IOs.

There are some problems with the type of dialectical good/bad opposition of the helpful NGO and the self-interested donor or international agency that I reference. First, NGOs are an internally diverse population and criticisms largely rely on assumptions of what NGOs should be. Secondly, NGOs engaging in partnership could help build support for the more transformative development agenda at the level of the donor organisation or government. Third, it is not necessarily the case that on particular issues, NGO and donor positions are different to begin with. Meyer's study of environmental NGOs in Latin America finds that though the organisations were closely linked to governments and

\footnotetext{
${ }^{37}$ For example, the ILO trafficking prevention project is funded by the UK government's Department for International Development (DFID) (Beloe 2003; van de Glind 2003).
} 
designed to "capture Northern funds" in opportunistic ways, they were also committed and useful in the production of international public goods. She writes, "Self-interested economic behaviour is shown to be consistent both with opportunism and with altruism" (1279). This sets out the possibility that even if the accusation of close alignment to international or government development agendas is demonstrated to be true, it does not by extension imply a lack of positive intentions, loyalty or commitment to grass-roots goals of these organisations. ${ }^{38}$ However, Korten and Quizon suggest that without a clear vision, NGOs are likely to be co-opted "given their substantial dependence on funding from governments, businesses and international agencies" $(1995,141)$. They lay out six particular areas of change and concern about NGOs accepting international funding that I use in chapters seven through nine to analyse and evaluate the trafficking prevention work of the organisations I study. In the remainder of this section, I present and elaborate on these six concerns, drawing parallel arguments from other researchers and theorists.

The first two are linked: the creation of bogus or opportunistic NGOs and the co-optation of legitimate NGOs who, with new opportunities, "find it easy to justify adjusting their agendas to the priorities of donors on the grounds that this will allow them to serve more people in need." The end result of this, the authors claim, is a disproportionate increase in "politically benign activities":

The fact that the foreign funding on which Asian NGOs remain dependent comes increasingly from official agencies, raises significant concerns regarding prospects that this funding will ultimately co-opt NGOs to the official donor agendas and away from their contributions to the transformative agenda (Korten and Quizon 1995, 152-4)

\footnotetext{
${ }^{38}$ Regardless of the motivations, Meyer insufficiently addresses the pressing issue of whether accountability to donors takes precedence over or conflicts with accountability to intended beneficiaries: she recognises donor goals and organisation goals but not beneficiary goals. This is a tendency in the literature which, unfortunately, I continue with this study.
} 
Funding will not be available for projects that donors do not support (Meyer 1995, 1286), so NGOs must either forego this source of funding for these projects, possibly abandoning the project itself, or make compromises to please the donor. According to Meyer, "NGOs will provide public goods, at best, in an uneven fashion - skewed toward international tastes or government objectives" (ibid.). Hulme and Edwards see this in terms of a loss of diversity among NGO types and interventions as NGOs change to better access to donor funding (1997, 8-9), an argument continued by Cooley and Roy: "When an organization's survival depends on making strategic choices in a market environment characterized by uncertainty, its interests will be shaped, often unintentionally, by material incentives" $(2002,13)$.

A third concern is short-term commitment to long-term needs. Donor agencies tend to offer short-term contract-like project-focused funding packages: a predictably constraining practice in the context where neither donors nor NGOs perceive their goals to be short-term (Korten and Quizon 1995, 153). As a direct result of the short-term projectspecific nature of donor funding, Fyvie and Ager expect a lower level of innovation than expected from the flat organisational structure of NGOs due to their lack of resources for innovation or unplanned activities $(1999,1388)$.

Legitimation of donor policies and projects is a fourth issue. International assistance has lost popularity with northern tax-payers, particularly where large-scale government projects have demonstrably not helped the poor. NGOs with their reputations as effective, grassroots, poor-focused organisations may be seen as a remedy. But this does not mean that funders change their approaches to reflect NGO goals or ways of working, "Mostly they look to NGOs to serve as contractors working under close donor supervision to help implement - and legitimate - donor designed and funded projects." According to Korten and Quizon, the World Bank is particularly guilty of this $(1995,154)$. These are the 
terms under which Levine explains the convergence of the historically different agendas of conservation and development NGOs in Tanzania. Though this may be partially explained by independent changes in both sectors, "NGOs may also be serving to carry out and legitimate the neoliberal policies of development institutions" in particular, international financial institutions (Levine 2002, 1043).

Fifth is the bureaucratisation of NGOs. Korten and Quizon see donor requirements to conform to standards of professionalism as driving out the "voluntary spirit" of NGOs and refocusing the accountability of NGOs away from beneficiaries and towards donors (Korten and Quizon 1995, 152-4; also Fyvie and Ager 1999, 1394; Hulme and Edwards 1997, 9). Hulme and Edwards find that as both southern (local) and northern (international) NGOs become closer to and more reliant on donors, they are more likely to become like donors and imitate their bureaucratic focus on unit cost, quantifiable output and logistical frameworks as organisational norms. These practices are inconsistent with NGOs as organisations that promote qualitative change and view planning and management as learning processes for communities and workers (ibid., 8). Fyvie and Ager see donor pressure for efficiency, quantifiable outputs and for NGOs to scale-up, moving them away from the grassroots (i.e. a trade off of quality in favour of quantity) $(1999,1388-94)$. A related phenomenon is the premium placed on skills required to fulfil donors accountability and reporting requirements. This is seen in NGO employment practices that favour those with English language and financial accounting skills (Hulme and Edwards 1997, 8-9).

Finally, donor-funding of NGOs is criticised for creating barriers to the selfreliance and empowerment of people's organisations. Korten and Quizon distinguish between donor-funded and community driven NGOs, and the way "many NGOs, even while espousing empowerment, have in fact been maintaining dependence on their own 
presence," through such means as diverting attention from mobilizing local resources (1995, 152-4). Hulme and Edwards echo this concern in their conclusions, "As is happening today in the large NGOs of both North and South, the focus of attention has shifted away from empowering others for independent action, towards empowering NGO leaderships and servicing the organisation and its own ends.” $(1997,282)$.

Fyvie and Ager take this line of argument further, pointing out that sensitivity to and reliance on donors leads to inter-NGO competition, itself limiting information-sharing $(1999,1392-3)$. Cooley and Ron come to a similar conclusion through a political economy approach. "Marketization" of activities through bidding and contracting (as is practiced by donor agencies and governments) "generates incentives that produce dysfunctional outcomes" rather than improving efficiency through "market-based initiative", forcing organisations towards competition despite their common normative origins (2002, 6-8).

Even within the literature described in this chapter, there is a constructivist recognition that bargaining, negotiation and influence between donors and NGOs is a twoway street (i.e. Hulme and Edwards 1997, 11). However, the authors emphasise the aspects of co-optation of NGOs:

Given these realities, it is almost inevitable that the official assistance agencies define the development problem in terms that are shaped more by the growth-centred development vision that gave them birth, the foreign policy agendas of the governments that created and fund them, and their own bureaucratic imperatives than by the needs and realities of the poor. (Korten and Quizon 1995, 149)

In the context of my work, where anti-trafficking work is new for organisations, their engagement reflects a type of entrepreneurship that may be understood as co-optation (where they change their work to substantively reflect donor agendas) or framing (where they rhetorically reflect donor priorities, maintaining more independence and fidelity to their own priorities and agendas). Preferences and priorities of donors represent opportunity 
structures for NGOs. ${ }^{39}$ The goals and ideals of donors informing their funding decisions and preferences are not necessarily shared by NGOs. Yet, to run their projects, all of the organisations in my study use and rely on donor funding (refer to table four, chapter three). Alec Bamford of CUSO Thailand reported that funding sources for Thai NGOs are almost all external, but even where domestic sources of funding are available, private and government preferences determine possibilities:

The NGOs were created through funding mechanisms that came from outside the country... Some of them have built up a domestic fund-raising base but those are mostly the NGOs that are dealing in something that's sexy that they can sell - so the child-focused NGOs have got it. Human rights NGOs can't access that kind of money. Environmental NGOs have no hope in Thai society. The Thai government has given money to NGOs in two areas: one is HIV/AIDS, where I think the effect has been pretty positive, basically because the Ministry of Public Health is by far the most sensible ministry; the other is Environment, where it's been the record is much patchier. (Bamford, 2003)

To date, Foundation For Women has enjoyed freedom to exercise their discretion in the design and implementation of project activities. However, the organisation is concerned about "the role of the international agencies - the funding agencies":

Some say that the funding agencies can participate at all levels, but some think that their role is just to fund us, to support us. On certain matters you can have a discussion or dialogue, but funders should not be like one of our staff... I think that it's the local agencies who should be the ones who decide what they would like to do, not just imposing the policies of the funding agencies... You know that trafficking is a hot issue and therefore everyone would like to do something. Like the UN agencies, nearly all of them working on this. ${ }^{40}$ (Skrobanek 2003)

\footnotetext{
39 Tarrow defines political opportunity structures as "consistent - but not necessarily formal or permanent dimensions of the political environment that provide incentives for collective action by affecting peoples' expectation for successes or failure." Theorists tend to "emphasise the mobilization of resources external to the group" (n.d., 13).

40 Though I do not delve into project budgets, Scrobanek also expressed concern about the percentage of funding going towards administrative costs and salaries for expatriats as opposed to that going directly into village-level implementation of activitites for certain projects.
} 
In the remainder of this chapter I present the two approaches to understanding the influences of donor agendas on the organisations they fund. Co-optation suggests that funding from donors profoundly and directly influences development organisations, and that these organisations limit their independence and change their agendas to access and maintain funding. Framing, drawn from social movement literature has insights explaining how organisations might mobilise support while maintaining more independence and pursuing their own goals and objectives. I ascribe indicators for co-optation and framing to each of Korten and Quizon's six concerns. Though my analysis and research does not fully address each of these issues, these six "symptoms" and implications of donor influence are key to my evaluation of projects and organisations.

\section{Co-optation}

Cress and Snow ask in their 1996 study of social movement organizations, "Does external support or patronage lead to co-optation or control?" Co-optation, answering this question in the affirmative, is the first of two concepts that I use to analyse donor-funded trafficking prevention projects and problematise funding relationships. This section outlines and clarifies what I mean by co-optation.

As suggested in the previous section, donor dollars have allowed NGOs to implement more projects and to grow in size and number. All of the trafficking prevention projects in my study are funded at least in part by official bilateral or multilateral donors. As Cress and Snow point out, such external support is generally understood to come with strings attached: "The literature suggests that external support comes with a cost: generally a loss of SMO autonomy; more particularly a moderating influence with respect to SMO objectives and strategic actions" (Cress and Snow 1996, 1104). ${ }^{41}$ Donor funding is

41 Along with most other theorists cited in this section,Cress and Snow focus on social movement organisations (SMOs). The organisations included in my study do fit under Cress and Snow's general classification scheme, 
associated with demands, conditions, accountability to donors and a potential loss of independence for the organisations receiving funding (Themudo 2002). It "distorts" the work of NGOs (UN NGLS 1995) and makes organisations less accountable to "constituent communities," diverting efforts to activities that are justifiable in donor reports (Igoe 2003, 863). By co-optation, I mean a significant discursive and substantive espousal and pursuit of donor positions and priorities. As I focus on development organisations, not donors, I employ the concept of co-optation relative to the NGOs' or IOs' willingness to take on donor agendas, rather than in terms of donors imposing agendas. NGOs and other development organisations may co-opt themselves, adapting themselves so as to better reflect and implement donor priorities, in the interest of gaining or maintaining access to funding.

When addressing co-optation, some theorists focus on the donor as the actor that is co-opting the NGO. For example, Selznick's definition of co-optation is "the process of absorbing new elements into the leadership or policy-determining structure of an organization as a means of averting threats to its stability or existence" (in Eckstein 1976, 151)..$^{42}$ Chan and Lee have a similar understanding, "Co-optation is the process of bringing outsiders (usually resource-poorer) inside (usually resource-richer) so that the outsiders' views can be put in line with those of the central authority" $(1991,291)$. This is not my

though, taking on both "caretaking" and "activist" roles $(1996,1094)$. I do not assume development NGOs to be less political than SMOs, nor do I assume caretaking in the context of development to be value neutral: the choices made in caretaking reflect and embody particular development paradigms. For example, Korten and Quizon refer particularly to "transformative" vs. "neo-liberal" development agendas $(1995,149)$.

${ }_{42}$ Eckstein discusses co-optation from the point of view of donors, or other more powerful actors choosing to become engaged with organisations like NGOs, who lack perhaps financial resources by have, perhaps, greater legitimacy, "Co-optation and incorporation primarily arose not because organizations per se had come to terms with forces in their environment nor because the regime, with its revolutionary nomenclature, was above all committed to serving the poor. Rather, they were responses to an 'opportunity structure' which induced leaders, largely for opportunistic reasons, to affiliate with national political and administrative groups, either individually or together with other members of their groups. The 'popular' or 'grass-roots' doctrine and organization facilitated acceptance of the 'official' party and the government and enabled the government to stand as the champion of local residents, while the co-optative process enhanced the stability of the regime" (Eckstein 1976, 162). 
approach, and this is not how I am defining or using co-optation in this thesis. My analysis includes donors insofar as they represent an opportunity structure for organisations seeking funding from them (i.e. they are willing to fund certain projects or activities that fit with or further their goals, but are unwilling to fund those which do not). I am not looking at the intentions or actions of donors, or their moves to co-opt, divert or disempower NGOs or other organisations. Donors have priorities, views and goals that are made known through their funding priorities and expressed through their funding choices. In my analysis, I emphasise the organisations which themselves choose to emphasise or take on projects that fit with donor ways of working, goals and priorities. In other words, I ask whether the organisations I study, particularly the NGOs, are co-opting themselves by bringing themselves into line with the priorities and agendas of the resource-rich (i.e. donors) in order to access funding.

In implementing trafficking prevention projects and tapping into donor funds, are organisations co-opting themselves? Korten and Quizon say that NGOs receiving or dependent on donor funding may "find it easy to justify adjusting their agendas to the priorities of donors on the grounds that this will allow them to serve more people in need" $(1995,152)$. From the perspective of my research, this implies that development organisations focus their organisational resources on designing and implementing projects that they expect to be funded because they reflect donor priorities and approaches. This could be considered a type of entrepreneurship, but as Najam and Maslyukivska pointed out, it is an entrepreneurship that is responsive to donor preferences. This responsiveness is different from development organisations designing and taking on projects because they reflect their own understanding of development needs. It is also different from basing agendas on the priorities articulated by the communities they serve. 
As I have not done time-series research, and as all of the organisations in my study both started and continue their projects with donor funding, I cannot examine changes before, after or with different levels of donor funding. In place of using this type of observation, I use independence from and criticism of donor positions as indicators. Independence and criticism are both inconsistent with an understanding in terms of cooptation. However, I do not assume that a lack of criticism or independence supports cooptation because, as Cress and Snow point out, it is possible that organisations and donors establish relationships based on shared views and approaches, "Such findings fit the resource dependency perspective in the broader organizational literature, which argues that the goals and actions of resource-dependent organizations are likely to resemble those of the organizations on which they depend" (1996, 1106; also see Chan and Lee 1991, 292).

Whether any such resemblance is by accident or entrepreneurial design is difficult to determine, but it is very relevant to my study. I consider it probable that organisations in my study and their donors both benefit from their donor-recipient relationship. ${ }^{43}$ It is also likely that they share the broad goals of development in general, and are committed to of reducing the harms associated with trafficking. Beyond these general aims, priorities, agendas and preferred ways of working may also be identical, and as such a funding relationship or even donor-dependency would not involve change or co-optation away from either organsiation's original position. As chapter four outlined, donor countries have fairly explicit policies and intentions to limit and reduce migration in general. These policies are accompanied by coercive and punitive responses like border crackdowns intended to stop irregular migration, though they may actually increase profits for traffickers and smugglers and increase the risks

\footnotetext{
43 The question of why donors choose to work through NGOs is not the focus of my work, but there are ample suggestions that it is related to the perceived legitimacy of the NGO and the flagging favour in which ODA and large government and bilateral development initiatives function (see, for example, Maslyukivska 1999, 16; Korten and Quizon 1995, 148).
} 
for certain migrant populations. There are also stated and explicit intentions on the part of some donors to use aid moneys to reduce migration pressures and to address trafficking by focusing on root causes in sending communities (where there is a great deal of overlap between root causes of migration and so-called root causes of trafficking), as well as a reluctance to protect the rights of trafficking victims as migrants. As mentioned in chapter four, there is evidence that these views and positions, though evident, are not universally shared. As my research is not sufficiently comprehensive to determine whether any such resemblance is the result of chance or cultivation, I can not interpret it as either supporting or contradicting an understanding in terms of co-optation. However, though donor, NGO and $\mathrm{IO}$ agendas may be similar, I do not expect them to be the same.

Though there is likely a great deal of shared ground between NGOs, IOs and donors when addressing trafficking, there are also points of difference. As discussed in chapter two, I assume donors will prioritise issues of state sovereignty and migration control, while NGOs will prioritise human rights considerations. In particular, I expect remedies calling for an opening of migration opportunities and an extension of rights to irregular migrants to be potentially consistent with the work of NGOs but not necessarily with donors. Once again, it is possible that a variable I neglect, namely differing positions from within donor country governmental departments, plays a role here. It is possible that development agencies, such as DFID, fund outside organisations to do work (including lobbying) that challenge and criticise their own governments' positions. Even so, a lack of criticism of donor positions could be consistent with co-optation. With so many possibilities for misinterpretation, I use the concept of inconsistency, indicated by projects or project activities that are incongruous with the larger context of the organisation, to indicate cooptation (see table six, below). 


\begin{tabular}{|l|l|l|}
\hline \multicolumn{1}{|c|}{ Table 6: Co-optation } \\
\hline \multicolumn{1}{|c|}{ Supports co-optation } & \multicolumn{1}{|c|}{ Inconclusive } & Contradicts co-optation \\
\hline $\begin{array}{l}\text { - Projects and activities that are inconsistent } \\
\text { with other projects or latger organisational } \\
\text { structure/ ideals of the implementing } \\
\text { NGO/IO }\end{array}$ & $\begin{array}{l}\text { - Projects, activities, thetoric } \\
\text { that mirror donor positions } \\
\text { and priorities }\end{array}$ & $\begin{array}{l}\cdot \text { Projects and activities that } \\
\text { challenge donor positions } \\
\text { and priorities }\end{array}$ \\
\hline $\begin{array}{l}\text { - Lack of criticism of donor positions even } \\
\text { where donor positions are inconsistent with } \\
\text { NGO/IO structure/ ideals }\end{array}$ & $\begin{array}{l}\text { - Lack of criticism of donor } \\
\text { positions }\end{array}$ & $\begin{array}{l}\cdot \text { Criticism of positions } \\
\text { associated with donors }\end{array}$ \\
\hline
\end{tabular}

In relations where organisations receive outside funding, co-optation is a risk, but not a foregone conclusion. As mentioned, goals may be shared across the donor-recipient divide or, despite concerns about co-optation and loss of independence, autonomy may not be compromised. Cress and Snow conclude that where donors and recipients do not already share agendas and priorities, outside funding has either moderating or professionalizing effects on social movement organisations $(1996,1104)$. Themudo found that donor funding did not alone determine autonomy:

The evidence collected shows that, counter to initial expectations based on the literature, state funding was neither necessary nor sufficient to produce NGO dependence on the state. NGOs can and often do pursue strategies to maintain their independence even in conditions of high reliance on state funding. Under the right conditions NGOs can and do 'bite the hand that feeds them'... (2002)

Though Jenkins and Eckert approach co-optation from the perspective and context of donor intentions, their findings also leave significant room for autonomy and fidelity to original agendas. Looking at the black movement in the US, they find that donor funding "channeled the movement into professionalization forms. But it did not divert the movement from the black power agenda or unruliness", suggesting that, " "channelling" is a more apt metaphor for analyzing the impact of elite patronage on social movements than the metaphor of "controlling" or "coopting" " $(1986,828)$. Donor funding raises concerns, but it does not necessarily result in what I have outlined as co-optation. Framing, presented in the remainder of this chapter, provides a different understanding. 


\section{Framing}

Even though NGOs and IOs rely on donor funding, co-optation, suggesting that organisations change in response to funding opportunities, is not a foregone conclusion. Framing provides an alternate way of understanding relationships between organisations and their donors. To motivate support, organisations frame and align their political agenda in ways that they expect to resonate meaningfully with their target audiences and so motivate action. Snow, Rochford, Worden and Benford explain frame alignment as follows, "By frame alignment, we refer to the linkage of individual and SMO [social movement organisations] interpretive orientations, such that some set of individual interests, values and beliefs and SMO activities, goals and ideology are congruent and complementary" (Snow, Rochford, Worden and Benford 1986, 464). NGOs and IOs may present and align their own agendas in ways that resonate with donor funding priorities, i.e. trafficking, primarily changing the way they present their work rather than the work itself.

Goffman's 1974 Frame Analysis presented the idea that humans actively classify, organise and interpret experience, through frames and framing processes used to "locate, perceive, identify and label" occurrences and information $(1974,21)$. This approach to cognition and the construction of meaning has since been taken up across social science disciplines (Benford and Snow 2000, 616). It has also been applied to organisations, initially by David Snow and colleagues relative to social movement organisations (SMOs) to examine how they group, identify and label certain phenomena in order to motivate action or mobilise resources (McAdam, McCarthy and Zald 1996, 5). In their 1986 text, Snow, Rochford, Wardon and Benford expanded Goffman's primarily psychological "frame analytic perspective" and applied it to resource mobilization, "By rendering events or occurrences meaningful, frames function to organize experience and guide action, whether 
individual or collective." This has been further applied by theorists like Keck and Sikkink to the international level in their analysis of the tactics of trans-national advocacy networks (TANs) (1999).

Reviewing the literature on framing analysis, Benford and Snow present framing processes as one of three keys to understanding social movements (the other two are resource mobilisation and political opportunity) (611). For my analysis of trafficking prevention projects, I apply this in a slightly different manner: framing processes as a strategy for resource mobilisation for NGOs and IOs. Their ability to mobilise resources depends on their success in targeting and selecting frames that resonate with donors, who themselves partly determine political opportunities for these organisations.

There is specialised terminology around this approach. Frame alignment is the generalised concept of framing, a precursor for and motivator of participation (or, in the context of my study, gaining funding) (Snow et al 1986, 464). Strategic framing processes include selecting, organising, and ordering complex reality through problem definition; offering solutions and providing justification for action (diagnostic, prognostic and motivational framing respectively) (Snow and Benford 1988, 201). For Keck and Sikkink, core framing tasks include negotiating shared understandings, particularly around the idea that something needs to change, but also around who is to blame for the current situation and what alternatives there are for responses or remedies $(1999,615)$. I have already suggested that different stakeholders have different diagnoses, prognoses and motivations when addressing trafficking. For example, I suggested in chapters two and four that human rights advocates and development workers may see trafficking as a problem of restrictive migration regimes and exploitation, while the Trafficking Protocol interprets it as organised crime. 
Also important to my work are organisational frames (Evans 1997, 454), meaning an organisation's "general, central or primary frame" (Gerhards and Rucht in Keck and Sikkink $1999,618)$. For example, from the organisations in my study, the ILO is primarily organised around labour issues and Save the Children UK around children and child rights. I rely on organisational frames to suggest (in)consistency and use this to distinguish evidence of cooptation from that of framing.

Snow, Rochford, Worden and Benford describe four framing processes used to these ends: bridging, amplification, extension and transformation $(1986,464)$. This is the how of framing. Of these, bridging and transformation are most relevant to my analysis. This explains how organisations link their own agendas and priorities to those of donors. Frame bridging is the linking of two or more "ideologically congruent but structurally unconnected frames" around a particular issue (ibid., 468). For organisations working against trafficking, this may involve designing information campaigns etc. that conceptually link ("bridge") trafficking with another frame (i.e. human rights or organised crime) in order to mobilise resources and support for their work. Frame transformation is required and used when the chosen frame does not resonate with, or indeed conflicts with "conventional lifestyles or rituals and extant interpretive frames." (ibid., 468). To secure mobilisation, organisations may need to discard old frames and define their work in terms of new, more motivational ones. They work to redefine an activity or event that is already meaningful relative to one framework, which is proving ineffective in terms of resource mobilisation or other goals, in the terms of another new and inspiring frame, "such that they are now 'seen by the participants to be something quite else" " (Goffman 1974, 45; Snow, Rochford, Worden and Benford 1986, 474). For example, as I suggest in chapters six and nine, IOs and NGOs 
redefine their development interventions in terms of trafficking outcomes, a frame transformation from "development" to "anti-trafficking".

At particular times and in particular societies, certain frames are more compelling, more recognised and more used than others. Benford, Snow et al. refer to these as master frames and global interpretive frames (Snow, Rochford, Worden and Benford 1986, 475). Master frames are large scale, widely accepted and highly motivational concepts. An example of a master frame is that of human rights. Thus the strategy of presenting gender equality or migrant's rights as human rights. Global interpretive frames are easier to explain through example: I suggest that one of the dominant new global interpretive frames has its home in the US national security framework. Appraising the world through this lens has changed perspectives and rearranged priorities on civil liberties, immigration policy (see Stasiulis and Bakan 2003, 29-30), military investment, international relations and so on such that they are now interpreted in terms of security.

Looking at trafficking discourse, I find a variety of master frames at play, including organised crime (particularly strategic as an attribution, it meets the motivational needs of a short causal chain to a perpetrator and has proven successful in mobilising UN and national government support ${ }^{44}$ ); human rights (human rights advocacy is well established in the NGO and IO community and has a great deal of currency internationally); human security (which is becoming established as a master frame, as more organisations and interests align and identify themselves with it); gender equality; and women and children (in the case of trafficking as victims). One might even argue that trafficking itself is fast becoming a master frame. Trafficking has gained sufficient currency and sway internationally that other projects

\footnotetext{
44 Joachim finds that criminal and human rights framings of trafficking resonate most strongly with the UN (Joachim, 2002: 18). Keck and Sikkink observe that responses are more effectively motivated when this includes a short causal link made to an identified "perpetrator" (1999, 616).
} 
are aligning themselves with trafficking discourse, or working to label their efforts and goals as "anti-trafficking". Like Sanghera (2002), I find this problematic. It conflates trafficking with, for example, sex work. Though trafficking is powerful for mobilising resources and support, it does not have a monopoly on "badness". However, it may be tactically more effective.

The success of these efforts, as well as framing for resource mobilisation, depends not only on the extent to which the chosen frame resonates with the organisations at which they are targeted, but also the political opportunity structure (obstacles and opportunities) in which the organisations are working (Joachim 2002, 18). As such, even if I find framing to be the better explanation, it still implies that organisations are on one level reinforcing rather than challenging donor positions (i.e. a primary framing task seems to be packaging things in ways that donors already prefer, rather than challenging and changing these preferences).

Projects are informed by the frames they work with, and the processes of negotiation and creating meaning are continuous. Framing processes can be seen as having already occurred to mobilise the resources and political will internationally to create the UN Trafficking Protocol, as well as to mobilise resources for projects. Though both the protocol and project designs are static documents, the ways in which they are understood, interpreted and implemented are not. Framing theory potentially provides insight into ways of understanding NGO engagement in anti-trafficking: perhaps it is evidence of donor cooptation, or perhaps it is evidence of strategic framing on the part of NGOs to try to capture donor resources for current work, reframed. In the latter case, anti-trafficking work may be seen as putting old wine in new bottles (i.e. doing the same old thing but calling it something new). Given framing's constructivist nature, organisations may consider their product to be new wine! 
Beyond using the generalised idea of framing to explain how organisations may tap into donor resources without substantively changing their own agendas, particular framing terminology and ideas are useful for my analysis. As I have indicated, I rely on the concept of organisational frames to determine whether organisations implementing trafficking projects in ways that are consistent with (framing) or inconsistent with (co-optation) their objectives and other work. I also compare how organisations frame trafficking itself, diagnostically and prognostically. For example, in chapter two I demonstrated that many of those working in Cambodia and Thailand, including organisations from my study, "diagnose" trafficking in the sub-region as an outcome of restrictive migration regimes. In terms of prognoses and responses, both donors and implementing organisations may frame development activities (microfinance, education, gender promotion, etc.) as potential remedies to problems associated with trafficking (i.e. addressing the root causes), bridging community development to trafficking prevention (see chapters six and nine). I have already mentioned that frame bridging and transformation are key to linking organisational frames and work agendas to donor goals and priorities. Table seven (below) sets out criteria for accepting co-optation vs. framing relative to each of Korten and Quizon's six concerns highlighted in the first part of this chapter. My criteria are not unproblematic. ${ }^{45}$ But they are my conceptual starting point, operationalising these six areas of concern and distinguishing co-optation from framing for my analysis of the NGOs' and IOs' trafficking prevention work in chapters seven through nine. Before looking at the trafficking prevention projects of these organisations, chapter six examines trafficking and potentially responses to trafficking conceptually, using theories and models of migration.

\footnotetext{
${ }^{45}$ For example, observations of "resource capturing" behaviour is consistent with both theories.
} 


\begin{tabular}{|c|c|c|}
\hline \multicolumn{3}{|c|}{ Table 7: Co-opted or Reframed? } \\
\hline Concern $^{46}$ & Co-opted (indicates co-optation) & Reframed (indicates framing) \\
\hline $\begin{array}{l}\text { Emergence of } \\
\text { bogus or } \\
\text { opportunistic } \\
\text { NGOs (NGOs as } \\
\text { primarily donor- } \\
\text { responsive) }\end{array}$ & $\begin{array}{l}\text { Objective of resource-capture dominant, } \\
\text { new organisations/ projects "out of the } \\
\text { blue" } \\
\text { - Little evidence of organisational identity } \\
\text { (particularly where potential conflict with } \\
\text { donor interest) } \\
\text { - Projects repeat donor agendas }\end{array}$ & $\begin{array}{l}\text { - Multiple, continuing objectives, } \\
\text { organisations taking up projects that are } \\
\text { consistent with organisational frame } \\
\text { - Evidence of organisational identity } \\
\text { beyond donor funding objectives } \\
\text { - Broader, possibly politicised engagement } \\
\text { in issues, possible contradiction of donor } \\
\text { position in advocacy/ work }\end{array}$ \\
\hline $\begin{array}{l}\text { Agenda change to } \\
\text { match donor } \\
\text { priorities }\end{array}$ & $\begin{array}{l}\text { Do not take on activities that donors do not } \\
\text { fund } \\
\text { - Homogeneity of activities across different } \\
\text { organisations } \\
\text { - Uncritically accept and implement donor } \\
\text { policy }\end{array}$ & $\begin{array}{l}\text { - NGO influence on donor agendas, ways } \\
\text { of working, priorities } \\
\text { - Organisations of different types engage in } \\
\text { different interventions } \\
\text { - Possibly accept but criticise/ add to } \\
\text { donor policy }\end{array}$ \\
\hline $\begin{array}{l}\text { Projects match } \\
\text { donors time- } \\
\text { cycles and } \\
\text { funding periods }\end{array}$ & $\begin{array}{l}\text { - Short-term commitment to long-term needs } \\
\text { - Lower levels of innovation and } \\
\text { responsiveness (implementers not } \\
\text { innovators) } \\
\text { - Match donor time-lines; focus on } \\
\text { quantifiable indicators }\end{array}$ & $\begin{array}{l}\text { Long term involvement with target } \\
\text { groups, consistency } \\
\text { - Merging of organisational innovations } \\
\text { and technologies } \\
\text { - History and intention of long-term } \\
\text { commitment; or project designs that are } \\
\text { not high-input, attention to qualitative } \\
\text { change }\end{array}$ \\
\hline $\begin{array}{l}\text { Legitimisation of } \\
\text { donor policies } \\
\text { and projects }\end{array}$ & $\begin{array}{l}\text { - Neither rhetoric nor action to challenge } \\
\text { larger framework of IOs (especially IFIs) } \\
\text { - Avoidance of controversial issues, especially } \\
\text { expansion of migration rights } \\
\text { - Focus on knowing what donor positions are }\end{array}$ & $\begin{array}{l}\text { - Rhetoric/action critical of donors } \\
\text { - Politicised engagement in issues } \\
\text { - Focus includes informing donors of } \\
\text { alternate positions }\end{array}$ \\
\hline $\begin{array}{l}\text { Prioritise donor } \\
\text { standards of } \\
\text { professionalism } \\
\text { (i.e. English } \\
\text { language, } \\
\text { quantifiable } \\
\text { outputs) }\end{array}$ & $\begin{array}{l}\text { Professional, language skills for receiving } \\
\text { country emphasised } \\
\text { - Planning and management conducted as } \\
\text { precedent to not part of learning processes for } \\
\text { beneficiaries } \\
\text { - Focus accountability away from beneficiaries } \\
\text { and selves towards donors; competition and } \\
\text { limited information sharing between NGOs }\end{array}$ & $\begin{array}{l}\text { Accommodation of donor needs without } \\
\text { sacrificing organisational or beneficiary } \\
\text { needs } \\
\text { - Continued infusion of participatory } \\
\text { processes (beyond mere symbolism) } \\
\text { "Indicators" of success drawn from } \\
\text { community or organisational goals, } \\
\text { accountability based on meeting these } \\
\text { goals }\end{array}$ \\
\hline $\begin{array}{l}\text { Communities } \\
\text { depend on } \\
\text { external funds }{ }^{47}\end{array}$ & $\begin{array}{l}\text { Definition of problems in ways including or } \\
\text { requiring NGOs for their solution }\end{array}$ & Same \\
\hline
\end{tabular}




\section{CHAPTER 6: Trafficking as migration}

Diagnosing trafficking as an outcome of restrictive migration regimes and prescribing the remedy of increasing migration opportunities, particularly for lower-skilled and lower income migrants, does not fit with many donor-country policies. However, responding to trafficking and other undesired migration by addressing root causes does. Bettina Scholdan makes this very point in her analysis of the role of development assistance in conflict prevention: "the paradigm of aid as a form of conflict prevention and resolution is closely related to, if not determined by another new paradigm: preventing migration through eliminating its root causes" ${ }^{348}$ (2000).

The UN Special Rapporteur on Violence Against Women takes the position that trafficking must be viewed in the context of migration, particularly of harms committed against migrants and the shortage of safe and legitimate migration opportunities:

Women move and are moved, with and without their consent, for a myriad of reasons. Trafficking in women ${ }^{49}$ must be understood to exist within a continuum of women's movements and migrations. The Special Rapporteur is of the firm belief that women and all other persons must enjoy freedom of movement... trafficking must be considered in the broader context of violations that are committed against women in the course of their movement and migrations. (UN Special Rapporteur on Violence Against Women 2000,6)

This is echoed by the UN Secretary General, who criticises the current protocols for focusing on trafficking and smuggling only as transnational crime, pointing to the need to

48 " "Aid in place of migration?" is the title of a compilation of papers presented at a joint meeting of UNHCR and the International Labor Organization that took place in Geneva in 1992. W.R. Böhning and M.-L. Schloeter-Parades. Aid in place of migration?. Selected contributions to an ILO-UNHCR meeting. Geneva: International Labour Office 1994." (Scholden 2000). Scholden further suggests that "the root cause strategy does not primarily flow from the idea that it is indeed better to prevent human rights violations from happening and thereby removing the necessity to flee but from the factual unwillingness of industrialized states to protect refugees and from the difficulty to clearly distinguish between Convention refugees and persons who have left their countries of other reasons" (Scholdan 2000).

49 "Despite recognition of trafficking as a global phenomenon that cuts across age and gender, in accordance with her mandate and expertise, the Special Rapporteur has limited this report to trafficking in women.

However, the definition proposed and the analysis provided of core elements, trafficking routes, causes and consequences, etc., are not age specific and, in some cases, not gender specific..." (UN Special Rapporteur on Violence Against Women, 2000: 6) 
focus on the direct consequences of "discordance between the number of persons who wish (or are forced) to migrate and the legal opportunities for them to do so." In order to respond to problems of trafficking, immigration policies must be reviewed and changed (UN SG 2001, 7). As suggested in chapters two and four, this is not the approach of the Trafficking Protocol, nor does it fit with continued restrictive migration policies. It seems ironic that the Trafficking Protocol and some donor approaches partition trafficking and responses to it from questions of workers rights for migrants (incidentally, a diagnostic and prognostic frames used by anti-trafficking advocates and workers), yet they endorse and support trafficking prevention measures that are essentially aimed at addressing the root causes of migration.

Migration models tend to focus on one of three levels: micro-, macro- or meso- and each privileges certain factors in explaining migration and migration decisions, suggesting a particular approach for changing migration outcomes (including trafficking). In this chapter, I introduce each of these in turn, and follow with a discussion of a fourth set of considerations that emphasise political and policy-related determinants. Together they provide a basis for a multi-layered understanding of how organisations may conceptualise trafficking within the migration framework, and how (i.e. at what level) interventions might prevent trafficking (see table nine, below). This lays out how different development interventions, only some of which are trafficking specific, are bridged to trafficking reduction.

The best known micro-economic approach is the Harris-Todaro model, which uses wage differentials, the cost of migration and the probability of finding employment to explain population flows (Todaro and Smith 2003). The new economics of migration looks at the household level (Stark 1991), focusing particularly on migration as a familial or 
individual strategy for survival or a route to upward social mobility or emancipation (Sharpe 2001, 4-7). Both emphasise migration decisions informed by factors in sending and receiving areas. These factors are primarily economic conditions and opportunities, but political, environmental, social and cultural conditions can be included in the economic terms or as separate variables (Stahl 1995, 218-19; Agesa and Agesa 1999, 43). Changing these factors (or perceptions of them) would also change migration decisions and outcomes.

Castles and Miller challenge the assumptions of micro models, maintaining that the migration decision is not the cause of migration but the effect of social, economic and or political changes (2003). This approach focuses on structure, "the general conditions creating migration pressures" (Boswell and Crisp 2004, 10), privileging structural factors that are seen to determine the actions of populations rather than the specific decisions of those individuals and communities (Harzig 2001, 23). Changing migration outcomes would rely on changing the systems and structures that determine them. Though both micro and macro models include factors in sending and receiving areas, many responses to trafficking to date privilege supply-side factors such as poverty, disparity, a lack of opportunity and social and political factors (see table eight, below)..$^{50}$

\section{Table 8: Causes of Trafficking?}

- Poverty and food insecurity, expectations of access to the workforce and better money; realities of labour abuse and lack of protection (Banerjee n.d., 2)

- Poverty and food insecurity, dysfunctional home life, low education and lack of knowledge, personal problems and history of sexual abuse (Tumlin 2000, 11-2)

- Poverty, inequality, disparity, racism, a need for women to "claim their rights" including the right to legal migration and work (Lin Chew in Population Council 2001, 13)

- Low wages and the absence of economic opportunities in sending areas, past colonial orientalism and the desire for a western lifestyle, which itself is propagated by the media and by returnees (van Impe 2000, 118)

- Economic factors including poverty, political factors including repression or persecution, war or genocide or environmental degradation (Williams 1999)

- Lack of employment at home and lack of information on how to protect their rights overseas; over-control of women's movement through official channels making women morc vulnerable to traffickers (Ralph 2000, 4)

${ }^{50}$ Root causes and a "culture of prevention" are seen beyond trafficking, i.e. conflict prevention. 
Looking at illegal migrant smuggling and trafficking from the nexus of human security and national security, Beare suggests that "push" factors are more robust than "pull". Migrants are "fleeing" the bad conditions, be they environmental, political, social or economic $(1999,23) .{ }^{51}$ This understanding suggests responding to trafficking by focusing on root causes of migration in sending areas. For example, anti-trafficking projects may attempt to increase economic or educational opportunities in villages, improve conditions for women or work towards greater food security. As suggested in my discussion of the US Trafficking in Persons Report, I am critical of the idea that these conditions are causes of trafficking and that these solutions will solve trafficking problems. These conditions may encourage migration and influence or limit the type of migration available (i.e. risky, blind) and addressing them will first affect migration. Impacts on trafficking outcomes can only be expected if it is assumed that this is a demographic group for whom less risky or blind migration choices result in fewer trafficking outcomes. Even so, as suggested by Marshall, such interventions may be more appropriately called "vulnerability reduction" (2003). Acknowledging that certain conditions or characteristics like poverty or gender correlate positively with a certain type of harm (i.e. trafficking) does not lead me to assume that a causal relationship exists between them. Root causes terminology in the case of trafficking and in general focuses attention, including blame, on to victims and away from the perpetrators of harms and the selective social and legal response mechanisms that enable such abuses to continue. It also neglects the potential role of migration and remittances in improving conditions in sending areas as well as the disjuncture between demand for migration

\footnotetext{
51 Economic opportunities and well being, environmental and political security can be identified as both push and pull factors, depending on what is assumed to be "normal". This is a conceptual move that Beare does not make in her assumption that stability, rather than instability, is the norm.
} 
opportunities and the restrictions, border control and crack downs in migrant-receiving countries.

Meso-theories of migration look to social relations, networks and social ties, and use ideas of social capital to explain people's mobility. People rely on their social networks both for information and access with which to make more informed decisions about migration and define what is possible. This explains migration trends to and from specific areas and to specific areas and occupations (Harzig 2001, 24), pointing out networks and social capital building migration patterns and their tendency to reproduce and amplify themselves over time (Beare 1999, 22). This level of analysis is particularly interesting: in migration decisions, people rely on the information they have access to, from the people they know and the experiences they have. Both sanctioned and unsanctioned migrants rely on migration experts, including neighbours, previous migrants from similar areas and backgrounds or professionals, to provide information and assistance (see chapter two). For higher income and more powerful potential migrants, lawyers, travel agents and immigration consultants fill this role; for the poorer and less powerful, agents and smugglers who may be less reputable and unable, by definition, to work within the boundaries of the law are relied upon. The biggest asset that all migration professionals have, in both legal and illegal movements including trafficking, is information. Their control of information enables them to charge fees, gain profits and direct migrants (Sabieszczyk 2000, 398-408). As an anti-trafficking intervention, expanding people's network may increase the information and resources they can access, potentially changing migration decisions, paths and outcomes. 


\begin{tabular}{|c|c|c|}
\hline Intervention & Action & Interpretation \\
\hline $\begin{array}{l}\text { Knowledge of } \\
\text { Dangers/'Tricks of } \\
\text { traffickers } \\
\text { (Micro) }\end{array}$ & $\begin{array}{l}\text { Public education to inform and change } \\
\text { perceptions on the risks of migrating, } \\
\text { limited to warnings }\end{array}$ & $\begin{array}{l}\text { Reduce trafficking by reducing } \\
\text { migration through fear. Reduces } \\
\text { choices unless accompanied by } \\
\text { information on how to } \\
\text { mitigate/respond to dangers } 52\end{array}$ \\
\hline $\begin{array}{l}\text { Knowledge of safer/ } \\
\text { legal migration }{ }^{53} \\
\text { (Micro) }\end{array}$ & $\begin{array}{l}\text { Information campaigns to change } \\
\text { perceptions on suitable/ available modes of } \\
\text { migration, encouraging legitimate, } \\
\text { organized or state sanctioned modes }\end{array}$ & $\begin{array}{l}\text { Provide information and tools for } \\
\text { potential migrants, linking harms with } \\
\text { certain types of migration, providing } \\
\text { information on what are believed to be } \\
\text { safer ways }\end{array}$ \\
\hline $\begin{array}{l}\text { Social Capital } \\
\text { Expansion }^{54} \\
\text { (Meso) }\end{array}$ & $\begin{array}{l}\text { Day trips, study tours, introductions and } \\
\text { information sessions to make communities } \\
\text { and people aware of, in contact with, and } \\
\text { able to use the resources of other } \\
\text { organisations, individuals and networks }\end{array}$ & $\begin{array}{l}\text { Change the resources and information } \\
\text { with which someone migrates or } \\
\text { chooses not to migrate (not necessarily } \\
\text { only migration related i.e. agricultural } \\
\text { extension networks) }\end{array}$ \\
\hline $\begin{array}{l}\text { Expand local } \\
\text { economic } \\
\text { opportunities } \\
\text { (Micro) } \\
\end{array}$ & $\begin{array}{l}\text { Income-generating activities (IGAs), micro- } \\
\text { credit or savings schemes for small } \\
\text { enterprises or business development } \\
\text { programmes }\end{array}$ & $\begin{array}{l}\text { Change the "need" to go for economic } \\
\text { migrants, as well as the economic status } \\
\text { from which migrants go }\end{array}$ \\
\hline $\begin{array}{l}\text { Expand human } \\
\text { capital } \\
\text { (Micro) }\end{array}$ & $\begin{array}{l}\text { Education to expand literacy and numeracy } \\
\text { in communities, improve the quality of or } \\
\text { access to schools for children; vocational } \\
\text { and skills training for the job market }\end{array}$ & $\begin{array}{l}\text { Increase opportunities and reduces } \\
\text { vulnerabilities by increasing education. } \\
\text { Children's education may delay full-time } \\
\text { work or migration }^{55}\end{array}$ \\
\hline $\begin{array}{l}\text { Change the } \\
\text { regulatory Regime } \\
\text { (expand or extend } \\
\text { "rights") } \\
\text { (Macro/ Policy) }\end{array}$ & $\begin{array}{l}\text { Advocacy for change in policy, } \\
\text { enforcement, implementation of policies, } \\
\text { legislation, the judicial system (i.e. } \\
\text { citizenship/ access to state services for } \\
\text { excluded parties) }\end{array}$ & $\begin{array}{l}\text { Change individuals' status as } \\
\text { "unprotected" in source and/or } \\
\text { destination country }\end{array}$ \\
\hline
\end{tabular}

Where there exists both a possibility of employment, and a great profitability of employing cheap migrant labour for positions and at prices that nationals will not accept, there are profits and benefits to receiving countries (Beare 1999, 23). Yet, as I have already suggested, despite demand for their labour, migration regimes systematically discriminate against low-skill, poor migrants who would fill these positions. This reflects neither the demand for low-skilled workers in sending areas, nor the demand for migration opportunities from low-income areas: "Illegal trafficking in labor arises because governments

52 If they provide information about safer and/or legal means of migrating, providing information that could actually be used by the communities that they are presented to, are less anti-migration because they are not attempting to directly discourage migration, rather to encourage safer migration.

${ }^{53}$ I do not assume that "legal" migration results in "safe" migration. As Sabieszczyk (2000) points out, trafficking is not limited to irregular migration, and the law works differently for different people.

54 The World Bank defines social capital as, "the norms and networks that enable collective action." (2003).

55 Although, in many situations children may be required to migrate to attend school.

${ }^{56}$ Unlike other intervention types, this type of intervention is directed at national governments (primarily) for the benefit of communities and individuals. 
refuse to recognize the economic need for imported manual labor. Imperfect information about job availability, access, and mobility make these potential migrants prey to agents and labor recruiters" (Phongpaichit 1999, 76). Some migration models carefully attend to supply and demand but neglect the political: "The major empirical problem confronting models of international labor migration is that migration flows are constrained by immigration policy. This policy, in turn, is influenced by various special interest groups" (Stahl 1995, 210).

Power systems are heavily implicated in migration policy of receiving countries, "Thus, we need to be reminded that it is often political power rather than knowledge that shapes immigration policy; policy is thus related to the consequences of immigration as perceived by those with the power to dictate policy" (Stahl 1995, 227). By extension, to change immigration policy, normative change and advocacy rather than (or supported by) more information is needed. Policies are formed based on perceptions and biases of powerful groups in receiving countries and in turn change options, structures, and even networks through which people migrate particularly from sending areas. ${ }^{57}$ Where supply or demand exists beyond the limits of the politically allowable flows, there is a profitable entry point for traffickers and smugglers. ${ }^{58}$

\footnotetext{
${ }^{57}$ Returning to Saith's criticisms and emphasis of domestic (receiving country) politics as a determinant of migration policy there is simultaneous demand for restrictive migration policies (to protect "security," "jobs," "identity," restrict "crime and drugs" assumed to be associated with migrants) and for low-wage labourers, at wage levels unacceptable to nationals (so we see, for example domestic populations in rich countries unemployed yet unwilling to do certain jobs like fruit picking or for certain rates of pay). Under these conditions, the optimum is a restrictive policy with a tacit understanding that cheap migrant labour is desired. Regardless, as discussed in the previous section, labour-exporting policies in sending countries are not accompanied by receptive policies in receiving countries, even where demand for foreign labour is high. ${ }^{58}$ State-sanction constructs the individual or communities involved as "legal" or "legitimate" migrants, possibly enabling them to access certain rights, visibility or legal mechanisms of protection, or avoid certain punitive actions. Even within this group of "legal" migrants, there are groups (ethnic, geographical, socio-economic, religious, etc.) with less access to these rights and protections, and for whom the would-be protectors are themselves antagonists (i.e. Vietnamese communities in Cambodia; highland Burmese-ethnic minority groups in Thailand). Alternately, migration without documentation resulting in the construction of an "illegal" or "irregular" migrant by the state authority and a barrier to accessing these rights, protections and freedoms.
} 
Migrants reliant on smugglers are vulnerable to trafficking. In receiving areas, migrants' limited knowledge of local language, customs and laws combined with their lack of social support networks and distrust of the police makes them easier to manipulate and exploit and make trafficking very lucrative (van Impe 2000,118). It is not only the unwillingness of the victim to turn to the police and their lack of social support networks, but also a lack of political will amongst governments, law enforcers, and communities in receiving countries to advocate for and protect the rights of individuals who are portrayed and constructed as illegal. I pointed this out in chapter four, in my discussion of other international and national legal instruments that cover the abuses, crimes and harms associated with trafficking. The failure of states to apply these tools contributes to the sustainability of the trade.

It is difficult for those committing abuses against populations labelled "illegal" by states to be brought to justice (especially where the sector they labour in is also "illegal," i.e. the sex trade). There is little de facto or legal disincentive for abusing these populations. Boswell and Crisp suggest, "smuggling and trafficking also occurs with the passive or active collaboration or officials in sending, transit and receiving countries" $(2004,15)$. Seeing trafficking within the context of (illegal) migration suggests that tighter border and movement controls are not insufficient to stop trafficking, but that they may increase reliance on smugglers and underground markets that effectively make migrants more vulnerable to trafficking scenarios. Yet, it is the exception rather than the rule that donor governments open migration or expand migrant worker rights to address trafficking:

The contradiction between the economic case for liberalization and the political pressures for closure has contributed to a number of negative and for the most part unintended consequences. First the absence of legal rights for migration has led to a significant expansion in human trafficking and smuggling networks which are both dangerous and exploitative in nature. 
For the majority of would-be migrants and refugees, these routes represent the only way to enter one of the industrialized states. (ibid., 1)

Trafficking is possible at least in part due to disjuncture between both supply and demand for migration, restrictive migration regimes that force migrants towards illegal or dangerous migration arrangements and labour and legal regimes which construct migrants and workers as illegals, cutting them off from mechanisms of protection (SCA n.d., 29; Beare 1999, 23; Sabieszczyk 2000, 398-408; Phongpaichit 1999, 76; UN SG 2001, 6-7; Williams 1999, 2; Saith 1999, 289). None of these aspects are gender neutral. Systematically, women have less access to legal migration, less protection for their work in labour codes, and fewer resources (material and social) to draw upon for support. Lin Chew shows that over-reliance on legal mechanisms compounds limitations on movement and employment opportunities for young women. Her conclusion is that women need to "claim their rights" including the right to legal migration and work (in Population Council 2001, 13).

Worldwide, women comprise a disproportionate number of the poor, marginalised and oppressed. Stasiulis and Bakan find estimates that there are 20 million undocumented migrants and that, "Most migrants originate from the poorest regions in the word and an augmenting percentage are women" $(2003,2)$. Applying the insights of gendered political economy to the labour market, it is unsurprising that state sanctioned, authorised, visible migration paths are unavailable to most women. Though some visas are available to women for factory and domestic work, the jobs that women typically have access to are not those for which foreign governments offer visas. For these women, regardless of their ability to mobilise resources, legal migration is not an option (Sabieszczyk 2000).

The twentieth century has seen more migration, a "feminisation" of migration and a growing politicisation of migration, with bilateral and multilateral relationships and national security policies increasingly focused on international migration (Castles and Miller 2003, 7- 
9). Numbers of women migrants are increasing both in absolute and relative terms, and though this has attracted new attention to women as migrants, as Sarasúa points out, gender has never been a "neutral characteristic in migration": male and female points of difference include legal status, access to public spaces, access to family resources, level of consumption and obligations to the family unit $(2001,51)$. Gender bias is also demonstrated in statemigrant relations and policies attempting to govern population movements (Harzig 2001, 24). Yet mainstream theory has primarily focused on the single, male, economically motivated migrant (Sharpe, 2001, 2). At the same time, trafficking literature has been reluctant to move beyond the female or child in the sex trade as the trafficking victim. In her investigation of discourse around the migration of women in the early twentieth century, Barbara Henkes asks, "To what extent did the perspective that migrating women were potentially vulnerable victims of male lust dominate public debates? Was there also space for a perspective which treated migrants as self-confident, enterprising young women?" $(2001,225)$. These questions are equally pertinent when applied to trafficking and migration discourse in the early twenty-first century. There is a tendency towards archetypes: the male migrant (with agency and control, needing discipline for infractions) and the female victim (who is gullible, vulnerable and requiring protection). In recent years, observations of the feminsation of migration and concerns about women's vulnerability and the risk of trafficking (particularly for women from developing nations), while trafficking has been conceptually linked to women and children as its victims and the sex trade as its purpose. One outcome has been potentially well-intentioned restrictive controls on the movements of women, which result in women relying on more hidden and underground routes of migration. Another has been the relative abundance of anti-trafficking projects specifically targeting women and children. 
Through the gendered political economy, particularly the gender-differentiated labour market in receiving countries, more "legitimate" jobs and visas for these jobs are available to men. For example, visas and employment are available internationally through legal channels for construction workers and other jobs predominantly associated with men, while domestic work and sex work, primarily associated with women, are frequently excluded from international and domestic labour regulations (Stern 1997, 234; Piper and Uhlin 2002, 174; Sabieszczyk 2000, 414). Following these insights, Ratna Kapur suggests that given the structural limitations imposed by the gendered political economy, if one sees trafficking as irregular migration or sex work then this in and of itself demonstrates gender bias (in Population Council 2001, 22).

There are other differences. Harzig points out that refugee status, linked with civil and political rather than social or economic rights, has resulted in the current situation where the majority of refugees granted status is men, even though the majority of displaced people world-wide is women $(2001,18-9)$. Social expectations are different for women, and pressures for migration may enter the culture:

... the Filipino woman is highly socialized to sacrifice herself to help support the family. This particular gender-role socialization makes her susceptible to many negative -often exploitative- experiences abroad such as accepting dehumanizing work or a marriage proposal from a stranger in order to earn money for the family back home. (van Impe 2000,118)

Van Impe also notes that migrating allows women to acquire status and power within the community and family. This idea of migration as a means to increased social and economic power directly contradicts her idea that migration is a personal sacrifice that women take because they are socialised to do so. I consider this less a theoretical flaw than an expression of the complexity of evaluating these issues, except where the idea of being "socialised to sacrifice" plays into exoticism and orientalism. As pointed out by Doezema (2001) and 
Mohanty (1991), there are problems with portrayals of and by western women and feminists as "liberated" "modern" and "advanced" in contrast to her backwards, tradition-constrained sisters in the south. Though rarely heard in reference to citizens of rich western countries, the single classification "women and children" flourishes in trafficking literature: often with little or no distinction between them, infantilising women, juxtaposing the child-like female victim (gullible, vulnerable, requiring protection) and the male migrant (strong, in control).

Underlying many of these concerns are ideas of potential costs and benefits to migrants and their beneficiaries. I cannot advocate for or against migration because I cannot assume that the situation in the village is "good" nor that migration will necessarily have a "bad" result. Migration outcomes are not easily assessed, as the economic, psychological and social costs for the individual, family, community and even home economy must be weighed against the direct benefits as well as the benefits and costs which would have been incurred had a different decision been taken. For Phongpaichit, transnational migration is costly for victims, their families, social support systems, and sending societies. Migrants rarely learn useful skills, and the majority of remittances are for immediate consumption, not investment: "Most often, migration is just a short-term survival strategy with no sustainable and long-lasting beneficial impact on their families and community" (1999, 95). Savings and skills-development are desirable, but so is short-term survival! Recognising these complexities and noting that migrants and trafficking victims generate significant revenue for businesses, states and especially for agents (ibid., 98), perhaps the question is how to reduce and eliminate harms while accruing more benefits to potential migrants.

The remainder of this thesis focuses on information from my interviews with representatives of NGO and IO trafficking prevention projects in Thailand and Cambodia, drawing on the ideas and analytic tools of the previous chapters. In chapter two I suggested 
that the Trafficking Protocol is not strong on human rights and does not address trafficking as a violation of migrant or labour rights, even though trafficking in the Greater Mekong Sub-region is often characterised as labour-seeking migration plus exploitation. Chapter four expanded on idea that major donor countries have an overall negative approach to migration (particularly with respect to poorer, lower skilled migrants), including tendencies towards restrictive migration policies, some intentions to use official development assistance (ODA) to reduce migration pressures from developing countries and a focus away from receiving areas when addressing trafficking. In chapter five, I raised six specific concerns about reliance on donor funding and presented co-optation and framing as alternate analytical concepts for understanding how organisations engage with donors to access funding and what degree of influence this might have on their agendas and priorities. As explained, though the literature focuses on NGOs, my research includes IOs. Aside from national governments, NGOs and IOs are the major actors in development. Though IOs projects may obtain core-funding internally, from their parent organisations, they also obtain funding the same way the NGOs do: by submitting project proposals to donors. In this chapter, I have looked at intersections of migration and trafficking, beginning with migration models and their insights for interventions to change trafficking and migration outcomes, including the possibility that tighter restrictions on mobility increase reliance on smugglers and the risk of being trafficked.

Table ten, below, reintroduces the organisations I focus on. In the remaining chapters, I examine these organisations and their work relative to my concerns that with donor funding, they become implementers of donor policy, and that through their antitrafficking projects, they are part of an anti-migration agenda or are derailed from a more politicised approach. I ask whether projects are better explained in terms of framing 
processes or co-optation. ${ }^{59}$ I look at three components of each project: definitions of trafficking (chapter seven), target groups (chapter eight) and interventions (chapter nine). In each chapter I begin by clarifying my expectations as to what might indicate co-optation vs. framing, building from the concepts and distinctions set out in chapter five. Then I give a generalised statement of my findings before presenting a more detailed organisation-byorganisation comparison and analysis.

\begin{tabular}{|c|c|c|c|c|c|}
\hline \multicolumn{6}{|c|}{ Table 10: Overview of Organisations } \\
\hline Organisation & Interview with & Area/ Type & Start & Donors & Frame \\
\hline $\begin{array}{l}\text { Development and } \\
\text { Education Project } \\
\text { for Daughters and } \\
\text { Communities } \\
\text { (DEPDC) }\end{array}$ & Sompop Jakantra & $\begin{array}{l}\text { Thailand/ } \\
\text { NGO }\end{array}$ & 1989 & $\begin{array}{l}\text { Bilateral, } \\
\text { multilateral, } \\
\text { Private }\end{array}$ & $\begin{array}{l}\text { Child anti- } \\
\text { trafficking }\end{array}$ \\
\hline Mirror Art Group & $\begin{array}{l}\text { Parisuda Sudha- } \\
\text { mongkala (Moo) }\end{array}$ & $\begin{array}{l}\text { Thailand/ } \\
\text { NGO }\end{array}$ & no data & $\begin{array}{l}\text { Multilateral } \\
\text { (ILO) }\end{array}$ & $\begin{array}{l}\text { Hill tribe pride, } \\
\text { empowerment }\end{array}$ \\
\hline $\begin{array}{l}\text { Cambodian } \\
\text { Women's Crisis } \\
\text { Centre (CWCC) }\end{array}$ & Nopsarin Sreyroth & $\begin{array}{l}\text { Cambodia/ } \\
\text { NGO }\end{array}$ & $\begin{array}{l}1997 \text { (org } \\
\text { and project) }\end{array}$ & $\begin{array}{l}\text { Bilaterals, } \\
\text { through } \\
\text { northem } \\
\text { NGOs } \\
\text { (TDH), } \\
\text { multilateral } \\
\text { (ILO) }\end{array}$ & $\begin{array}{l}\text { Violence } \\
\text { against women }\end{array}$ \\
\hline $\begin{array}{l}\text { Cambodian } \\
\text { Migtation and } \\
\text { Development } \\
\text { Committee } \\
\text { (CMDC) }\end{array}$ & Ros Sokham & $\begin{array}{l}\text { Cambodia/ } \\
\text { NGO }\end{array}$ & $\begin{array}{l}1997 \\
\text { (IMDC } \\
\text { since 1993) }\end{array}$ & $\begin{array}{l}\text { Bilaterals, } \\
\text { Bilaterals } \\
\text { through } \\
\text { NNGOs, } \\
\text { multilateral } \\
\text { (UNICEF) }\end{array}$ & $\begin{array}{l}\text { Women and } \\
\text { children }\end{array}$ \\
\hline $\begin{array}{l}\text { Save the Children } \\
\text { UK (SC UK) }\end{array}$ & Nwe-Nwe Aye & $\begin{array}{l}\text { Sub-regional } \\
\text { (inclusive)/ } \\
\text { INGO }\end{array}$ & $\begin{array}{l}1999 \text { (PAR } \\
\text { project) }\end{array}$ & $\begin{array}{l}\text { Bilateral } \\
(\mathrm{UK})\end{array}$ & $\begin{array}{l}\text { Child rights, } \\
\text { child } \\
\text { participation }\end{array}$ \\
\hline $\begin{array}{l}\text { UN Inter-Agency } \\
\text { Project on Human } \\
\text { Trafficking in the } \\
\text { Greater Mekong } \\
\text { Sub-region (UN- } \\
\text { IAP) }\end{array}$ & $\begin{array}{l}\text { Phil Marshall (sub- } \\
\text { regional), Hang } \\
\text { Vannack } \\
\text { (Cambodia) }\end{array}$ & $\begin{array}{l}\text { Sub-regional } \\
\text { (including } \\
\text { Myanmar)/ IO }\end{array}$ & $\begin{array}{l}\text { Project: } \\
1999 \text { (start } \\
\text { work June } \\
2000 \text { ) }\end{array}$ & $\begin{array}{l}\text { Bilateral and } \\
\text { multilateral }\end{array}$ & $\begin{array}{l}\text { "overarching } \\
\text { mechanism" or } \\
\text { coordinating / } \\
\text { gap filling } \\
\text { (structural); }\end{array}$ \\
\hline $\begin{array}{l}\text { ILO Mekong } \\
\text { Sub-Regional } \\
\text { Project to Combat } \\
\text { Trafficking in } \\
\text { Children and } \\
\text { Women (TICW) }\end{array}$ & $\begin{array}{l}\text { Hans van de Glind } \\
\text { (sub-regional); } \\
\text { Prungchit } \\
\text { Phanawathanawong } \\
\text { (Thai); Khleang Rim } \\
\text { (Cambodia) }\end{array}$ & $\begin{array}{l}\text { Sub-regional } \\
\text { (excluding } \\
\text { Myanmar)/ IO }\end{array}$ & $\begin{array}{l}\text { Project: } \\
2000 \text { (1998- } \\
99 \text { research } \\
\text { and funding } \\
\text { proposals) }\end{array}$ & $\begin{array}{l}\text { Bilateral } \\
\text { (Japan, UK) }\end{array}$ & $\begin{array}{l}\text { Labour Rights; } \\
\text { child Labour }\end{array}$ \\
\hline
\end{tabular}

${ }^{59}$ I exclude the possibility that organisations are separate from and unaffected by donor policy as all of the organisations I study have actively applied for and receive donor funding. 


\section{CHAPTER 7: Defining trafficking - What's the problem?}

A clear starting point is whether the IOs and NGOs included in my study accept the UN Trafficking Protocol definition. As discussed in chapter two, the Trafficking Protocol definition and its organised crime approach were both unsatisfactory for organisations concerned with issues of human rights in general, and migrant rights in particular. For the organisations in my study, there are four possibilities:

1. They accept the Trafficking Protocol definition as is.

2. They accept the definition and rhetorically bridge it to their organisational frame.

3. They accept the definition, bridge it to their organisational frame and criticise it.

4. They do not accept the Trafficking Protocol definition.

I expect all organisations to accept the protocol definition in some way. I assume that the projects of the UN and the ILO will accept the definition as is (the first option) since they are both IOs and both part of the UN system (admittedly itself a diverse collection of organisations with often competing interests). It is expected that the NGOs will be less likely to accept the protocol in its entirety given that the definition has already been identified as problematic. If NGOs accept the protocol definition as is, and it is contradictory to or inconsistent with their other work, I consider this evidence supporting the claim that they are co-opted towards donor agendas and change for the purposes of resource mobilisation. Behaviour consistent with options two and three, where NGOs bridge their organisational frames to aspects of the Trafficking Protocol, demonstrates the sort of continuity that I interpret as support for framing as an analytical tool. Criticism of mainstream donor positions, though not a component of framing, does demonstrate autonomy and so is counter-indicative of co-optation.

\section{Findings}

From all of my interviews, NGOs and IOs alike accept the Trafficking Protocol and women and children are with few exceptions a particular area of concern, if not the sole 
focus (chapter eight addresses this in more detail). The consent of children, particularly to sex work, was considered irrelevant by all organisations.

The Thai NGO Development and Education Programme for Daughters and Communities (DEPDC) is the organisation most independent of the Trafficking Protocol. Established in 1989 (then known as Daughters' Education Programme, DEP), eleven years before the Trafficking Protocol, DEPDC has always worked on prevention, "trafficking has been being used by DEPDC for more than ten years" (Jakantra 2003). DEPDC's work with and ideas about trafficking predate the protocol. As such, donor attention and resources devoted to anti-trafficking since the late 1990s cannot be used to explain this organisation's anti-trafficking work and the Trafficking Protocol cannot be assumed to be the basis of DEPDC's understanding. However, items on DEPDC's website confirm acceptance of the protocol definition (Jakantra 2003; DEPDC 2003).

DEPDC defines the distinguishing features of trafficking as exploitation with "no independence, and an inability to get out of the situation," rather than deception and the abuse of power (Jakantra 2003). This shifts the focus from an initial exercise of agency at the time of migration or movement to the conditions and the ability to exercise agency at the destination point. Over time, some changes have occurred in the ways DEPDC understands and responds to trafficking. Changes that have occurred seem to reflect economic, migration and regulatory changes influencing trafficking, not changes in donors' or governments' definitions. For example, the expansion of destinations beyond the sex trade:

[In the past] if you want to cross the border and you can get a cheap job if you can work if you receive the cheap job then you can get it. So there is noone smuggling or trafficking for labour: it doesn't exist ... But now, right now, with the countries change and economics change, poor countries, rich countries, labour is a big problem - labour market - factories, industry, new industries - not just everyone can cross border and get a job - they have a middle man, the gangs or the companies who arrange for people to go. (Jakantra 2003) 
DEPDC's acceptance of the protocol is consistent with its previous and on-going work, and though this may be seen as much a convergence of agendas as a framing effort, independence from the protocol suggests that it is not evidence of co-optation.

The Mirror Art Group (MAG), also a Thai NGO, explicitly states their acceptance of the Trafficking Protocol definition (Sudhamongkhala 2003). As the project has received funding from the ILO Project to Combat Trafficking, this is expected. However, while the ILO project clarifies their understanding of trafficking in terms of ILO conventions, particularly as they relate to child trafficking (see below), the Mirror Art Group approaches trafficking as part of a broader system of problems and challenges faced by ethnic minority groups in Thailand, "We want to work as a mirror between urban people and the rural Thai people, to raise awareness of the issues they face and empower villagers to recognize and face the changes in modern Thai society" (Sudhamongkala in World Bank n.d.). MAG's understanding of trafficking does not hinge on age or gender, and is part of this larger organisational concern with the difficulties and challenges faced by hill tribe ethnic minority communities (Sudhamongkala 2003):

... in traditional hill tribe villages, we would not see youth being trafficked or exploited. But, as the Thai government forced these migratory people to become stationary and to farm one piece of fatigued land; as interactions with the material culture of the city became more frequent, turning relative poverty into actual poverty; and as the lack of education, vocational skills, ability to speak Thai, opportunities, Thai citizenship, knowledge and awareness of the dangers of leaving the village converged, the former safe haven of the mountains has become the source of an endless stream of innocent people unprepared to cope with the unjust situations they are thrown into. Sweatshops and prostitution are the high-profile exploitation scenarios, but seemingly honest work can become instantly dangerous without the naive young people in the middle having caught the subtle warning signs. (MAG n.d.)

However, their project focuses particularly on youth and women. This is an alignment of trafficking with MAG's organizational frame and their critical stance in terms of 'Thai 
government treatment of ethnic minority groups. As with DEPDC, there is no obvious conflict between this and the protocol, and in both cases the organisational approach and understanding of trafficking reflect the organisation's previous and continuing work. However, the focus on children and women is different from MAG's other work. The Cambodian Women's Crisis Centre (CWCC), also a recipient of ILO funding, accepts the protocol definition:

... we are following international law... we would say the act of one person, to lure or to entice another person, for his own benefit... for the purpose of prostitution - this is not the only purpose, like forced labour like begging or even selling some parts of the body like the organs. Actually we also follow the international agreements and conventions. (Nopsarin 2003)

CWCC informs their practice with the Cambodian Law on Suppression of Kidnapping, Trafficking and Exploitation of Human Persons, which focuses on trafficking for sexual exploitation. ${ }^{60}$ The limited focus on the sex trade is considered problematic by CWCC amongst others (Pilorge 2003; Ashby 2003; Ros 2003; Nopsarin, 2003):

... concerning the trafficking, we really wish that the adoption of the new draft law were passed soon in order to fit the demands of our victims and our society. We have a law on this, but it was not a very good one as we think. It is just referred to as the Sex Trafficking Law. Anyway it doesn't cover the definition of what is trafficking. For example, the intent or the purpose of the law refers to trafficking for the purpose of prostitution only, but not for the purpose of begging or forced labour or anything like that. And not only the adoption of the draft law, we also want the implementation. (Nopsarin 2003)

At the time of the interview, a new draft law on trafficking was before the Cambodian parliament, but virtually all government work had been put on hold for the July 27,2003 national elections.

Because they are an organisation working primarily from a concern about violence against women, the Cambodian trafficking definition's exclusive focus on the sex trade, with

\footnotetext{
${ }^{60}$ Passed 16 January 1996, article 2: "The kidnapping of human persons for trafficking/sale or for prostitution and the exploitation on human persons, inside or outside of Cambodia, shall be strictly prohibited."
} 
assumptions that women and children are its victims, does not interfere with CWCC's work.

The following excerpt from their web site indicates that this does not prevent them from

engaging critically and advocating for change:

In Cambodia, there are approximately 50,000 prostitutes of whom $64 \%$ were trafficked or sold into sexual exploitation... large numbers of Cambodians are trafficked into Thailand and forced into begging, prostitution and other forms of forced labor before being deported back to Cambodia if they are discovered by the Thai authorities. On average, 1500 people are returned from Thailand every month... All victims should have intervention, so that they can escape from the violent situations they endure. (CWCC homepage)

Even so, CWCC advocates for improvements to the Cambodian national law, basing their arguments not on the international conventions; rather, on what they know of trafficking from their experience working in-country (Nopsarin 2003). This suggests an engagement in trafficking that is consistent with CWCC's organisational frame and advocacy and understandings informed by local contexts.

Throughout all of their work, the Cambodian Migration and Development Committee (CMDC) focuses on homeless women and female heads of households and their families (Ros 2003; PDCC n.d.). Though their target group is limited to women and children, the organisation's acceptance of the protocol definition includes the idea of men as trafficking victims, and trafficking for purposes beyond the sex trade. For CMDC, trafficking involves movement and exploitation against the will of the victim:

Trafficking? Trafficking, it means people who have been taken from place to other place, willing or unwilling. Because "traffic" means that people try to do something against the will of the people who - for instance promise them to get some job in the garment factory with the high pay, say that 70 dollars per month. Besides that, they take them and they sell them in the brothel. Or, to jobs like a slave - forced labour. I think in Thailand, men as well have been slaves in their jobs, because they have been away from the home for more than five years, seven years, ten years, but come home with nothing. To go fishing in the boat... they don't allow them to come to shore. That is also trafficking. People have been taken away and promised something, but unfortunately they lie and they give another thing - without pay...(Ros 2003) 
This includes the protocol's three components: movement, deceit or abuse of power, and exploitation for the benefit of another. Yet, the explanation is grounded in the organisation's experience, suggesting continuity rather than change in both taking up antitrafficking work and in how trafficking is conceptualised. Despite this broader understanding, CMDC like CWCC continues to work with its limited target group. This tendency is also exhibited by the international NGO, Save the Children UK.

The Save the Children UK (SC UK) sub-regional project accepts the UN Trafficking Protocol (also referred to as the Palermo Protocol), including the components of transportation, lack of consent, and the exploitative purpose. They also reject the idea that crossing geographic or political borders is a necessary component: "We do accept the Palermo Protocol, but we don't limit ourselves just to the Palermo" (Aye 2003):

... the victim in an unfamiliar milieu where she is culturally, linguistically or physically isolated and denied legal identity or access to justice. Such dislocation increases trafficked women's (and children's) marginalisation and therefore increases the risk of abuse, violence, exploitation, domination or discrimination both by traffickers and by State officials such as the police, the courts, immigration officials, etc. (SC UK 2002, 7)

SC UK clarifies that in order for consent to nullify claims of trafficking, this consent must extend to "the conditions or the nature of the work to be done" (ibid., 7).

Though acknowledging trafficking as a broad issue affecting populations outside of their target group, the project's focus on children is consistent with SC UK's characteristic child-rights and child-participation emphases. SC UK accepts the protocol definition and links their broader understanding to, amongst other things, child rights:

Despite the limitations of the Palermo Protocol, most SC UK programmes refer to it for a definition of trafficking. In practice, however, programmes tend to use a pragmatic approach to cases that are not clear-cut, using the best interest of the child and the Convention on the Rights of the Child as the bases for the intervention. (Reale 2003, 2) 
In its criticisms, SC UK highlights certain "gaps" from the Trafficking (Palermo) Protocol.

For example, mandatory enforcement on trafficking related offences vs. discretionary

protection and assistance for victims:

The focus of the Convention Against Transnational Organised Crime and the supplementary Palermo Protocol is crime control. They are not human rights treaties. However, for the first time, the instruments contain numerous provisions to protect and assist trafficked persons who agree to become witnesses. However, they do little to protect the rights of trafficked persons who do not become witnesses and while there is an obligation on states parties to enforce law on trafficking related offences, protection and assistance for victims is discretionary. Governments were almost unanimous in opposing mandatory language. This means that victims' protection is left to national laws with the consequence that victims of trafficking are still criminalized in some countries. (ibid., 11)

Recalling that SC UK identifies the denial of legal identity and access to justice as key contributing factors, discretionary responses are immensely problematic. This excerpt and the position it takes is a direct criticism of the emphasis in the Trafficking Protocol's frame on fighting organised crime and the relative neglect of human rights outcomes. The protocol continues to allow countries to not respond to the human rights abuses committed against migrants, trafficking victims and other marginalised groups by their citizens or in their countries.

Interestingly, when it came down to using this contested definition as a basis for their anti-trafficking work, SC UK takes a "yes, but..." approach, suggesting that even though framing certain issues as trafficking may be highly motivational for upstream donors and bridging development or other projects to trafficking outcomes an effective way to access resources, trafficking may be a frame that is disagreeable to (or even an obstacle to working with) downstream communities and intended beneficiaries:

We use the broader migration approach. So we don't jump into trafficking because we think that first of all, trafficking is something that is very sensitive. You don't go into a community village and ask "Who is trafficked in your community?" That's like insulting them, offending them, because 
trafficking in all these countries means that you sell your own children for you to eat your food - very derogatory. The other reason is that trafficking and migration are in some cases not very well demarcated - you take the 14 year old girl and take her away from her family and send her to the brothel and take money for sending the girl there than this is clear cut trafficking. But a 15 year old girl voluntarily goes from Laos to Thailand to work in a factory or in domestic work but a broker took one year payment from the employer there and she had to work for the whole year without getting any money... Then on the other hand, a sex worker who was already working a sex worker from Yongon deliberately went to the Chinese border because she thought that she'd get more money... Once she's there, she doesn't even get what was promised to her but she lived in an appalling situation in terms of bedding and food, and she is detained - she cannot go out there, her papers were confiscated, she was abused every day she had to - she was forced to sell drugs in addition to sex. And then people don't want to accept that this is a case of trafficking but actually it is. Although she knows that she's going to engage in sex work but she did not hope for that kind of situation. So those are the many kind of vague areas. So we thought that is why we don't want to limit ourselves to trafficking only but we want to open ourselves to other exploitation and abuse which children are subject to. (Aye 2003)

While trafficking does serve as a paradigm and title around which to centre the project and mobilise donors, it is not necessarily a rallying cause in villages. SC UK finds it problematic and so critiques it, choosing to work on the broader issues of migration and exploitation. Though SC UK bridges their work to the concept of trafficking, accepting and criticising the Trafficking Protocol definition, I interpret this as a rejection in practice of the trafficking paradigm as presented in the Trafficking Protocol.

SC UK accepts the protocol, criticises it and aligns and focuses on aspects and components that are contiguous with their organisation's frame and other work. While all of the NGOs had comments and criticisms about definitions and approaches to trafficking, Save the Children UK provided their critique in well-researched public documents that also inform the organisation in its work and its advocacy. ${ }^{61}$ This likely reflects the scale on which the organisation works and the more extensive resources and audiences available to them.

\footnotetext{
61 See, for example, Reale's Mapping and Anabysis of SC UK's Work on Trafficking (2003) and Save the Children Alliance's Comparative Study of the Legal Provisions of the Six Countries in the Mekhong Subregion with respect to Trafficking in Women and Children (2002).
} 
This critical component, surprisingly, is also seen amongst IOs: in addition to engaging in project activities, IOs maintain a critical dialogue at a number of levels related to their work.

As expected, based on its position in the UN system, the UN Inter-Agency Project (UN-LAP) is driven by the UN Trafficking Protocol, emphasising the three-part definition of "movement and exploitation characterised by loss of control over agency." They also by definition reject the idea that trafficking with consent is impossible due to the key distinction of "loss of control," unless the individual concerned was under 18 (Marshall 2003). ${ }^{62}$ While this seems to be a consistent and complete acceptance of the protocol definition, in discussing trafficking conceptually, criticisms emerge, "Officially we use the UN definition, but we also tend to talk about having as its main component movement and exploitation and being characterized by a loss of control over agency" (ibid.). The manager of UN-IAP at the time of the interview expressed concern that it is only after migrants and trafficking victims have lost control that they have any rights, including those to protection:

I think that one of the big problems that we have in trafficking is that although we've already identified rights of trafficking victims, that's a retrospective right. It's like saying you've got the right not to be raped after - only rape victims have the right not to be raped. And I think that in practice it's very hard to separate the rights of trafficking victims from the rights of migrants in general. I think that's one of the big shortcomings in the trafficking response, generally. And I think just as an example of that if you look at the Convention on the Rights of Migrant Workers and their Families it's never - when you look at the list of UN instruments relevant to trafficking that's never mentioned - nine times out of ten times it's not mentioned. Sure, it'll never take up as an instrument because it gives migrants more rights than the workers have in their own countries, and as you say it hasn't been signed by receiving countries, but you can't say it's not relevant to trafficking. For me, it's more relevant to trafficking than the trafficking protocol. (Marshall 2003)

\footnotetext{
62 Though I was asking question with the treatment of the potential or supposed trafficking victim in mind, it seemed that some responses were given in terms of dealing with perpetrators: as the national project officer for the UN-IAP in Cambodia explained, "The under-aged, even if they agree, the perpetrator still needs to be punished." (Hang 2003).
} 
These criticisms may not represent ideas shared by UN-IAP. However, comments from the national project coordinator for Cambodia supported these perspectives (Hang 2003), privileging the abuses people suffer, rather than ideas of how they got there and where they are from in formulating responses and interpreting the situations of trafficking victims. At least from Marshall's perspective, trafficking victims face two key problems: they are being exploited and they have lost control, "You know, in some ways I think the movement's a red herring - if a 14 year old girl is locked in a brothel, it doesn't really matter so much how they got there or where they're from. But now we have this paradigm which we're working within" (2003). Asked if the project takes on these issues about movement, Marshall said:

We certainly do, we've had a couple of articles in our newsletter in terms of the conditions - but more widely in terms of the relationship between migration and trafficking, yes. One of the things that we're most outspoken about is the role of migration control on trafficking, and saying that all evidence suggests that tighter border controls facilitate trafficking, not the other way around. (ibid.)

At the very least, the project provides a forum for the expression of critical views on migration and trafficking, and the seemingly intentional conflation of trafficking and smuggling:

... it's very hard when you have some donors almost it appears wilfully conflating the two and I think that if you look at the record of the Bali Conference on Smuggling and Trafficking, ${ }^{63}$ where the term smuggling and trafficking were used interchangeably, there are some governments that I think are using this as a Trojan horse to pursue anti-migration policies. Which is their sovereign right, of course. I just don't think it's their right to pursue anti-migration policies and call them anti-trafficking policies. (ibid.)

\footnotetext{
63 The Bali Process on People Smuggling, Traffickin in Persons and Related Transnational Crime has held two ministerial conferences, in 2002 and 2004 . Australia, a key player, reports in their 2003 foreign trade and policy paper: "Transnational crime, including people smuggling and trafficking, drug trafficking and money laundering, threates the sovereignty of Australia and other nations" (Commonwealth of Australia 2003, 46).
} 
These criticisms do not fit with the assumption that IO projects are merely extensions of donor policy. They also confirm that the work of IOs cannot be simply interpreted as extensions of donor policy.

The ILO Mekong Sub-Regional Project to Combat Trafficking in Children and Women (TICW) departs only somewhat from the protocol definition, augmenting their understanding of trafficking with ILO Conventions 182 (Worst Forms of Child Labour) and 138 (Minimum Age), as well as the UN Convention on the Rights of the Child (CRC), approaching trafficking from human rights and labour exploitation perspectives (ILO 2003, 1). Describing the role of the UN protocol in defining trafficking, Hans van de Glind, the ILO sub-regional project director said:

We use the Transnational Crime Convention Optional Protocol. But before that came into place we talked about trafficking as the threat of violence, use of violence, deception, in the process of recruitment and or transportation of a victim of trafficking with the end result being a form of labour exploitation, not necessarily being sexual exploitation. So it's much broader than sexual exploitation, and what the Transnational Crime Convention Optional Protocol did was, amongst others, create more clarity as to the role that children play in all of this, even if children consent to trafficking or being involved in labour exploitation that simple fact is irrelevant. Anybody below the age of 18 should not be doing this type of work... Not just sexual exploitation, but also servitude, bonded labour, other types of work that are really taking place in slavery-like conditions and that can be domestic work but it can also be work in a sweatshop, work on a plantation, as long as it is bonded or there is a slavery-like condition involved. (2003)

In the case of the ILO project, the emphasis on children (further addressed in the next chapter) can be understood with reference to pre-existing relevant tools from the same organisation. Conventions 182 and 138 are part of the ILO repertoire and the trafficking prevention project is managed under the ILO's International Programme on the Elimination of Child Labour (IPEC). It follows that these child-focused tools be incorporated into the project's understanding of trafficking: 
Well, for exploitation, we really go back to two key ILO conventions. One is ILO C138, it's the Convention on the Minimum Age of Employment, and it specifies at what age people are allowed to do particular types of work... In addition to that, there is the C182, which is the Convention on the Worst Forms of Child Labour, and that really specifies what constitutes worst forms of child labour and is quite clear in what this means. Consent of those under the age of 18 was considered irrelevant. (van de Glind 2003)

The Cambodian national project officer, Khleang Rim, similarly grounded the understanding of trafficking in ILO conventions, along with the Convention on the Rights of the Child (CRC) and Cambodian national law:

For the project work - it is based on Convention 182, the Worst Forms of Child Labour... this convention has also one article talking about trafficking issues. This is also linked to the Convention on the Rights of the Child article $34 . .$. we work based on the national law - the law on the suppression of trafficking, and also we work through the UN convention - that is the human rights and the meaning of trafficking for ILO-IPEC. (2003)

Khleang further emphasised that sexual exploitation of those under 18 was of particular concern and that their consent is not at all relevant. Asked whether the project's activities fit the organisation's understanding of trafficking, the sub-regional director responded by fitting the anti-trafficking project activities into context with the ILO's larger agenda:

... they fit within a broader framework which we currently call the decent work agenda of the ILO, the aim of the ILO is to really go for decent work which is not just work, but work in acceptable conditions. The organization is structured around four strategic objectives. One of them is a standard setting objective the second one employment creation, the third one social dialogue and the fourth one is social security and we see our trafficking project and the issue of trafficking as really a cross-cutting one, reaching out and covering these four different sectors. (van de Glind 2003)

Where the UN project seemed to be critical of the protocol, directly engaging with it, the ILO project bridges trafficking to other, pre-existing projects and frameworks that they use and work within, particularly child labour.

It is striking that all organisations I interviewed, independent of their framework and type, accept the Trafficking Protocol definition. At first glance this shared and incongruous 
combination of rhetorical dissatisfaction over the Trafficking Protocol amongst NGOs combined with universal acceptance of the definition support the idea that NGOs are malleable and do orient themselves towards capturing donor funds. However, my examination supports the more constructivist suggestions of options two and three (accept the definition and rhetorically bridge it to their organisational frame; accept the definition, bridge it to their organisational frame and criticise it) and the idea that organisations are engaged in a type of alignment consistent with their organisations. The UN Inter-Agency Project, a new UN entity, seems different in this respect. While other organisations are clearly lining up aspects of the protocol with components of their other work, there is no clear organisational frame for the UN-IAP. Though the sub-regional manager did mention the Convention on the Rights of the Migrant Worker, the approach of the UN project does not seem to be drawn from other organisational instruments. Criticisms and approaches to trafficking issues seem to be drawn from ideas about the contexts and restraints rather than a result of filtering through an organisational frame.

Generally, though the movement aspect of the definition was accepted by all of the organisations in my study, it was the exploitative nature of the work or the loss of control over agency (unless dealing with those under the age of eighteen) that was the key to distinguishing trafficking from non-trafficking scenarios. This is understandable, given that trafficking in the sub-region is generally conceptualised as beginning with migration that is at least to some degree voluntary, with elements of coercion, deception and abuse revealed later (see chapter two). The secondary organisations consulted during the fieldwork demonstrated a similar universal acceptance of the UN protocol definition, and a similar overwhelming tendency to focus on women and children. Of the differences observed between organisations, one set seems explicable in terms of scale. I have suggested that Save 
the Children UK's broadly critical approach relative to the Thai and Cambodian NGOs can be understood as reflective of the level at which it functions (with a home base in the UK, a network to other SC UK regional programmes, a network across the Save the Children Alliance and anti-trafficking activities taking place throughout the Mekong Sub-region). Revisiting the interviews with this idea of scale in mind and asking whether Thai and Cambodian NGOs critically engage in issues related to trafficking, I find that their advocacy and criticisms tend to focus on national laws, implementation and approaches rather than at the level of international discourse, explaining why they did not emerge in my discussion focused on points of disagreement with the protocol definition.

In Thailand, issues of particular contention were the failure of the government to extend citizenship rights to ethnic minority populations. For the Development and Education Project for Daughters and Communities (DEPDC) and the Mirror Art Group, members of ethnic minority groups (e.g. Karen, Lahu, Akha, Lisu, H'mong, Mien) comprised major portions of their target groups, and advocacy and action to get citizenship for them were also taken on by other projects of these NGOs. ${ }^{64}$ During the interviews, representatives of both the UN and the ILO projects raised the same issues and were particularly concerned with the Thai trafficking law's limited focus on women and children (increasingly problematic as Thailand has begun signing Memoranda of Understanding (MOUs) with neighbouring countries and is exporting this “flaw”) (van de Glind 2003;

\footnotetext{
${ }^{64}$ Many of these populations meet the official requirements and qualify for Thai citizenship, yet are unable to obtain documentation or recognition and face many barriers despite a King's message supporting their claims. Their citizenship goes unrecognized, they do not have citizenship cards, and they face many problems. Beyond police harassment and being treated as irregular migrants (though many have lived in Thailand for generations), these unrecognized Thai citizens are unable to own land (and so are forced to gather or labour for a wage on the land of others) and their children are unable to attend school (and so receive no education and must be cared for by a parent or older sibling) (see description of Mirror Art Group's "Thai Citizenship Project" on-line description (MAG)). Development and Education Project for Daughters and Communities has a day school for ethnic minority children in the area who are unable to attend state schools because they are not recognized as citizens.
} 
Marshall 2003). The UN project was also critical of the Thai government tendency towards crackdowns as a solution to problems of organised crime, particularly in terms of the drug trade, ${ }^{65}$ and concerns about this approach being taken relative to trafficking, "crackdowns on migrants, crackdowns on border movement, crackdowns on the sex trade in general - all of which are just likely to make things worse" (Marshall 2003).

In Cambodia, there were common concerns about law enforcement, impunity and corruption, as well as the treatment of Vietnamese immigrants and populations. Nopsarin Sreyroth of the Cambodian Women's Crisis Centre said,

... we're also looking for neutrality in the judiciaries regarding the cases of sex trafficking, because so far this case usually involves the powerful and the rich people and this makes the courts' positions very uncertain. And we look forward to the independence and the good judgement from the court. (2003)

Criticisms of a lack of neutrality amongst judiciaries were echoed by Ros Sokham of the Cambodian Migration and Development Committee "we have to make law enforcement and strengthening the legal structures, so by doing that I hope that in the future if you see people are corrupt you bring them to justice" (2003).

National NGOs are both critical and political in their anti-trafficking work. However, while the international NGO and IOs were critical of the international and national regimes, national NGOs tend to focus their criticisms on the context they work in.

\section{Conclusions}

Though all organisations accepted the Trafficking Protocol definition, my evidence supports the idea that there is continuity with organisational frames, and that this is consistent with framing rather than co-optation. This applies both to NGOs and IOs. Organisations align their anti-trafficking work with their broader organisational frames, with

${ }^{65}$ The War on Evil Influences, which continues today under Prime Minister Thaksin Shinawatra, ended over $21 / 2$ thousand lives the summer of 2003 (as I conducted the interviews for this project) in a campaign focused against the drug trade. 
the exception of the Development and Education Project for Daughters and Communities, whose organisational frame is itself anti-trafficking and the UN Inter-Agency Project, a new entity within the vast UN system for whom I was unable to identify a clear organisational frame. The IOs make this alignment using formal "tools" of their organisations, such as II.O labour conventions, while NGOs do so by fitting and aligning their anti-trafficking work with their other work (for example, Save the Children UK from within a child-focused rights-based focus; the Cambodian Women's Crisis Centre from the context of stopping violence against women; Mirror Art Group from the context of building and supporting hill tribe communities).

Points of difference between IOs and NGOs seem related to scale: NGOs politically engage at national and local levels (with Thai and Cambodian organisations looking at different components) while IOs and the international NGO engage discursively with the definition itself in addition to taking on these national challenges. It is also evident that IO projects cannot serve as a proxy for donor agendas. It was particularly surprising that the UN Inter-Agency Project, despite being organisationally the closest to the UNODC Trafficking Protocol, was by far the most critical of its limitations. Table eleven, below, outlines these conclusions relative to the concerns and indicators outlined in chapter five. In terms of the critical approach taken by the UN Inter-Agency Project, I must first reiterate that it is possible that this reflects staff opinions and perceptions rather than an organisational policy (if such a distinction can be made). However, a second possible explanation is that where NGOs are expected to be less critical as a result of their reliance on donor funding, IOs are in a unique place of stability and prominence that enables them to be vocal critics. This possibility was brought up by Tarrow in the conclusions of his article on social movements, "International institutions can play a facilitating role... This leads to the 
paradox that international institutions - created by states, and usually by powerful ones - can

be the arenas in which transnational contentions form" (n.d., 21).

\begin{tabular}{|c|c|c|}
\hline \multicolumn{3}{|c|}{ Table 11: Defining trafficking: Co-option vs. Framing } \\
\hline Concern & Comment & Conclusion \\
\hline $\begin{array}{l}\text { Opportunistic } \\
\text { NGOs / } \\
\text { Projects }\end{array}$ & $\begin{array}{l}\text { - NGOs and IOs do accept protocol definition, but align with and } \\
\text { manifest organisational frame } \\
\text { - Strong evidence of multiple objectives: NGOs and IOs take up } \\
\text { projects of that are consistent with the organisation goals } \\
\text { - Strong evidence of broader engagement in trafficking: NGOs and } \\
\text { IOs engage politically at the national or international level } \\
\text { (Note: difficult to speak of UN project in these terms) }\end{array}$ & $\begin{array}{l}\text { Support } \\
\text { framing } \\
\text { hypothesis }\end{array}$ \\
\hline $\begin{array}{l}\text { Agenda } \\
\text { change to } \\
\text { match donor } \\
\text { priorities }\end{array}$ & $\begin{array}{l}\text { - Cannot fully comment on whether take on activities that donors do } \\
\text { not fund (I did not survey all projects and sources of funding from } \\
\text { organisations) } \\
\text { - Cannot comment on whether NGOs influence on donor agendas, } \\
\text { ways of working, priorities: I did not survey donors } \\
\text { - Strong evidence that they accept but criticise/qualify donor policy: } \\
\text { all critical on international or national trafficking issues (IOs and } \\
\text { INGO more likely to directly challenge protocol; NGOs tend to be } \\
\text { more focused on national policy; this may signal donors as less central } \\
\text { restraints) }\end{array}$ & $\begin{array}{l}\text { Some support } \\
\text { for framing } \\
\text { hypothesis } \\
\text { Counter- } \\
\text { indicates co- } \\
\text { optation }\end{array}$ \\
\hline $\begin{array}{l}\text { Legitimisation } \\
\text { of donor } \\
\text { policies and } \\
\text { projects }\end{array}$ & $\begin{array}{l}\text { - Some evidence of rhetoric/action critical of funders evidence: } \\
\text { critical discourse focused on migration, by IOs and NGOs } \\
\text { - Strong evidence of politicised engagement in issues } \\
\text { - Strong evidence that focus on donor positions: all know, accept and } \\
\text { engage with Trafficking Protocol definition } \\
\text { - Cannot comment on whether focus includes informing donors of } \\
\text { alternate positions (observations of this are limited: international } \\
\text { NGO has advocacy papers, all participate in national stakeholders' } \\
\text { meetings) }\end{array}$ & $\begin{array}{l}\text { Support framing } \\
\text { hypothesis } \\
\text { Counter- } \\
\text { indicates co- } \\
\text { optation }\end{array}$ \\
\hline
\end{tabular}




\section{CHAPTER 8: Target groups - Who are the victims?}

The Trafficking Protocol, like previous conventions and agreements on trafficking, focuses particularly on women and children as victims and makes special mention of the sex trade as a destination sector. Where women and children are categorized together with little attention to differences (i.e. the greater agency and self decision-making power of adults) and contrasted against men, the stereotypes of the weak, vulnerable, easily fooled female/child trafficking victim, and the strong, decisive, deceptive/criminal male illegal migrant may emerge. This may also enable organisations and governments to ignore the ways in which men, too, are vulnerable and abused and to assume something intrinsic, rather than historical, about women's vulnerability. ${ }^{66}$

Turning to the question of whether women, children or men (or all) are the intended beneficiaries of anti-trafficking projects, I have expectations based in part on the insights into the relative strength of frames for mobilisation and the role that organisational frames play in how organisations defined and addressed trafficking from the previous chapter. In terms of political opportunity, I consider an emphasis on women and children an "easier" route to mobilising support because historically and currently a greater proportion of women and children are in positions of less power (economic, social, political, etc.). As such, they may be more vulnerable to trafficking and other forms of exploitation. A focus on women and children will be consistent with donor preferences and I expect organisations to reflect their organisational frame by focusing on the same target groups for their trafficking prevention interventions as they do for other projects.

\footnotetext{
${ }^{66}$ Interventions and responses based on past harms play into what Doezema, following Foucault's theoretical ideas, calls the politics of resentiment. recreating unequal power relations by basing on-going political action on a history of past harms, seeking redress, protection and assistance from the same groups responsible or complicit in these harms and thereby recreating and further entrenching the unequal power relationship between them (2001).
} 
As I suggested in chapter four, migrants (particularly irregular migrants) are increasing viewed as criminals and associated with violations of state sovereignty and the law. Extending discretional protection and limited acknowledgment to the harms suffered by unconsenting trafficking victims differs substantially from increasing worker or migrant rights or otherwise helping would-be "illegal" or "criminal" migrants. Women and children are perhaps considered less of a threat to national security and especially where portrayed and interpreted as victims, there is less threat in extending some limited rights (i.e. protection) to them. Donor support is more easily mobilised to assist these populations.

\section{Findings}

Starting with the Thai NGOs, the Development and Education Project for Daughters and Communities (DEPDC) initially focused exclusively on girls, "We have focused on young girls from the beginning, but after five years of the project we decided to cover boys as well" (Jakantra 2003). To do so, they had to find a donor willing to fund project activities for boys. While DEPDC's understanding of trafficking problems and solutions was flexible, funding from the initial donor was not: it was only for girls. Finding new donors facilitated the inclusion of boys:

The funds that we received later not just focus on girls: it's not "girl child" project, it's "children's" project. OK, then you can use the funds to support not just girls but boys too. The second reason is because some time that you rescue one family: they have brothers, sisters. Especially if their parents are in trouble, in jail or something, and you pick up one girl... and for the boy "Where should I go? Who can I stay with?" or something like that. So, cannot separate brother and sister from the same family... The first five years was just girls who are at risk of coming into child labour or child prostitution. But the second five years we also have children who are at risk, children who are in trouble: CEDC, Children in Especially Difficult Circumstances. That is the second reason. The third reason is because sex exploitation later involved with boys. Obviously, in Pattaya ${ }^{67}$ or some areas

\footnotetext{
${ }^{67}$ Pattaya has become notorious for sex tourism including paedophelia. This is changing with increased media attention and intolerance and prosectutions on the part of governments combined with improved legislation in
} 
of Thailand when they report about the paedophiles or sex tours, it's not just girls - there are boys in the brothels also, and they also recruit boys for sexual exploitation. So if you would like to protect children from sexual exploitation you should include boys. (ibid.)

The desire to expand and focus on "children" rather than "girls" was in response to observations of problems beyond female child sex trafficking to the broader problems faced by male and female children in exceptionally difficult circumstances (CEDC). New donors willing to work on these terms were sought. However, donor influence initially hindered the inclusion of boys: the desire to work with the broader population of children was stalled until a new donor could be found to work under these terms, rather than immediately integrating boys into on-going projects. This did not determine or limit DEPDC's actions beyond the short term, suggesting that responsiveness to community needs complements or takes precedence over donor preferences and established project structures.

This flexibility and responsiveness is seen in other dimensions of the project. In terms of an age focus, "We stop at 18 - that's by traditional law and by $\mathrm{CRC}^{68}$." However, this was is not a hard boundary:

You cannot just draw the line and say 18 and two days or three days or something. Sometimes when you're dealing with children on the street or displaced families, you cannot prove that how old necessarily they are. They can say 20 but maybe 13 . Or they can say 13 but maybe they're 20 . If you feel this looks young and she's not an adult, she's still a child, just help, we are not serious about that. (ibid.)

Flexibility denotes responsiveness to downstream needs of intended target beneficiaries.

Mirror Art Group's (MAG's) project, the second Thai NGO, by name focuses on only women and children. The organisation's goal is "helping the hill tribe people of Mae Yao sub-district to combat their everyday struggles with unemployment, poverty, drug

countries such as Canada and Australia allowing offenders committing acts of paedophelia overseas to be tried and convicted in their home countries.

${ }^{68}$ Convention on the Rights of the Child. 
addiction and lack of Thai citizenship" (World Bank n.d.). While the Project to Combat Trafficking in Women and Children also emphasises this, the gender focus on women and age focus on children departs from the MAG's other projects, which include all community members. This may be evidence of donor influence. The trafficking project was started with a funding proposal to the ILO anti-trafficking project (the ILO Mekong Sub-Regional Project to Combat Trafficking in Children and Women). Knowledge about the funding agency (the ILO) and its approaches and target groups might explain the title, language and target groups for MAG's project (which are more consistent with ILO's work than MAG's organisational frame). However, I have no specific comment from either organisation confirming this.

For both of these Thai NGOs' projects, there is a clear preference towards first, females, and second, youth, as target beneficiaries for anti-trafficking projects. This is also seen in the projects of the Cambodian NGOs.

The Cambodian Women's Crisis Centre (CWCC) reports, "Our project focus is only sex trafficking. So we usually deal with women and children especially... but you know right now the project is moving a bit to focus on some types - like forced labour too, so there's some change" (Nopsarin 2003). This is consistent with the organisation's violence against women focus, and emphasis of the sex trade also reflects the Cambodian national law's focus primarily on the sex trade as the destination sector for trafficking. In terms of an intended future focus on broader labour types, it is unclear whether this is a response to observations in the community in which they work (as in the case of DEPDC), anticipated changes to Cambodian anti-trafficking legislation, or influence from other organisations. Looking at other projects of CWCC, there are instances of the organisation changing policy 
as a result of downstream requests. For example, they began to include men in some of

their counselling services under some circumstances:

Originally, CWCC had a policy of only dealing with the women in cases of domestic violence. But one day, when exploring options with an abused wife, she asked why they were not talking to her abusive husband - he was the only one who could stop the violence. This caused the organization to reconsider their policy. They realized that women often depend on their husbands, and do not want to divorce or punish him, but just to make the violence stop. CWCC decided to take a new approach in domestic violence cases, counselling all the parties involved. They have found that this is very effective in stopping the violence. (UNIFEM 2001)

This demonstrates at least a precedent within the organisation for changes in inclusiveness based on downstream signals.

The Cambodian Migration and Development Committee (CMDC) also works with women and children, but where the Cambodian Women's Crisis Centre takes a position of central concern about violence against women, $\mathrm{CMDC}$ has an organisational focus on human rights and poverty alleviation for female-headed households, particularly the homeless (Ros 2003; UNIFEM 2001):

Normally, ICMC ${ }^{69}$ or CMDC is focused on women and children as the main purpose - all services are for women and children. [Question: And men?] Not entitled for our project. Because we support mainly for the widow head of family, for the young girls who are have been trafficked to the neighbouring country or around the country and to the children who are the victims of the war, things like that - the parents who are like, the father died and left only mother with no support and other things like that, and sick children, homeless families - we support that. So, in general we support women and children. (Ros 2003)

Both of these Cambodian NGOs consider children to have special needs, and greater vulnerability than women. When asked if they worked differently with women and children, CMDC responded:

It's different because the women you can easily to provide them the counselling and place them with the job and the business. But for the

${ }^{69}$ ICMC, Internation Catholic Migration Commission, is CMDC's parent organisation. 
children, it's much more difficult because they don't know what they're going to do, and the children are very vulnerable. Children who live with the homeless families - it means that they are the returnees from the border sites who stay in the country, have no land... or have, but the land's unsafe there are the landmines, there's still fighting ... while the children stay in the urban area, they are begging or they are sniffing glue because they're hungry... I asked them, why are you sniffing glue? Do you want to do it? What are you - what sort of thing made you want to do it? They say, "No, the first thing - I didn't know. But a friend of mine tells me that if you're sniffing that you will not be hungry and you'll feel happy." And then he tried, and that's true. Because when they're sniffing glue they feel not hungry. But physically they are the same, and they are pale. They have the heart problems, and they are thin because they haven't got any calories from the food to support the body... How can we support the children? (ibid.)

Children in any given circumstance require more care and are more vulnerable. It is clear that they face immense dangers, particularly living on the street. In many instances, to help, organisations have to help the whole family: putting children in shelters is not enough, "So if I take only the children go to the centre, they no longer stay. Because they are missing... "my brother" and "my sister" and "my mother" who stay without food, "Because when I stay we go begging or to do something to support the family" " (ibid.). CWCC shares this understanding of children having special needs, particularly when coming out of difficult situations (Nopsarin 2003).

The majority of these NGOs do not specifically target men in any of their general projects, nor in their anti-trafficking projects. The Mirror Art Group is the only one that does, and even for this organisation the anti-trafficking programme is entitled and oriented towards the combat of trafficking of "women and children". Even so, they consider men to be potential victims of trafficking and address this discursively. The representative of the Cambodian Migration and Development Centre said that trafficking was a problem, "for men, for everyone - that means trafficking in persons, men and women and children. But we're just looking for women and children as a target" (Ros 2003). Nopsarin of the Cambodian Women's Crisis Centre said: 
... concerning the trafficking, we really wish that the adoption of the new draft law were passed soon in order to fitting the demands of our victims and our society... just referred to as the sex trafficking law, anyway it doesn't cover the definition of what is trafficking. For example, the intent or the purpose of the law we refer to trafficking for the purpose of prostitution only, but not for the purpose of begging or forced labour or anything like that. (2003)

This broadening of the definition would implicitly include more men under the legislative

limits. Jakantra reaffirmed that trafficking includes men and women as well as children,

So trafficking covers lots more things than just sexual exploitation, but any kind of forms that exploit human rights, human beings: slavery, have no chance, have no independence to get out of the situations, no hope, weak, no choice, this is trafficking. [Question: Is trafficking the same, for women, for children, for men?] Yes. Yes, but different purpose maybe, but the same idea. (2003)

Understandings of trafficking extend beyond their direct work.

Despite their child-focus, Save the Children UK, like the Development and

Education Project for Daughters and Communities, does not use 18 to as a hard boundary.

SC UK works with children, but sees trafficking as a problem for adult men and women too:

We will focus on children. That doesn't mean that we will take in only 18 years and below - that we won't take in 18 years plus one day. One, because we are working with marginalised children who don't even know their own age, or we are working with children who don't have papers, and we are working with cultures who may have different measurements in terms of age and definition of children, or maybe those are the children who cannot afford to say the truth - like sex workers, they are never below 18 but they are never beyond 20 . And these are children who have lost their childhoodwho already suffered a lot - abuse, exploited, well before they are 18 and now it's not fair that they are 20 and we kick them out from out interventions. It's not fair, and they can be our very good committed volunteers and peer educators and partners ${ }^{70}$ so we accept them. (Aye 2003)

\footnotetext{
${ }^{70}$ Part of Save the Children UK's participatory approach includes working through community members, "Our resources don't only depend on the number of staff that we employ, but mostly we keep the low number of staff and rely our force more on volunteers and children and young people that we are working with in our target communities." (Aye 2003)
} 
Save the Children UK clearly focuses on children, but remains flexible on the issue, stating concerns about the well being of children and young adults as key and accepting trafficking as a broad problem, affecting men, women and children.

Though by name the ILO project covers women and children, in practice it is primarily child-oriented. Project documents and staff emphasise that this is not because men are not considered to be potential trafficking victims, but rather because the organisation has limited resources and considers children to be the more vulnerable population:

...the actual interventions in terms of how money is spent mainly focus on children and to a certain extent women and not so much men. Reason being not that men are not important - they are important, but 10.5 million may sound like a lot of money but for five countries, it's actually peanuts. So what you want to do is have some focus and for us the focus is definitely mainly on children, simply because their levels of vulnerability are, we think, higher than that of an adult man. We don't deny that a man in exploitative situation is problematic - it's still a violation of human rights, it's still very bad, but it's not our top priority. (van de Glind 2003)

The head of the Cambodian national ILO project reiterated that the focus was on children, but assisting children frequently means assisting families:

In terms of IPEC, ${ }^{71}$ it's focused on the children... But to assist the children, we can work also through the parents. When the parents can have a good income, for example, the income can assist the children to go to school. And we also work through the community... but the purpose is for the children. (Khleang 2003)

This was also the position of the Thai national ILO project: while children are the target beneficiaries, men are part of the target group for prevention at the community level because they are part of the family. Awareness raising includes men, as they are the heads of families and comprise the majority of village operating committees (Phanawathamawong 2003). ${ }^{72}$

\footnotetext{
71 The International Programme for the Elimination of Child Labour (IPEC) is the programme under which the Trafficking in Children and Women Project (TICW) is run.

72 Prungchit Phanawathamawong, the head of the Thai national ILO anti-trafficking project consented to being interviewed and included in the research, but not to be tape-recorded. She further expressed a preference not to be quoted verbatim. As such, I have paraphrased and cited the information from my interview notes with her.
} 
The ILO's focus on children makes sense, given that trafficking is addressed under IPEC.

Children are also the least controversial population and least grey area associated with trafficking with which to work. This is quite distinct from the approach taken by the other IO included in the study.

When the current UN Inter-Agency Project on Human Trafficking in the Mekong Sub-region project initially started (start date was in 1999 but project activities did not start until 2000), it had a different name and focus, "Phase one, our project was called UN InterAgency Project Against Trafficking in Women and Children. So actually we want to cover everybody but the project is called women and children... So in phase two, we changed our name to "Human Trafficking"” (Hang 2003). Representatives of the UN Inter-Agency Project were critical of the implications of excluding men:

...we do quite a bit of conceptual work on this. Again there's two issues on this - about men being trafficked. One is that if you ignore the fact that men are being trafficked, you ignore the men who are trafficked. But the second aspect of that is that it plays into a certain discourse, which is that trafficking is something being done by "bad" people to poor innocent victims with very little agency, rather than something which has a lot of structural dimensions. So neither men nor women are done a favour by leaving them out of this issue. (Marshall 2003)

Following my earlier discussion on gendered structural issues, a female-focused project growing out of a structural understanding would not be unwarranted. However, Marshall seems to be pointing to two things. First is the tendency of trafficking discourse to emphasise aspects of victimhood and lack of agency: the very definition of trafficking in the protocol requires that agency in some way be limited or negated, either by the means set out in Article 3(a) or by age, as set out in Articles 3 (c) and (d). Second is the association of women and children qua women and children with this vulnerability. 
As Thailand's trafficking law covers only women and children, and Memoranda of Understanding (MOUs) were being signed with Laos and Cambodia at the time of the research, concerns about exporting Thailand's limited focus were prevalent:

The law is being changed at the moment... we're very concerned about that because now they're doing an MOU with Cambodia which is only women and children -because all of their MOUs here only provide for that. And we're worried about this flaw being exported to other countries. (Marshall 2003)

\section{Conclusions}

Across organisations, with the exception of the UN Inter-Agency Project, the target groups for anti-trafficking projects were consistent with their organisations' other work, implying consistency with organisational frames. All of the projects, again with the exception of the UN project, focused on women and children or, in the case of the Development and Education Project for Daughters and Communities (DEPDC), Save the Children UK and the ILO project, on children. However, my ability to make clear conclusions about this is limited. My research does not consider whether organisational frames themselves are a result of political opportunity, and so defined by upstream sources. My analysis rests on the assumption that the organisations in my study are first not opportunistic or bogus (the fist of Korten and Quizon's six points) and secondly that their organisational frames are drawn from and based on what Najam considered self- or client focused responsibility (see chapter five).

Organisations seem to consider children to be more needy and vulnerable, lacking experience or capacity and, as such, limited in terms of agency. There were some suggestions that where funding was earmarked for anti-trafficking projects for "children" or "women and children" it was problematic without some sort of official change (in name in the case of the UN project; in name and donor in the case of DEPDC) to include men or 
male children as beneficiaries. It is possible that this focus on women and children is related to the greater vulnerability of women and children (be it perceived as inherent, or the result of structural and/or historical biases); the desire of donors to fund projects assisting those deemed "vulnerable" or "lacking agency" (i.e. because they are more needy or because they pose the least threat to the limited extension of migrant rights through the Trafficking Protocol); or NGO and IO sensitivity to this both in terms of their anti-trafficking and other work.

While all organisations thetorically accept men as potential victims of trafficking (regardless of Thai law and the MOUs) and consider sectors beyond the sex trade to be labour destinations for trafficking victims (regardless of the Cambodian law) it was the UN project representative critically took on the implications of this type of focus. Perhaps the $\mathrm{UN}$ project is anomalous rather than indicative of $\mathrm{IO}$ behaviour, but it is an example undermining the assumption that IOs are followers, rather than critics, of donor policy.

\begin{tabular}{|l|l|l|}
\hline \multicolumn{1}{|c|}{ Table 12: Target Populations: Framing vs. Co-option } \\
\hline \multicolumn{1}{|c|}{ Problem } & \multicolumn{1}{|c|}{ Comment } & \multicolumn{1}{c|}{ Conclusion } \\
\hline $\begin{array}{l}\text { Opportunistic } \\
\text { NGOs / } \\
\text { Projects }\end{array}$ & $\begin{array}{l}\text { - NGOs and ILO project target beneficiaries reflect donor focus on } \\
\text { women and children but are also consistent with organisational } \\
\text { target beneficiaries (with the exception of the UN-IAP and MAG) } \\
\text { - All reported critical understanding trafficking as including all groups, } \\
\text { even where their intended beneficiaries were limited }\end{array}$ & $\begin{array}{l}\text { Consistent with } \\
\text { framing, some } \\
\text { potentially } \\
\text { consistent with } \\
\text { co-optation }\end{array}$ \\
\hline $\begin{array}{l}\text { Agenda change } \\
\text { to match donor } \\
\text { priorities }\end{array}$ & $\begin{array}{l}\text { - One NGO (MAG), funded by the ILO project, reflected the ILO's } \\
\text { particular focus on children (and women), a limitation inconsistent } \\
\text { with their other projects } \\
\text { - One NGO (DEPDC) and one IO (UN) changed (project name/ } \\
\text { donor) to be more inclusive responding to downstream (beneficiary) } \\
\text { signals and in contrast to upstream (donor) signals }\end{array}$ & Mixed evidence \\
\hline
\end{tabular}




\section{CHAPTER 9: Interventions - What are the solutions?}

In this final analytical chapter I explore what organisations do to prevent trafficking in sending communities (i.e. pre-trafficking and pre-migration). This is an area where I expect my concerns to intersect dramatically. In Cambodia and Thailand, trafficking is generally understood (by the organisations) as beginning with migration that is "to some extent voluntary," and trafficking is approached from a "broader migration approach" (Aye 2003). Do interventions suggest aspects of "donor co-option" or even "anti-migration for anti-trafficking" approaches?

Article nine of the Trafficking Protocol lays out trafficking prevention measures for states parties (see table 13, below).

Table 13: Prevention, cooperation and other measures (Article 9 UN Protocol)

1. States Parties shall establish comprehensive policies, programmes and other measures:

(a) to prevent and combat trafficking in persons; and

(b) to protect victims of trafficking in persons, especially women and children, from revictimization.

2. States Parties shall endeavour to undertake measures such as research, information and mass media campaigns and social and economic initiatives to prevent and combat trafficking in persons.

3. Policies, programmes and other measures established in accordance with this article shall, as appropriate include cooperation with non-governmental organizations, other relevant organizations and other elements of civil society

4. States Parties shall take or strengthen measures, including through bilateral or multilateral cooperation, to alleviate the factors that make persons, especially women and children, vulnerable to trafficking, such as poverty, underdevelopment and lack of equal opportunity.

5. State Parties shall adopt or strengthen legislative or other measures, such as educational, social or cultural measures, including through bilateral and multilateral cooperation, to discourage the demand that fosters all forms of exploitation of persons, especially women and children, that leads to trafficking.

This sets up a foundation for NGO and government cooperation on anti-poverty, development and gender and race discrimination, where development projects have a history of focusing, in order to combat trafficking. Encouragement to engage in research, information, mass media, social and economic initiatives reinforces the need for experts in 
information gathering and analysis, as well as communication strategies and project design based on the gathered information.

Looking at types of interventions to determine whether they are pro-migration, antimigration or migration neutral is problematic. In isolation, certain aspects may appear antimigration, but this may be discounted when taken in the context of the variety of other project activities. I choose to conceptualise positions and potential impacts on migration in terms of the play between protecting or cutting off individuals and communities from the choice to migrate vs. empowering individuals and communities, expanding the options they chose from, as well as the resources with which they go (or stay).

The possibility that projects focus on reducing or preventing migration (or even certain types of migration) may reflect receiving countries' interest in preventing or limiting migration. As discussed in chapter four, though not necessarily universal amongst or even within particular governments, there are some generalised donor approaches and positions that suggest this preference for continued restrictive migration policies and practices. Alternately, it is possible, particularly when dealing with vulnerable populations, that there is a sense that they need to be "protected", in this case from the decision to migrate. I recognise that protection is sometimes necessary and is a valuable response and short-term strategy, but am concerned about it being a long-term or final goal in the absence of more empowering objectives. It includes setting up a relationship of dependency and assumptions that outside bodies "know better" or indeed have the right or duty to make decisions for groups they consider to be vulnerable. This recreates and reinforces positions of marginality and unequal power relationships which directly link to the initial position of vulnerability, marginality, or being in need of protection. Empowerment involves building access to the tools, skills, resources and networks to expand opportunity sets and enhance their ability to 
make decisions (including those outsiders may view as "wrong" or even "harmful" decisions), working towards changing, rather than entrenching, positions of marginality. There are times and places where people require protection. This is generally the category into which children are assumed to fall and protection need not be inconsistent with a longer-term goal oriented more towards empowerment. However, for the purpose of this analysis I equate the idea of protection with interventions that are, effectively, anti-migration.

I conceptualise attempts to control movement or restrict the choices available as more protectionist, and attempts to expand resources with which to make choices including the choice to migrate - as empowering. Drawing from my discussion of migration and typology of trafficking prevention interventions (chapter six), interventions can be categorised as trying to change micro, meso, macro or political aspects. At the micro level, interventions may try to change the decision to migrate or the ways in which people migrate through public awareness campaigns, expanding local economic or educational opportunities. It is the first of these two which potentially reduces rather than expands opportunities. Where there is a focus on the "tricks of traffickers" and "dangers of migration" intended to stop people from choosing to migrate without an accompanying provision of information on ways to reduce, avoid or respond to these harms (other than by not migrating), I understood this to be more protectionist.

Expanding economic or educational opportunities, on the other hand, can be understood as increasing options and opportunities and empowering individuals whether or not they chose to migrate. Expanding economic opportunities may increase the numbers of people who chose not to migrate, because their need to do so decreases or because their resources increase. As such, I classify this as neutral. 
At the meso level, I understand any expansion of social capital as an empowering intervention. By encouraging and developing linkages and connections between communities and existing NGOs, civil society organisations, government departments, etc (whether to improve access to education, health, agricultural resources, or to advise or assist in migration decisions), people's resources and opportunities are increased.

At the macro level, in terms of what organisations can and do engage in, there is major overlap with the policy level. Organisations may be involved in the production and dissemination of information, intended to inform, alter or influence decision-making. They may also be involved in direct lobbying to pursue structural change in favour of certain political goals, be it the expansion of opportunities for women, the inclusion of certain sectors in domestic labour codes, etc.

In the remainder of this chapter, I look at the macro, meso and micro components in turn. But first I present some brief responses to and evidences about the third and fifth of Korten and Quizon's concerns, namely that projects match donor time-cycles and funding periods, and that organisations prioritise donor standards of professionalism.

\section{Donor time-cycles, funding periods and professionalism}

My comments on donor time-cycles, funding periods and prioritisation of donor standards of professionalism are brief. Donor dollars are important to projects and organisations, and projects run on donor dollars are constrained by the amount that donors allocate, the number of years the project is approved (time cycles), and the donor's particular reporting requirements (i.e. English language reporting). Mitigating this influence is the relative abundance of potential donors (OECD countries, multilateral organisations, etc. as well as the availability of private sources of funding). This abundance allows organisations to seek now or additional donors in order to support their work, as was done by the 
Development and Education Project for Daughters and Communities when they wanted to expand their project to include boys (see chapter eight). Donors may fund particular interventions in a "bulk sum" amount, or they may provide a specified budget to a specific project or programme for a specific period of time (typically three years). Without money, projects stop. As Ros of CMDC explained, “[It's] a very crucial time for CMDC now, because we don't know whose funding we can get. And we need funds to support women and children - both homeless families and anti-trafficking" (2003).

In addition to being dependent, recipients are responsible for accounting for this money, and with the OECD's and other aid organisations' increasing focus on the impact of aid, they are increasingly required to establish goals and demonstrate that they are achieved (OECD-DAC). There are overall preferences for quantifiable indicators, project activities broken down into "logistical frameworks" (logframes) and for English language reporting (see World Bank Operation Policies and Country Services, n.d.). As an example, of the 22 interviews I conducted, all but two were conducted completely in English (one of these two, with the Cambodian Women's Crisis Centre, was conducted with the assistance of the organisation's Khmer-English translator) even though all but four of the people I interviewed were Cambodian, Burmese or Thai. As discussed in the next section, they also produce regular reports, most of which are available in English. English language skills serve donor, not recipient communities. I suggest that donor funding implies that projects match donors time cycles and funding periods and that organisations prioritise donor standards of professionalism.

\section{Political and Macro: Production and Dissemination of Information}

To different degrees, all of the projects engage in the production of experts and information. Larger organisations tend to produce and disseminate more information, 
sponsor and encourage more studies, engage more experts, and host, arrange and attend more stakeholder meetings. Smaller NGOs actively participate, sometimes pooling resources for advocacy purposes (Skrobanek 2003). This section provides a superficial overview of the types of these activities. I have not done a detailed review or analysis of the methods or context of these advocacy and dissemination activities.

The ILO Project to Combat Trafficking produces and distributes a broad selection of trafficking resources, including lessons learned and best practices documents, ${ }^{73}$ as well as exploratory policy papers for the consumption of the community of anti-trafficking projects. UN Inter-Agency Project (UN-IAP) turns out a quarterly newsletter, Step-by-Step ${ }^{74}$ that serves as an information and debate forum for anti-trafficking stakeholders in the subregion. These are all available in English.

Commissioned and disseminated by the two IOs, Ronald Skeldon's exploratory policy paper, Irregular Migration in the Greater Mekong Sub-region: Policy Dimensions of a Growing Issue, has particular relevance in the discussion about migration and anti-migration leanings of project interventions. It advocates considering trafficking as an outcome of, amongst other things, restrictive migration regimes and reducing trafficking by expanding these regimes:

It will be argued that, unless more channels are opened to facilitate the legal movement of greater numbers of people, the issue of trafficking cannot be adequately addressed. That is not to say that the opening of borders will automatically lead to a reduction in trafficking. However, the creation of more, or broader, legal channels for movement is an [sic] significant step towards the better management of migration and, ultimately, to the eradication of the worst forms of abuse associated with the exploitation of migrant labour. $(2001,37)$

${ }^{73}$ ILO Sharing Experience and Lessons Learned (SELL) Notes and Summary Notes: Technical Intervention Areas (TLAs). 74 Step-by-Step is available on-line from http://www.un.or.th/TraffickingProject/Publications (last accessed 1708-2004). 
Though produced and funded by IOs, this is a direct challenge to the type of restrictive migration regime and resistance to the expansion of migrant rights associated with donors, yet produced and distributed by the office of an IO, not an NGO.

Save the Children UK, the other international-scale organisation, also produces and publishes a large amount of information, largely communicated through the network of Save the Children Alliance. This includes advocacy and analysis papers as well as research findings, for example participatory action research (PAR) reports such as Small Dreams Beyond Reach and Breaking Through the Clouds; research and advocacy reports including Comparative Study of the Legal Provisions of the 6 Countries in the Mekong Subregion with respect to Trafficking in Women and Children and Cross-border Community-based Initiatives Against Trafficking in Cbildren in the Mekong Sub-Region.

The four domestic NGOs all produce documents for donor and domestic audiences, including regular English and local-language project reports, summarising and analysing activities to date. Mirror Art Group also maintains an interesting and detailed website, and has produced videos providing information about their organisation and project for the broader population. Relative to the others, The Development and Education Project for Daughters and Communities (DEPDC) produces an unusually large volume of written advocacy and information relative to the other national NGOs. In addition to regular newsletters for funders, past volunteers and other interested parties, the DEPDC is also home to an information-gathering centre for statistics and details about trafficking, child abuse, and other harms.

All of these NGOs are also engaged in advocacy for change at the national level and participate in coalitions and stakeholder meetings. As mentioned, both of the Thai NGOs (along with the ILO, the UN and the Save the Children UK project) are involved in 
advocacy for citizenship rights for ethnic minorities. When I asked about advocacy and whether and how DEPDC lobbies for policy or political change, Jakantra responded: ... we have a network in many countries all over the world, and our volunteers also communicate every day. So the government, the people in the high positions also recognize that DEPDC has some kind of role in the world movement about human rights, about girls and women- when we talk and when we write and when we complain it is feedback - quite strong, also... they invite me to talk in public, to criticize the plans. I think they give me the important position to criticize about the policy of children and women many times, and I learned there are lots of new laws that have been changed after that. (2003)

The director and founder of DEPDC, Sompop Jakantra, has gained a certain respect and authority around issues of child trafficking and child rights, ${ }^{75}$ and has been able to use this position to gain attention and support for these issues.

The Cambodian Women's Crisis Centre (CWCC) works on gaining attention, resources and support for combating violence against women and for carrying through with amendments to the trafficking law to change the Cambodian legislative provisions to a focus beyond sex trafficking, "CWCC also aims to reduce violence against women through training, media campaigns, community organizing, and legal advocacy" (CWCC homepage). They target national and local interests to gain support, attention and change for the women who are their clients, working with and targeting, amongst others, "Ministries, officials and Members of Parliament; releasing press statements" (ibid.). As mentioned in chapter eight, both CWCC and the Cambodian Migration and Development Committee (CMDC) advocate for neutrality in the judiciary and the enforced, impartial rule of law.

From this overview it seems that generally, all organisation do produce and disseminate information. Key differences between them seem to be that IOs focus their

\footnotetext{
75 These include the following honours: 1994 Social Worker Award from Thai PM Chaun Lekpai (1994); Social Innovator Ashoka Fellow Award from Ashoka USA (1994); USAID funded and invitation to do a tour and information exchange in the US (1996); Hero for Today in Readers Digest (Singapore) (1996); Nominee for the Nobel Peace Price (1998).
} 
work more on an international scale, and that the priority concerns differ from country to country (relative to the national context). From my research, the larger degree of information production and distribution by the IOs and the international NGO relative to local NGOs may be explained in terms of them having greater resources to earmark for these activities.

\section{Micro and Meso: Safer Choices through Awareness Raising and Human Capital}

All of the projects included awareness raising components, some warn and inform of the dangers of migration, some build knowledge and linkages (human capital) towards safer paths of migration. From my research, all of the organisations have project components that warn of the dangers of migration. All but the Development and Education Project for Daughters and Communities (DEPDC) also engaged in "safer paths" education of some description. DEPDC takes the position that for children, migration (i.e. solo incomeseeking migration) is not desirable. The organisation's explicit aim is to prevent this from happening by identifying children on the brink of migrating, intervening, and providing those children with a place to stay if their home is not suitable, and an education (formal or informal, depending on the child's needs and abilities):

Children need to be protected more than adults because children - it's risky for children, to let them go to survive in a society in which they have a lot of gangs, mafia, traffickers, drugs, and abusive. And the society - countries in this area are not prepared. We don't have mechanisms or structures that protect children very well. For example, public awareness or reporting systems or safety net...it's not enough. You have to protect first prevention is really necessary, before they enter into the city. (Jakantra 2003)

Earlier I suggested that one difference between children and adults is the implied degree to which they do need to be protected. The director's comments indicate that he feels that while migration is also risky for adults (women, in particular), it is their right and in order to benefit them some type of safer migration education is useful and perhaps necessary: 
I think women - migration is also dangerous, but since they are adults they maybe can take care of themselves and we should have allow them to migrate. But they should get enough information before they start to leave one place to another place. First they have to learn. If there's something wrong, can they call? Can they call to someone - which organisation? What kind of people that they can ask for assistance? You know, like when they come to the town - there are hundreds of places that they can just go and report - organisations that temple, the church, police station, or NGOs or you know - that kind of thing. (ibid.)

This type of education includes the idea of social capital building: this would be a type of social capital "to go" where potential migrants are given ideas about or put in touch with resources that they can draw on. Ideas of social capital are strong in the project's work. Following are some examples of how DEPDC in practice builds and relies on this:

- 'Daughters' and 'sons' building social capital amongst their peers (DEPDC 2003, 2)

- Community elite (teachers, monks, etc.) identifying children at risk (ibid.)

- 'Graduates' fighting for children in difficult circumstances (DEPDC 1999, 45)

- Parents participating in infrastructure and other aspects of the campus (ibid., 77)

Within the community, DEPDC engages in awareness campaigns and advocacy about dangers of trafficking, tricks of traffickers and the ways that sending children for work violate rights and laws, educating community leaders, parents and youth:

Well, actually we teach them about the laws, and about the prosecution: can do or not can do; accept or not accept; legal or illegal - more than anything else because societies understand lots of things. They are not stupid at all, they are clever and they know lots of things... so what we try to inform them about is because we want to stop them get bigger, get involved deeper or decide to do against the law. (Jakantra 2003)

For Jakantra, the institution of the law, illegality and the threat of punishment based around that, even though it needs to be improved and better implemented, is useful in discouraging families from forcing, encouraging, or even allowing their children to migrate for work. It also implies that it is not necessarily ignorance of potential harms that leads to risky migration decisions. The idea that "if only they knew the risks, they wouldn't go" has been criticised by other organisations in this study, notably the UN Inter-Agency Project, seriously 
questioning the efficacy (not merely the protectionist overtones) of "dangers of migration" awareness to prevent trafficking.

The Mirror Art Group (MAG), the second of the Thai NGOs, bundled these two types of awareness-raising together. According to the ILO Sell Notes (2002), Mirror Art Group trained and used a group of former child labourers in drama for awareness raising. The drama group presented scenarios of dangers and facilitators encouraged villagers to think of possible solutions. This combines the awareness raising components with human capital building for the performers, who gain skills and confidence; as well as social capital expansion, as it provides an avenue through which communities can build links with each other. It encourages critical thinking and the production of knowledge by at-risk communities on how to mitigate their vulnerabilities and respond to dangers, in essence encouraging them to solve their own problems (ILO Sell Notes 2002, 1). MAG also produced a video on trafficking and child labour (in Thai, Akha and Lahu languages) that includes telephone numbers that can be called in case of emergencies (ibid., 3.). These activities demonstrate the type of innovation and proximity to target groups that is hoped for from NGOs.

The Cambodian Women's Crisis Centre (CWCC) focuses their information campaigns on sex trafficking, particularly of women, within the context of fighting against violence against women. In particular, their activities include, "producing nation wide television and radio spots on issues such as sex trafficking; organizing public forums; producing publications" as well as "conducting education sessions about sex trafficking in affected communities; organizing special events; creating media campaigns that advocate for women's rights; and creating programs for the victims of violence against women" (CWCC 
homepage). There are components acknowledging the need for information about

possibilities as well as risks:

... we introduce the tricks that the traffickers entice or use with the victims and we also use some law on sex trafficking - for example the law on the Suppression of Kidnapping, Trafficking and Sexual Exploitation of Persons, and in addition to this we also provide the people information where they can seek assistance when they have a problem. (Nopsarin 2003)

CWCC's broader organisation has a community networking project with a mandate of “organizing a referral system for women to access CWCC's services, and networking with partner NGOs and Ministries to provide services such as legal assistance, health care and vocational training to victims." (CWCC 2002), essentially building social capital to increase opportunities and reduce vulnerabilities.

The Cambodian Migration and Development Committee (CMDC) similarly works to disseminate information about the risks and tricks of traffickers and encourage less risky and less blind forms of migration. For example, CMDC works to network and train community representatives on "dangers of immigration and trafficking" with a focus on women and children, including speaking about urban "opportunities" in terms relative to the rural perspective (i.e. potential migrants may already know about rural-urban wage differentials, but they may not know about price differentials or the cost of rents in the city) (Ros 2003). Programmes encourage more critical thinking about migration, particularly of children:

Because the people who have no money, have no job and poverty is a main issue, and well poverty - people can't earn money, can't support the family and the trafficker easily comes and talks and promises them the opportunity to get a better job, to get better pay or to get something else. So this is the major issue of trafficking in here. [Question: Can trafficking be prevented?] That is why we do the networking and awareness programmes to the community: to create networking from the community base - like selected volunteers people to work in the community to spread information; and then to let them know to make the workshop with the school teachers, with authorities with the relatives for people to be aware of what is the dangers in the immigration and the trafficking issues because we cannot prevent any migration because that's a right - people they can go, they can move... but 
just to weigh, to balance the problem. Because if you let your children you be trust with someone who you know clearly and you be confident that people will be safe - that's OK; or your relatives somewhere. But why the people you don't ever know? ...they just left for a few moths and then they come with nice things - jewellery, money - you imagine how- what job they do to earn it? And how did they find the money? ... think about that, and to balance the problem of money and security of life. (ibid.)

The international NGO and the two IOs have greater resources to rely on for drawing conclusions about projects and project activities. Beyond the interviews and some project reports, there are also best practices, advocacy and other publications intended for broader stakeholder audiences. Like all other organisations, Save the Children UK engages in awareness projects about risks and the tricks of traffickers $(2002,2)$, and round this out with information about safer migration, including a variety of campaigns and content like "what you need to know if you go," including ideas terms of payment/conditions, safe repatriation, and so on:

Most migrants are not familiar with the environment, laws and basic facts about the country to which they will migrate. Raising awareness about these issues can reduce risks associated with migration. Contents of information will include immigration and labour laws of the host country, but will include the use of communication strategies that will reach children and young persons who may be illiterate and for whom 'laws' are too remote. (SC UK 2002, 22)

There is an intention to build capacity within target communities and government partners, rather than reliance on the implementing organisation (i.e. the NGO). Nwe-Nwe Aye, Cross Border Project Coordinator of the Southeast and East Asia and the Pacific regional office of Save the Children UK explained the project's trafficking prevention through awareness raising as follows:

In terms of prevention, what we usually do is raise awareness and behaviour change, and capacity building for the partners. It's not an easy project... raising of awareness is not going to get us everything. It's not only the traffickers' tricks because some people think - although we see these people as traffickers, the communities don't see them as such. For them, they are the friends who look for jobs for their kids, who will see them across the 
border, take them to the strange land to find jobs, protect them from being arrested by the police. And they are the messengers who will bring back their children are safe and sound, they're working happily; or bring back letters, money, remittance; bring back contact numbers... we have to accept that that there are in fact good brokers, but at the same time we have to highlight that there are some traffickers - intermingled or mixing in the crowd - who really have real bad intentions of exploiting these people. These are not clear cut because some kids would say that the broker takes two months pay: it's acceptable; but if they are taking one year's payment without getting even their consent, then that is exploitation that they cannot accept. So we are trying to highlight that some of the people have the bad intention of sending these kids to the brothels or exploiting them in inhumane ways, which has to be highlighted because otherwise, these kids won't come back with bad stories, because that is loss of face. ${ }^{76}$ (Aye 2003)

Save the Children UK maintains consistent use of technologies throughout their projects: they are focused on child empowerment. The project was designed based on participatory action research (PAR).$^{77}$ Project interventions are designed based on recommendations from the target group (i.e. children). They are implemented using resources drawn from this population (i.e. volunteers and peer educators), and evaluated and refined by these same populations: "Through participatory action, we can empower children and young people to design, produce and disseminate their own education materials using their own channels, a more cost-effective and sustainable way of promoting knowledge among target populations" (SC UK 2002, 3-4). They are not insensitive to donor preferences or upstream demands; however, the organisation has maintained and prioritised sensitivity to downstream needs of intended beneficiaries and target communities. As part of networking and capital building, SC UK emphasises building access to services - beyond basic services. They help communities to improve their own access by helping to mobilise

\footnotetext{
${ }^{76}$ A desire not to lose face may prevent migrants from including the stories their difficulties when they return to their village. As such, those hearing the stories of returned migrants likely receive an unrealistically optimistic impression of the experiences of previous migrants.

${ }^{77}$ Participatory action research (PAR) is in the methodological family of participatory rural appraisal (PRA).
} 
existing or encourage new community groups and facilitating networks of service providers and professionals (ibid., 3, 34).

Both the UN and ILO either directly implement awareness raising campaigns, or fund NGOs to do so as part of their project. Like the NGOs, both engage in some degree of "tricks of traffickers" education, along with providing information to potentially assist individuals should they chose to migrate. Similar to the Save the Children UK project, the UN Inter-Agency Project (UN-IAP) finds evidence that fear of losing face prevents returning migrants from sharing bad parts of their experiences and that knowing risks is not likely to change migration patterns. The UN-IAP includes awareness raising campaigns in Vietnam, Cambodia and Myanmar:

... we're trying to move to a life skills/safe migration approach. So we say, look this is the reality of life: in Bangkok the streets aren't paved with gold etc., this is $\mathrm{HIV}$, these are the risks that you might come across. But if you must go, if you are going to go - here are some of the things that you need to know about. The one question that we can't answer is what do people do if they get in trouble. We can't answer that at the moment and this is, again, something that I want to be working on - strengthening the national hotlines... it's becoming pretty obvious - what you find is that as soon as people go into communities and start talking to people it becomes hard to maintain this "If only people knew, they wouldn't go...". (Marshall 2003)

The UN project does not necessarily implement such interventions itself. From the beginning set up as an "overarching coordination mechanism", the UN project was intended to enable and foster cooperation amongst stakeholders working on anti-trafficking issues, and engaging in interventions that fit its mandate either by funding others to do them, or as gap-filling or experimental interventions so as not to be in funding competition with other organisations. This was done in part in the interests of focusing on coordination, and in part in the recognition that competing with other organisations to implement and gain funding for project activities may be an obstacle to coordination. The Cambodian project 
coordinator explains that though the organisation is involved in this type of prevention project, it has an institutional preference for coordinating, not implementing:

The project is not supposed to directly implement the activities against trafficking, but it would rather do the coordination in the field of trafficking because we know that there are a lot of NGOs and government agencies in this country very, very good at the activity - some have a lot of projects in the field of protection, reintegration, prevention, community awareness raising something like that. So we know they have a lot of NGOs and projects - the really done the activity in this country. But we came here because we want to encourage them to do the coordination to strengthen the cooperation between each other. (Hang 2003)

Even so, Hang had clear ideas on awareness raising for trafficking prevention that extend beyond warnings of dangers, “... prevention should include the awareness raising, should include training the police and the communities; should include distribution of leaflets. For example if they go to Phnom Penh they have a problem, who can they contact? What NGO can they go to for services?" (ibid.).

Like the UN, the ILO project also funds other organisations to implement. Unlike the UN-IAP, direct interventions beyond "gap-filling" are part of the ILO's mandate. Some interventions involve skills training using government departments as experts, advisors or trainers or education. These activities have the side effect of building community social capital, increasing access to services and mobilize workers and employers' organisations (ILO 2003, 3) Other examples of harnessing social capital include using peer education on issues of reproductive health ${ }^{78}$ and child rights, as well as setting up a "community watchdog" system (in Chiang Rai, Thailand) (Phanawathamawong 2003). Awareness raising includes information about the "tricks of traffickers" (ILO SELL-11 2002), using trafficking awareness curriculum and teacher training for use in public schools as well as

\footnotetext{
${ }^{78}$ Peer education on reproductive health is an intervention funded in part by the ILO project and implemented in northern Thailand by the Planned Parenthood Association of Thailand's Northern Project.
} 
presentations of this through video, drama, discussion, and so on (Phanawathamawong 2003).

The ILO project funds and implements projects that use local resources: NGO partners have trained and deployed returned former trafficking victims to act as peer educators/publish their stories (ILO SELL-11 2002), building on ideas of social capital. Awareness programmes also promote gender equality, community caring and support, promote the Convention on the Rights of the Child (ILO, SELL-11); as well as encourage pre-departure training including receiving country language, culture and law; skills; return and reintegration:

If the people are poor - if a good opportunity or job, they have to migrate to get income... we have to have it good and well organised. It means legal migration, for example to Thailand, Malaysia or Korea. We have to organise well: organise for migration management, for example pre-departure: have to provide services for the migrant worker in pre-departure, including language or culture or receiving country law or skills related to their work when they go out... they have to prepare proper return for the migrant worker and also when they return how to reintegrate in the community. This also includes for the banking system when they are abroad: how to send the money to the family at home. Migration good if we are well organised. So it means that first we have to prepare - fast. If they need a job, we have to do very quick. If too late or long, they have they cannot: illegal migration. (Khleang 2003)

This is a pragmatic approach. It recognises that people are migrating via the paths available, sometimes in risky ways, often out of economic need. Though Khleang suggests communities should learn about safer and less risky ways of migrating, and though organised, legal migration is clearly preferred, irregular migration fills a need. In the case of Cambodia and Laos, the MOUs with Thailand seem to hold some limited promise for enabling faster and cheaper legal short-term labour migrants to go to Thailand and work in 
certain sectors. ${ }^{79}$ The ILO points out that some of their work with government officials has already had positive benefits in the area of faster, cheaper, easier legal migration:

Up to now we have just provided capacity building to the department Ministry of Labour, especially for the Department of Employment and Manpower to responsible on this we provide scholarships, study tours in Hong Kong and Manila how to develop a good system of the migration worker... now after the study tour, we can see the passport is reduced to only 20 US dollars - from very high cost to 20 dollars for migrant workers ... So the strategy for the future: how to link to the grassroots for the poor people. Maybe provincial Department of Labour can set up a registration centre or pass information... we will discuss more on this. And the Cambodian government just signed an MOU on employment with Thailand: this is also a good opportunity to implement and prepare migration management system. (Khleang 2003)

It seems that in different ways and with different messages, NGOs and IOs each conduct awareness raising and human capital building activities directly informing migration decisions (except for DEPDC). There is a plurality of approaches and methods, along with a general acknowledgement that for target populations and their peers, migration can be risky and reducing this risk is difficult. Two things are noteworthy here. First, there are indications that NGOs are closely aligned with their intended beneficiaries and engage in more innovative and responsive projects. Unfortunately, my analysis has not gone in to the type of systematic and detailed analysis that could firmly demonstrate or support these suppositions. Second, to the extent that organisations work to expand legal migration regimes, they are trying to expand the numbers of people with access to legal mechanisms of assistance and protection. This is not anti-migration, and it is a great step towards inclusion, but it may not challenge the exclusionary structures by which only "legal" immigrants have protection of their rights to not be exploited or abused by the citizenry protected.

\footnotetext{
${ }^{79}$ I have already mentioned the MOUs, which include an MOU between the Government of the Kingdom of Thailand and the Government of the Kingdom of Cambodia On Cooperation in the Employment of Workers and an MOU on Bilateral Cooperation for Eliminating Trafficking in Children and Women and Assisting Victims of Trafficking. Article 1 (4) of the former requires all parties to "apply all necessary measure to ensure... Prevention of, and effective action against, illegal border crossings, trafficking of illegal workers and illegal employment of workers."
} 


\section{Micro: Expansion of Local Opportunities: Education, income and employment}

Projects attempt to build economic opportunities as well as economic and human

capital. Table 14, below, provides an overview of projects' involvement in these

interventions.

\begin{tabular}{|c|c|c|}
\hline \multicolumn{3}{|c|}{ Table 14: Expanding Local Opportunities } \\
\hline Organisation & \begin{tabular}{|c} 
Economic opportunity/ \\
capital
\end{tabular} & Human capital \\
\hline $\begin{array}{l}\text { Development and } \\
\text { Education Project for } \\
\text { Daughters and } \\
\text { Communities (DEPDC) } \\
\text { Thailand-NGO }\end{array}$ & 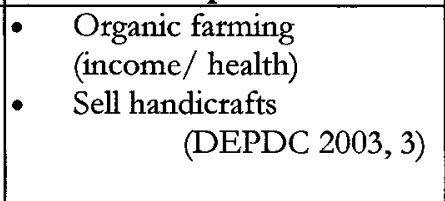 & $\begin{array}{l}\text { Education as tool to prevent girls from } \\
\text { entering sex work } \\
\text { Non-formal education } \\
\text { Vocational training } \\
\text { (DEPDC 1999, 16; DEPDC 2002, 2-3) }\end{array}$ \\
\hline $\begin{array}{l}\text { Mirror Art Group (MAG) } \\
\text { Thailand-NGO }\end{array}$ & \begin{tabular}{|l} 
Income generating \\
activities (IGAs) \\
Community credit and \\
microcredit schemes \\
Micro-finance \\
(ILO SELL and TLAs)
\end{tabular} & $\begin{array}{l}\text { Life skills camps (Thai language, rights, } \\
\text { "create consciousness about caring for } \\
\text { their community" and "solve problems } \\
\text { concerning labour exploitation." } \\
\text { Rural skills training } \\
\text { (ILO SELL and TIAs) }\end{array}$ \\
\hline $\begin{array}{l}\text { Cambodian Women's } \\
\text { Crisis Centre (CWCC) } \\
\text { Cambodia-NGO }\end{array}$ & $\begin{array}{l}\text { Economic alternatives to } \\
\text { trafficking project } \\
\text { (Nopsarin 2003) }\end{array}$ & $\begin{array}{l}\text { [Not part of trafficking prevention, but do implement } \\
\text { vocational and non-formal education for victims of } \\
V A W]\end{array}$ \\
\hline $\begin{array}{l}\text { Cambodian Migration and } \\
\text { Development Committee } \\
\text { (CMDC) } \\
\text { Cambodia-NGO }\end{array}$ & 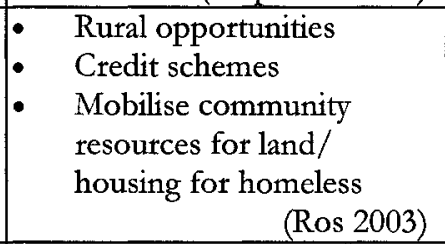 & $\begin{array}{l}\text { Shelters and non-formal education for } \\
\text { parents (especially displaced/ homeless } \\
\text { children and families) } \\
\text { - Formal education for children } \\
\text { - Job skills training for parents } \\
\text { (Ros 2003) }\end{array}$ \\
\hline $\begin{array}{l}\text { Save the Children UK (SC } \\
\text { UK) } \\
\text { Sub-regional - International NGO }\end{array}$ & $\begin{array}{l}\text { Facilitate development of } \\
\text { alternative livelihood } \\
\text { strategies } \\
\text { (SC UK 2002,19) }\end{array}$ & $\begin{array}{l}\text { Technical training for professionals } \\
\text { Develop/ update training material for } \\
\text { local partners } \\
\text { Facilitate children's participation in } \\
\text { national/regional forums } \\
\text { Mobilise peer educators } \\
\text { - Participatory curriculum } \\
\text { (SC UK 2002, 19-22) }\end{array}$ \\
\hline $\begin{array}{l}\text { UN Inter-Agency Project } \\
\text { (UN-IAP) } \\
\text { Sub-regional-IO }\end{array}$ & $\begin{array}{l}\text { Advocate poverty } \\
\text { alleviation } \\
\text { (Khleang 2003) }\end{array}$ & No data \\
\hline $\begin{array}{l}\text { ILO Project to Combat } \\
\text { Trafficking (ILO-TICW) } \\
\text { Sub-regional - IO }\end{array}$ & $\begin{array}{l}\text { Income generating } \\
\text { activities (IGAs) } \\
\text { Credit schemes } \\
\text { Micro-finance IGA and } \\
\text { revolving funds } \\
\text { Market analysis on } \\
\text { economic opportunities } \\
\text { (ILO SELL; ILO TLAs, ILO } \\
\text { 2003, 3; Phanawathamawong } \\
\text { 2003) }\end{array}$ & 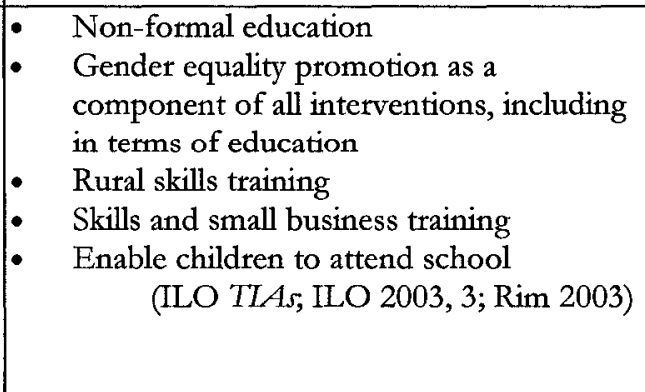 \\
\hline
\end{tabular}


Such interventions have long been the bread and butter of development projects.

Community development has long included components focused on education (e.g. flexible schooling, non-formal education, vocational training, teacher training, rural schools expansions, curriculum development) as well as employment and income generating components (e.g. revolving funds, income generating activities, credit and savings schemes, etc.). The novel component in these cases is ascribing the goal of "trafficking prevention" to them (i.e. bridging them to trafficking). My discussion examines how the organisations reframe these interventions in terms of trafficking outcomes. Again, my discussion is limited. Research and analysis of projects, including attention to target groups' involvement in and evaluations of interventions, would provide a broader perspective for evaluation.

In some cases, the connection between traditional community development work and anti-trafficking outcomes is quite directly made. The Development and Education Project for Daughters and Communities (DEPDC) explains, “... the longer a girl stays in school, the greater the probability that she will stay out of sex work... School attendance limits the hours of work and defines the character and the conditions of employment that children can undertake" $(2003,2)$. For others, reductions in poverty levels and increases in levels of education and opportunities are expected to decrease either the numbers of people leaving sending areas, or change the ways in which they leave, resulting in fewer trafficking outcomes.

Framing development interventions as trafficking prevention (i.e. diagnosing aspects of trafficking as development problems and prescribing development interventions as a remedy) includes reframing certain aspects and components as root causes of trafficking (i.e. poverty, illiteracy, low opportunity), and of income generation, economic opportunity building and education as remedies or solutions to these causes, resulting in trafficking 
prevention. For NGOs and IOs, this alignment effectively procures funding, transforming the goal of these activities from the less motivational community development qua community development to community development qua trafficking prevention with all of its links to strong master frames, including human rights (women's rights, child rights, etc.). These are new diagnostic (i.e. poverty as a root cause of trafficking), prognostic (i.e. income generating activities for trafficking prevention) and motivational frames.

Given the limited success of community development efforts to date and perceptions that they are not highly successful (rural poverty and lack of opportunity have long been the problems that NGOs focus on), recasting these efforts in terms of a new goal that fits with a new and highly motivational framework (i.e. trafficking) is a successful tactic of resource mobilisation or even maintaining old support. By engaging in this reframing of community development, IOs and NGOs alike are able to harness more resources or maintain access to support for community development, and change their understanding of what they do. Unlike community awareness and human capital building interventions, previously discussed, where content as well as aim have been adjusted to address trafficking issues, these interventions do not necessarily change. The upstream impact of this reframing is the effective mobilisation and capture of donor funds to implement, or continue to implement, community development projects, working with essentially the same target groups and with many of the same technologies and interventions. This boils down to a reframing of goals and a continuity of activities.

Though I cannot draw conclusions on the impact of this reframing in target communities and intended beneficiaries downstream, I do wish to raise some initial concerns. From one perspective, if individuals and communities were not poor, disadvantaged, or lacking opportunities in their home areas, they would have fewer reasons 
to migrate (i.e. fewer "push" factors or characteristics encouraging migration) and should they choose to migrate, they would have more resources and lower levels of vulnerability in doing so. These better-off migrants may also face fewer political, social and structural barriers to safer migration, as the welcome and assistance extended to migrants seems to increase along with their wealth and status. Such interventions have at least the potential to reduce the incidence of trafficking from the areas they work in (I have done no research focused on this so I cannot demonstrate this), but given the constructivist nature of framing, they also have the potential to shift the understanding of the mechanism of causality of trafficking to those populations that are the victims of these crimes, rather than the perpetrators. Reiterating Kapur's suggestion from chapter five, if one sees trafficking as irregular migration or as sex work, given the structural limitations imposed by the gendered political economy, then this in and of itself demonstrates gender bias (in Population Council 2001, 22).

The Development and Education Project for Daughters and Communities (DEPDC) does engage in these types of community development interventions, but they consider them to be trafficking prevention because they intend to create a direct barrier to children's migration: before children migrate, they and their families are encouraged and coerced into abiding by Thai laws thereby ensuring their children are educated. Where families cannot or will not support children to do this, these children are moved to the campus of DEPDC. While DEPDC does address some so-called root causes, their trafficking prevention outcomes result from this direct obstacle to child migration. Jakantra suggests that root causes may make people vulnerable, but do not cause trafficking:

I think the demand of the market ... if some people have a need - if they need to have service from women or children, they come to this area of the world and they buy it. And there are lots of people who've learned that children with no education, children with no nationality, children with ethnic 
minorities, children who've lost parents or something, they are vulnerable. So this is the information that comes from agent tours to promote the countries or traffickers. So I would like to say this is the structure of the organised crimes - it's very strong, it's very organised - rich producing information, rich receiving ... and second thing is money talks in this region in this area - everything is like corruption is a big problem.... And also the corruption that the government, that the authorities the people - village leaders - they know that this is something illegal but they do nothing to stop this type of business process or cycle. Because many people benefit from involved direct or indirect they receive lots of interest from that. (2003)

By this understanding, poverty, lack of citizenship status, low education and other factors make people vulnerable because potential exploiters know that governments and other authorities are unlikely to intervene to assist these disenfranchised groups. This potential vulnerability is not intrinsic, it is the failure and refusal of state mechanisms to extend the same responses to crimes committed against these populations as are extended to wealthy, educated, majority groups within society. State mechanism may even profit from the exploitation of these groups, through corruption, bribes and even tourist dollars!

The UN Inter-Agency Project is directly critical of the idea that root causes are indeed the causes of trafficking:

I have a problem with the way the term prevention is used. If you ask people who are doing prevention what it is they're trying to prevent without allowing them to use the word trafficking, people often go around in circles. What core prevention programmes are actually trying to prevent is people migrating, or at least give people other opportunities and I think that's problematic. Because there's no - it's a strong link been established between levels of poverty, levels of education and levels of migration because it's been shown that most people aren't quite as ignorant of the risks of migration as we think, but it is a bit of a lottery and some people come back with money and some people don't. But also that traffickers - where there are classical traffickers, they will just tend to move. So by actually reducing trafficking in one village it doesn't necessarily mean that you're preventing it... Not all of our agencies share this view. If you talk to ILO-IPEC, I regard what they do as vulnerability reduction and they call it prevention... A brothel in Chiang Mai which we know people are being trafficked into: that gets confiscated, that would have a much bigger impact than growing a few pineapples in a small village in Laos. (Marshall 2003) 
Even where activities have the result of trafficking reduction in one village, undoubtedly a desirable end in and of itself, this does not imply a reduction in trafficking: the incidence may simply increase in other areas. ${ }^{80}$ While vulnerability reduction remains a desired and valuable goal, it is not necessarily the case that vulnerabilities cause trafficking, nor that reducing the vulnerabilities of one (or many) specific groups of people will reduce the overall incidence of trafficking, given that there are other communities, and the demand for people to be trafficked remains unaltered. I do not suggest that there is not intrinsic value in assisting any given individual or community even where such interventions do not influence macro-conditions. However, for those intending to reduce trafficking and the harms associated with it, local successes do not imply any overall change in scale or incidence. Marshall also brings up the question of victim-blaming:

And I think it also plays into this blame - association of the blame on trafficking to the sending country - for abuses which are happening in places of destination. So you know, if someone gets shot in a fishing boat in Thailand or if somebody gets locked in a brothel in Australia - that's really the country that has the problem. But I think the way that trafficking is conceptualised allows people to turn that on its head a bit, by saying you prevent trafficking by running small projects in a village in Laos. In terms of protection I think again it comes back to the fact that it's very difficult to separate protection of trafficking victims from the protection of migrants, and we need to be doing more to allow migrants to access their rights. (2003)

Table 15, below, reviews this information relative to Korten and Quizon's concerns.

\footnotetext{
${ }^{80}$ Interestingly, this quotation marks the first time my analysis has found components consistent with framing trafficking in terms of organised crime on the part of the UN project.
} 


\begin{tabular}{|l|l|l|}
\hline \multicolumn{1}{|c|}{ Table 15: Interventions: Framing vs. Co-option } & \multicolumn{1}{|c|}{ Comment } \\
\hline \multicolumn{1}{|c|}{ Problem } & \multicolumn{1}{|c|}{ Conclusion } \\
\hline $\begin{array}{l}\text { Opportunistic } \\
\text { NGOs / }\end{array}$ & $\begin{array}{l}\text { - Aside from trafficking-specific awareness raising content, } \\
\text { interventions resemble typical community development with the } \\
\text { end of trafficking prevention ascribed to them } \\
\text { - Organisations seem to maintain consistent technologies across } \\
\text { projects }\end{array}$ & Supports framing \\
\hline $\begin{array}{l}\text { Agenda change } \\
\text { to match donor } \\
\text { priorities }\end{array}$ & $\begin{array}{l}\text { - No evidence of non-donor funded projects (may be lack of } \\
\text { rigour) } \\
\text { - Continuity of these project technologies even where funding } \\
\text { cycles are renewed, donors changed or stated outcome (i.e. } \\
\text { trafficking prevention) altered } \\
\text { - Some evidence of homogeneity of activities across different } \\
\text { organisations, may be explained in terms of organisations } \\
\text { drawing from limited common technologies and working in } \\
\text { similar contexts (analysis not sensitive to nuances) }\end{array}$ & $\begin{array}{l}\text { Ambiguous: } \\
\text { homogeneity of } \\
\text { activity type } \\
\text { extends beyond } \\
\text { anti-trafficking81 }\end{array}$ \\
\hline $\begin{array}{l}\text { Some evidence that organisations of different types engage in } \\
\text { different interventions, no systematic investigation }\end{array}$ & \\
\hline $\begin{array}{l}\text { Projects match } \\
\text { donors time- } \\
\text { cycles and } \\
\text { funding periods }\end{array}$ & $\begin{array}{l}\text { Projects do match donor time-cycles and funding periods. } \\
\text { However, efforts to mobilise resources are on-going and are } \\
\text { directed towards the same target populations and communities } \\
\text { and tend to continue rather than change the majority of } \\
\text { interventions (even where new ends, such as trafficking } \\
\text { prevention, are ascribed to them) }\end{array}$ & \\
\hline
\end{tabular}

\footnotetext{
${ }^{81}$ As cited in chapter three, Ness and Brechin maintain that organisations all draw on "a common stock of technology" $(1988,271)$. As such, homogeneity is to be expected.
} 


\section{CHAPTER 10: Conclusions}

In my examination of NGOs' and IOs' sending area trafficking prevention work, I asked how projects did or did not fit with an anti-migration framework or NGO co-option through donor funding. Based on my analysis, I find co-optation and associated assumptions of agenda change and a lack of independence less compelling than an understanding drawn from framing for understanding the influence of donor funding on NGO and IO projects. My evidence suggests that NGOs take up trafficking in ways that are consistent with their organisational frames and other work, and that there has been a rhetorical shift. This suggests that in designing and presenting projects, organisations are framing their work in terms of what donors want to hear. In addition, there is evidence that despite potential reliance on donor dollars, organisations maintain both the independence and the will to be critical of certain aspects of donor and/or national policy.

NGOs are not insensitive to donor requirements: this was an aspect I never doubted. Beyond the knowledge that all of the NGOs in my study have actively applied for donor funding, there are two pieces of evidence for this: NGOs use donor reporting language and markers for success (i.e. English and quantitative, potentially time-bound indicators); and they discursively frame their projects in terms that donors are inclined to support. Both indicate the type of upstream accountability that is assumed to detract from both self- and downstream accountability. And yet, my analysis indicated substantial fidelity of organisations to certain target groups and organisational ideals.

The NGOs I studied are implementing projects and working with groups that are consistent with their other work. Furthermore, from my initial analysis, what they are actually doing in terms of trafficking prevention interventions is largely community development, renamed and reframed as trafficking prevention (though there are trafficking- 
specific interventions). This demonstrates use of framing tactics, supporting the instrumentalist ideas of framing as a means for gaining support. NGOs do not so much change to match donor requirements. Rather they change what they say to match donor requirements. As a caveat, though many interventions seem not to be trafficking-specific (except in goal), tending to continue general community development efforts, I do not assume that rhetorical changes ("what they say") are value-neutral or free from implications beyond resource mobilisation.

Following are some of the key conclusions that I have drawn from my analysis.

\section{NGOs reflected donor standards in project documents and design. "Upstream"} accountability is a reasonable expectation and concern

All organisations worked and reported in English when dealing with donors and the public.

Project cycles matched donor funding cycles, and ideas of "quantitative indicators" and formats including "logistical frameworks" are used by NGOs. My analysis was insensitive to the innovation of projects. This is an area where more detailed research and analysis could provide useful insights into NGOs' so-called comparative advantage in innovative work and project design. While I gave a few examples of such innovation, I am unable to make any conclusions about whether this innovation is compromised by funding.

\section{The focus of organisations (both NGO and IO) in terms of definition of the problem and selection of target groups was consistent with previous work. This supports "framing" as an explanation.}

There was an overall tendency of organisations as a whole, as well as in their anti-trafficking projects to focus on women and children. Some organisations broke from this pattern. 'The Development and Education Project for Daughters and Communities sought funding from new sources part-way through their project to expand their target group to include boys. The Mirror Art Group, with funding from the ILO project, uncharacteristically restricted 
their trafficking project's focus (at least in name) to women and children, while the UN

Inter-Agency Project changed its name during the second phase of its project from

"Trafficking in Women and Children" to "Human Trafficking" so as to be more inclusive.

\section{Interventions were consistent with organisations' previous work. This supports "framing" as an explanation.}

Though advocacy and awareness campaigns took on trafficking-specific components, they supplemented other campaigns. Organisations discursively connected standard development interventions with the goal and outcome of trafficking reduction.

\section{NGOs and IOs were critical of national and international positions, including those associated with donors. This counter-indicates co-optation.}

Organisations took positions that were openly critical of national and international policies, including those associated with donors. This suggests that funding relations do not preclude criticisms of donor agendas. It may also be evidence of the variety of positions which exist within donor agencies. It is possible that individuals and groups within donor agencies are able to support alternative or dissenting positions by funding outside organisations to lobby for or pursue them. Though mentioned in chapter four, my analysis has not focused on this.

\section{Organisations targeted criticisms on national or international regimes based on their scale.}

The projects of the international NGO (Save the Children UK) and the two IOs (UN and ILO) included campaigning and advocacy directed towards the international community, particularly donors, as well as issues of national concern. National NGOs focused more extensively on the national regimes in which they work. This suggests scale, not funding interests, as explaining what seemed to be a lower degree and focus of criticism of the international regime from national NGOs. 


\section{Projects of IOs sometimes behave as donors, funding NGOs to implement components of IO anti-trafficking projects.}

This is a type of development sub-contracting that, from the literature, is also seen from some international NGOs. The dynamics of this were not a key component of my analysis. This may reflect the efforts of IOs to capitalise on NGOs' popularity and supposed innovative approaches and proximity to communities.

\section{IO projects were not merely extensions of donor agendas. This was unexpected.}

As with NGOs, the ILO trafficking project was closely aligned with previous and on-going work (i.e. the ILO Child Labour project) in terms of how trafficking problems were defined and who their target groups are. The UN project, a "new" entity in the UN system, engaged to a lesser degree in this type of alignment and framing, but was the most critical of trafficking definitions, approaches and donor policy, despite accepting and being at least inpart driven by the protocol and its definition. Both the UN and the ILO were strong and vocal advocates for extended migration regimes and protection of migrant rights as keys to reducing trafficking and the harms associated with it.

The remainder of this conclusion focuses on three things: first, responses and possibilities for changing trafficking outcomes; second, potential connotations beyond resource mobilisation of framing; and finally, implications of the finding that contrary to expectations, IO projects were not merely an extension of donor agendas. I also suggest some areas for future research.

\section{Changing Trafficking Outcomes}

On issues specific to trafficking, though the debate has seemed to focus on organised crime vs. human rights as frames, I pick up on three possible policy responses that may effectively change incentives and change trafficking outcomes. 
First, despite my criticisms of root causes, addressing conditions that make people and populations vulnerable, as exemplified by all organisations in my study, is essential. Better livelihoods, more information, and increased opportunities are necessary and desirable development goals in and of themselves for any given population at any given time. They may also reduce trafficking outcomes for these populations. However, a key component of this is recognising that these populations are vulnerable at least in part because of the lack of political and social will to extend to them the same types of responsive, protective and other mechanisms from which other populations benefit.

Seeing trafficking in the sub-region as a subset of migration and acknowledging vulnerabilities to be increased by a lack of migration status suggests placing more focus on receiving countries and areas where the abuses of trafficking are taking place. This would include expanding legal migration regimes to substitute for trafficking (as advocated by the UN and ILO-funded exploratory policy paper) and responding to crimes independently of the characteristics or identity of the victims (i.e. treating the perpetrators of kidnapping, forced labour, rape, etc. the same regardless of the migration status of the victim). The latter would be a first step in setting up the types of disincentives for abusing marginalised populations that are already in place for others and may be more readily realised than an opening of migration. As Wong Sak Hoi suggests, “... smuggling and trafficking in human beings can be more effectively curbed in the long-term when the prospects for regular entry are improved and migrants can rely on state authorities, rather than smugglers or traffickers, to help them realize their goals" $(2004,79)$. However, this may be difficult to realise given the as yet unchanged political opportunity restraint in the form of wealthier nations continuing to favour restrictive migration regimes. 


\section{Root Causes and Framing}

In the context of my research, I found that many NGOs and one of the two IOs were framing community development as trafficking prevention, identifying underdevelopment or poverty as a root cause of trafficking. In a regime where migrant rights are already unpopular with donors, what are the implications of claiming that poverty the cause of the exploitation and abuse of migrants that is labelled trafficking? Though there was no evidence of this from the organisations in my study, such a supply-side focus may encourage regulation of victims as a means to reduce the harms committed against them (i.e. preventing trafficking of women by stepping up barriers to women's migration) as well as victim-blaming if they should engage in "risky" behaviours (e.g. leaving the village, migrating). This is congruent with what I consider a dominant approach of understanding and addressing trafficking from the position of donor policy: migration control and focus on the victim's status, consent or age (rather than exclusively on the abuses, exploitation or conditions they are subject to) in order to define the crime, playing into protective rather than empowering impulses.

These critical questions may be applied to root causes arguments in general. They are successful framing in terms of resource mobilisation, able to get the resources and support projects that genuinely benefit and are in the interests of the target groups (i.e. improved livelihoods), and they may indeed be the only way to continue to motivate resources for this type of work. However, the very term "framing" implies presenting interventions in ways that fit with what donors are already willing to support, rather than challenging and demanding change. This is even more problematic where engaging discursively changes the understanding the organisation has of itself, as is expected given the "thinking, reasoning" nature of framing. While the idea of root causes is a key component 
to framing community development as trafficking prevention and harnessing donor funds, even where projects do not change, this framing reinforces ideas that donors are already inclined to accept, supporting rather than challenging donor positions. Looking at the work of the organisations I studied, this is at least in part mitigated by their critical engagement with donor or national discourse about certain aspects of trafficking.

Consciously problematising framing approaches in terms of their negative as well as positive (i.e. resource mobilisation) outcomes may be essential to reduce this aspect of potential co-option. Perhaps framing coupled with vocal advocacy challenging dominant positions, as was seen to some degree with all of the organisations in my study, is the best way to address short-term and longer-term goals.

\section{IOs beyond donor agendas}

The rather surprising finding that suggests IOs are potentially more critical despite their status as essentially donor organisations may be a result of scale. Further research may help identify whether this is an accident or a trend. Alternately, it may be a result of being in a position of stability in terms of funding and profile that enables them to be critical. If IOs enjoy more varied and stable sources of funding compared with a greater instability of funding for NGOs, this may ensure them a position of greater stability from which to critically engage. Furthermore, while I have consistently presented donor voices as a united front, a more realistic analysis would see donor policy as the outcome of an internal struggle that includes dissenting voices (see Allison 1969, 693-696; Welch 1992, 114-122). Though particular positions dominate and become donor policy, IOs may represent a space for continued expression for dissenting voices from within governments.

Having said this, when acting as donors to NGOs, IOs present the same obstacles and requirements of other donors, in terms of demanding upstream-accountability in project 
planning and reporting and short-term commitment to long term goals and interventions and methods that fit their agendas. Furthermore, though they may be more critical and in a stable position to remain more critical, IOs do not demonstrate the proximity to or alignment with communities and individuals at the "grass-roots level". As such, future research may find that IOs are useful tools for political change and plurality and functional venues for the proliferation of dissenting views (both internal and external), but lack comparative advantage in terms of working with local communities to shape or implement development projects.

\section{Suggestions for Future Research}

A broader study drawing out community impacts (i.e. downstream impacts) of discursive alignment with frames based on donor ideals (i.e. discursive construction for upstream audiences) would provide more information and different perspectives on donorrecipient-beneficiary relationships. This would enable theorists to begin to talk about more than merely changes to NGO structures, politics and ways of working and to prioritise the most important group in development projects: intended beneficiaries. A component of this may include a study of projects implemented by NGOs compared to IOs and private sector development organisations setting criteria for and looking for varying degrees of innovativeness and responsiveness which are expected to characteristics of NGOs.

Considering this, where opportunities and assistance for poor would-be migrants remain limited, it is difficult to separate trafficking from the spectrum of abuses faced by migrant workers. Redirections of migration policies and practices could change this:

We feel that governments should realize that by their restrictive migration policies, they're actually in a way stimulating trafficking. And by acknowledging that there are huge flows of migrants in an economic context where there is huge disparity, for instance affluent areas in Thailand and not so well off areas in Laos and in Cambodia... This acknowledgement would 
be a good starting area for thinking outside of the box and for seeing legal labour migration as an alternative to trafficking. (van de Glind, 2003)

While willing migrants remain vulnerable to exploitation, abuse and to being trafficked en route as a result of their reliance on smugglers and exclusion from the protections of the law, trafficking cannot be meaningfully separated from migration. As pressures and political will to assist rather than discriminate against poor migrants grow, both in the Greater Mekong Sub-region and internationally, perhaps opportunities for men, women and children will increase and the abuses they suffer will decrease. 


\section{APPENDIX 1: List of interviews}

\section{Primary}

Aye, Nwe-Nwe, Save the Children United Kingdom (SC UK), 2003. Interview by author, 17 July 2003, Bangkok, Thailand. Mini disc recording and transcript, personal archive.

Hang Vannak, United Nations Inter-Agency Project to Combat Human Trafficking (UN-LAP), Cambodia, 2003. Interview by author, 23 July 2003, Phnom Penh, Cambodia. Mini disc recording and transcript, personal archive.

Jakantra, Sompop, Development and Education Project for Daughters and Communities (DEPDC), 2003. Interview by author, 8 July 2003, Mae Sai, Thailand. Mini disc recording and transcript, personal archive.

Khleang Rim, ILO-TICW Cambodia, 2003. Interview by author, 22 July 2003, Phnom Penh, Cambodia. Mini disc recording and transcript, personal archive.

Marshall, Phil, UN-LAP, Sub-regional, 2003. Interview by author, 19 June 2003, Bangkok, Thailand. Mini disc recording and transcript, personal archive.

Nopsarin Sreyroth, Cambodian Women's Crisis Centre (CWCC), 2003. Interview by author, 30 July 2003, Phnom Penh, Cambodia. Mini disc recording and transcript, personal archive.

Phanawathanawong, Prungchit, ILO-IPEC Thailand, 2003. Interview by author, 23 June 2003, Bangkok, Thailand. Transcript, personal archive.

Ros Sokham, Cambodian Migration and Development Committee (CMDC), 2003. Interview by author, 31 July 2003, Phnom Penh, Cambodia. Mini disc recording and transcript, personal archive.

Sudhamongkala, Parisuda (Moo), Mirror Art Group (MAG), 2003. Interview by author, 9 July 2003, Mae Yao, Thailand. Mini disc recording and transcript, personal archive.

van de Glind, Hans, International Labour Organisation Mekong Subregional Project to Combat Trafficking in Children and Women (ILO-TICW), 2003. Interview by author, 17 June 2003, Bangkok, Thailand. Mini disc recording and Transcript, personal archive.

\section{Secondary}

Angsuthanasombat, Kannika (Jeng), Asian Research Centre for Migration (ARCM), Institute of Asian Studies, Chulongkorn University, 2003. Interview by author, 24 June 2003, Bangkok, Thailand. Mini disc recording and transcript, personal archive.

Ashby, Janet, Asia Regional Cooperation to Prevent People Trafficking (ARCPPT), 2003. Interview by author, 25 July 2003, Phnom Penh, Cambodia. Mini disc recording and transcript, personal archive. 
Bamford, Alec, CUSO Thailand, 2003. Interview by author, 6 June 2003, Bangkok, Thailand. Mini disc recording and transcript, personal archive.

Banerjee, Nipa, Canadian International Development Agency (CIDA), 2003. Interview by author, 17 July 2003, Bangkok, Thailand. Mini disc recording and transcript, personal archive.

Beloe, Tom, Department for International Development United Kingdom (DFID) 2003. Interview by author, 17 July 2003, Bangkok, Thailand. Mini disc recording and transcript, personal archive.

Hironraks, Thongkorn, CIDA/Canadian Embassy, 2003. Interview by author, 17 July 2003, Bangkok, Thailand. Mini disc recording and transcript, personal archive.

Intharat, Varaporn and Kelly O'Brien, Empower Chiang Mai, 2003. Interview by author, 3 July 2003, Chiang Mai, Thailand. Transcript, personal archive.

Panwaviseth, Bundit. Friends of Women Foundation (FOW), 2003. Interview by author, 20 June, 2003, Bangkok, Thailand.

Pillorge, Naly. Ligue de defense cambodgienne aux droits des homme (LICADHO), 2003. Interview by author, 29 July 2003. Phnom Penh, Cambodia. Mini disc recording and transcript, personal archive.

Sary Moni, International Organisation for Migration (IOM), 2003. Interview by author, 28 July 2003, Phnom Penh, Cambodia. Mini disc recording and transcript, personal archive.

Skrobanek, Siriporn, Foundation for Women (FFW), 2003. Interview by author, 24 June, 2003, Bangkok, Thailand. Mini disc recording and transcript, personal archive.

Srimongkol, Tassanee, Planned Parenthood Association of Thailand (PPAT) Northern Project, 2003. Interview by author, 2 July 2003, Chiang Mai, Thailand. Transcript, personal archive. 


\section{APPENDIX 2: Coercion in trafficking}

\begin{tabular}{|c|c|c|c|}
\hline \multicolumn{4}{|c|}{ Examples Coercion and Trafficking } \\
\hline Place & Evidence & Perpetrated Coercion & Coercive Structures \\
\hline \multirow[t]{2}{*}{$\begin{array}{l}\text { Pre- } \\
\text { migration } \\
\text { (sending atea) }\end{array}$} & Evident & $\begin{array}{l}\text { Kidnapping } \\
\text { Abduction } \\
\text { Debt-bondage agreement } \\
\text { "Purchase" of one person from another } \\
\text { (i.e. children from parents) }\end{array}$ & $\begin{array}{l}\text { Poverty/inequality } \\
\text { Discrimination } \\
\text { Social/political repression } \\
\text { Repressive family situation } \\
\text { Abusive family situation } \\
\text { Sense of familial obligation } \\
\end{array}$ \\
\hline & Hidden & False promises/ deceit & \\
\hline \multirow[t]{2}{*}{$\begin{array}{l}\text { During } \\
\text { migration }\end{array}$} & Evident & $\begin{array}{l}\text { Abuse } \\
\text { Diversion of destination } \\
\text { "Sale" from transporter to exploiter }\end{array}$ & $\begin{array}{l}\text { Geo-political barriers } \\
\text { Restrictive/ discriminatory } \\
\text { migration policies/ practices }\end{array}$ \\
\hline & Hidden & $\begin{array}{l}\text { False promises/deceit } \\
\text { Diversion of destination }\end{array}$ & \\
\hline \multirow[t]{2}{*}{$\begin{array}{l}\text { Post- } \\
\text { migration } \\
\text { (receiving area) }\end{array}$} & Evident & $\begin{array}{l}\text { Abuse } \\
\text { Confinement } \\
\text { Forced labour } \\
\text { Unpaid labour } \\
\text { Payment of debt-bondage Labour in } \\
\text { sectors/ conditions not agreed } \\
\text { "Sale" from transporter to exploiter } \\
\text { Realisation of "falseness" of promises } \\
\text { Inability to leave/ request improvements } \\
\text { in conditions }\end{array}$ & $\begin{array}{l}\text { Gender/ race discrimination } \\
\text { Biases against migrants } \\
\text { Cultural/ language barriers } \\
\text { Lack of access to redress through } \\
\text { existing authorities and } \\
\text { mechanisms }\end{array}$ \\
\hline & Hidden & Non-payment of wages & \\
\hline
\end{tabular}




\section{APPENDIX 3: Application to Research Ethics Board}

Lay Summary: Trafficking and Migration: International Policy and Programmes

I ask how anti-trafficking projects understand human trafficking and design projects and programs to prevent trafficking. In particular, I look at how anti-trafficking efforts overlap with or affect migration and try to develop a means to classify the ways anti-trafficking incentives have impacts on migration. I focus on prevention activities in source or sending countries where it is difficult to distinguish between different types of movements. As far as possible, I will use data collected or generated by these programmes to provide both a profile of trafficking in the Mekong Sub-region and of projects with different treatments of migration. International organizations and non-governmental organizations are the focus of the study because they are major actors and have political and economic influence in the region. Thailand and Cambodia have been selected as the countries in which to conduct this research because they are regional centres of activity and are politically open relative to the other countries in the region.

Travel Dates and Locations

June 2003 - Bangkok and Chiang Rai, Thailand (duration: approximately one month) July 2003 - Phnom Penh, Cambodia (duration: approximately two weeks)

\section{Methodology and Procedures: Field Work}

a. Conduct search of databases for programmes and projects

b. Follow-up on initial contact with organizations to determine suitability for participation

c. Obtain consent and interview five project staff from each of three projects or programmes

- Interviews are expected to take one hour per staff member, one up to two hours where project documents are not available

- Interviews may be conducted in "instalments" to accommodate schedules

- Interviews will be recorded except where subjects are not amenable

d. Gather and review project documents (desktop study)

e. Consent will also be requested from participants to contact via e-mail for clarification

f. Participants will be given the option to receive and respond to the final research paper

\section{Description of Participants}

Participants are staff and managers of development projects working on anti-trafficking projects. All will be public officials working in recognized positions on legitimate and recognized initiatives in the region. The majority will be "foreigners" (i.e. staff associated with the organizations, primarily from developed and donor countries). No vulnerable populations (i.e. trafficking victims or potential victims) are included as subjects for investigations. As all of these organizations abide by strict ethical codes of confidentiality and client protection, all information gathered from these sources about vulnerable populations will be devoid of identifying or compromising details and managed respecting confidentiality.

\section{Recruitment Process}

Projects or programmes will be selected based on suitability for the project, aiming for three projects with established trafficking prevention activities with different institutional approaches, and on the interest or ability for projects to participate. Project and programme staffing is public knowledge, and so interview participants will be selected from these lists. Five will be selected from each project or programme, aiming for one country director, one project manager, and three staff. Participants will not be offered any compensation.

\section{Risks}

Though trafficking is a sensitive subject, risk is mitigated by the fact that the countries chosen as the locus for research (Thailand and Cambodia) were welcoming for research activities and visas were quickly and easily obtained. This demonstrates open political knowledge, and acceptance, of the research. As participants ate public officials being interviewed about public information, risk is minimal.

\section{Benefits}

There are no known direct benefits to individual participants in this research.

Research results will be made available to participating organizations for their information, which perhaps they will find informative or useful for practitioners or those involved in policy debates on trafficking. 
Informed Consent

All participants will be given and read the letter of informed consent (see Appendix 1: Letter of Information) and given the option of agreeing to participate or declining to participate in the research. Those who agree to participate will be asked to read and sign an informed consent

Anonymity of Participants

Participants will not be offered anonymity or confidentiality due to the public nature of their work and positions. However, should any participants wish to be interviewed but maintain anonymity of name, organizational affiliation or both, these requests will be discussed, noted on the informed consent form, and respected.

\section{Confidentiality of data}

Interview tapes and transcripts will be stored securely at all times during and following the research process. As a researcher, I take responsibility for the secure and ethical management of the data I gather. While overseas, files will be stored in locked safes at guesthouses when I am travelling and in locked filing cabinets in CUSO country offices when I am working there. Upon return to Canada, interview files and materials will be stored in a locked filing cabinet that I maintain. Files will be kept following the defense of my thesis in January 2004 for future reference for publication. Interview participants will be made aware of the plans for maintaining and securing data.

\section{Research Instrument: Questionnaire for semi-structured interviewing} Part I: Information about the participant

What is your name/nationality/educational and professional background? / What is your position within the organization and what are your current job responsibilities? / What is your history with the organization and with other similar organizations?

\section{Part II: Anti-trafficking policy and activities of the organization}

What is the policy driving the organization in general and programming for anti-trafficking activities, and the design of anti-trafficking interventions? (Documents available?) / What is the scope and nature of the organization's understanding of trafficking and anti-trafficking initiatives? / What is the organization's policy approach to migration? / What are the programmes, projects and interventions that have been designed to impact trafficking? (Documents?) Particular attention to prevention activities in sender countries/areas. / Where are interventions or projects located, what are their histories and time lines? Particular attention to prevention activities in sender countries/areas. / How do these interventions work to reduce trafficking? How can you tell if they're working (both that it is possible to influence trafficking in this way, and that these particular interventions are having the desired results)?

\section{Part III: Impacts or perceived impacts of project activities}

What are the results of internal and external progress evaluations, impact studies and evaluations of activities? Is there a baseline or non-project area against which this is measured? (Documents available?) / What is/are the anti-trafficking project(s) source(s) of funding? Do these donors influence project design? / How have project activities been received by target populations and other representatives in target communities? / How have host governments responded to the project? / What is your personal or institutional interpretation of the reliability or accuracy of interpretation of impacts that we have discussed?

\section{Dissemination}

The research will form the basis for my thesis, a public document. Research findings, following the guidelines set out by the Bill McWhinney Memorial Scholarship, will be publicly presented upon return in public presentations (venue to be determined) and a condensed version of the thesis to be submitted for journal publication. 


\section{REFERENCES}

Agesa, Jacquiline and Richard U. Agesa. 1999. Gender differences in the incidence of rural to urban migration: Evidence from Kenya. Joumal of Development Studies 35(6), 36-58. London: Frank Cass.

Allison, Graham T. 1969. Conceptual models and the Cuban Missile Crisis. The American Political Science Review 63(3) (September), 689-718.

Archavanitkul, Kritaya. 1998. Combating the Trafficking in Children and their Exploitation in Prostitution and Other Intolerable Forms of Child Labor in Mekong Basin Countries. Bangkok: Institute for Population and Social Research Mahidol University and ILO-IPEC.

Arnold, Christine and Andrea M. Bertone. 2002. Addressing the sex trade in Thailand: Some lessons learned from NGOs. Part 1. Gender Issues 1(2) (March), 26-52.

Asia Regional Cooperation to Prevent People Trafficking (ARCPPT). 2003. Gender, buman trafficking, and the criminal justice system in Cambodia.

Asian Development Bank (ADB). 1995. The Asian Development Bank and non-governmental organizations: Working together. ADB.

http://www.adb.org/Documents/Brochures/ADB_and_NGOs/default.asp (accessed 22 October 2004).

Atmar, Haneef and Jonathan Goodhand. 2001. Coherence or cooptation?: Politics, aid and peacebuilding in Afghanistan. The Journal of Humanitarian Assistance (30 July). http://www.jha.ac/articles/a069.htm (accessed 28 October 2004).

Baldaccini, Anneliese. 2003. United Kingdom (country-report). EU and US approaches to the management of immigration, eds. Jan Niessen, Yongmi Schibel and Raphaele Magoni. Brussels: Migration Policy Group. http://www.migpolgroup.com/uploadstore/uk.pdf (accessed 14 October 2004).

Banerjee, Upala Devi. n.d. Globalization, crisis in livelihoods, migration and trafficking of women and girls: The crisis in India, Nepal and Bangladesh. India. http://www.hrw.org/reports/200/japan/12-recommendations.htm (accessed 30 March 2003).

Beare, Margaret E. 1999. Illegal migration: Personal tragedies, social problems, or national security threats? In Illegal Immigration and Commercial Sex: The New Slave Trade, ed. Phil Williams, 11 - 41. London: Frank Cass Publishers.

Bebbington, Anthony and Roger Riddell. 1997. Heavy hands, hidden hands, holding hands: Donors, intermediary NGOs and civil society organisations. In NGOs, States and Donors: Too Close for Comfort? eds. Hulme and Edwards 107-127. London: MacMillan.

Benford, Robert D. and David A. Snow. 2000. Framing processes and social movements: An overview and assessment. Annual Review of Sociology 26, 611-39.

Boswell, Christina and Jeff Crisp. 2004. Poverty, international migration and asylum. UN University-World Institute for Development Economics Research (UNU-WIDER) Policy Brief, no. 8. Helsinki, Finland: UNU-WIDER.

Brown, David L. and David C. Korten. 1991. Working more effectively with nongovernmental organizations. In Nongovernmental Organizations and the World Bank, eds. Samuel Paul and Arturo Israel, 44-93. Washington, DC: The World Bank. 
Cambodian Women's Crisis Centre (CWCC). 2002. Annual Global Report (JanuaryDecember). Phnom Penh: CWCC.

Canadian Council for Refugees (CCR). 2003. Trafficking in women and girls. Report of meetings (fall). Montreal: CCR.

Caouette, Therese M. 2001. Small Dreams Beyond Reach: The Lives of Migrant Children and Youth Along the Borders of China, Myanmar and Thailand. A Participatory Action Research Project of Save the Children (UK). Bangkok: Save the Children UK.

Castles, Stephen and Mark J. Miller. 2003. International Population Movements in the Modern World: The Age of Migration $3^{\text {rd }}$ edition. London: Guilford Press.

Chan, Joseph Man and Chin-Chuan Lee. 1991. Power change, co-optation, accommodation: Xinhua and the press in transitional Hong Kong. The China Quarterly 126 (June), 290-312.

CATW International. n.d. Thailand: Trafficking. The Factbook on Global Sexual Exploitation. http://www.catwinternational.org/fb/Thailand.html (accessed 12 August 2004).

Coalition Against the Traffic of Women (CATW). n.d. Prostitutes work, but do they consent? http://www.uri.edu/artsci/wms/hughes/catw (accessed 8 August 2004).

Commonwealth of Australia. 2003. Chapter three: Fighting terrorism and global threats to our security. In Advancing the National Interest: Australia's Foreign and Trade Policy Wbite Paper, 36-48. Canberra: Commonwealth of Australia.

Cooley, Alexander and James Ron. 2002. The NGO scramble: organizational insecurity and the political economy of transnational action. International Security 27(1) (Summer), 5-39.

Cress, Daniel M. and David A. Snow. 1996. Mobilization at the margins: Resources, benefactors, and the viability of homeless social movement organizations. American Sociological Review 61(6) (December), 1089-1109.

Dall'Oglio, Luca (Permanent Observer to the United Nations). 2004. Statement to UN General Assembly (Agenda item 96: Crime Prevention and Criminal Justice) (12 October). New York. http://www.iom.int/en/news/unga_96_121004.shtml (accessed 31 October 2004).

Danish Church Aid Cambodia [bome page]. http://www.bigpond.com.kh/users/dca/ (accessed 21 December 2003).

Dauvergne, Catherine. 2004. Sovereignty, migration and the rule of law in global times. Modern Law Review 67(4) (July), 588-615. Oxford: Blackwell Publishing.

de Fonseka, Chandra. 1995. Challenges and future directions for Asian NGOs. In Government-NGO Relations in Asia: Prospects and Challenges for People Centred Development, eds. Noeleen Heyzer, James V. Riker and Antonio B. Quizon, 57-76. NY: St Martin's Press.

de Haan, Arjan. 2000. Migrants, livelihoods, and rights: The relevance of migration in development policies. Social Development Working Paper No. 4. DFID.

Development and Education Programme for Daughters and Communities Centre (DEPDC). 2003. DEPDC in detail. Mae Sai: DEPDC.

DEPDC. 2002. DEPDC Fact sheet. Mae Sai: DEPDC.

DEPDC. 1999. DEPDC: 10 Years of lessons learned 1989-99. Mae Sai: DEPDC. 
Doezema, Jo. 2001. Ouch! Western feminists' 'wounded attachment' to the third world prostitute. Feminist Review 67 (Spring), 16-38.

Doezema, Jo. 2002. Who gets to choose? Coercion, consent and the UN Trafficking Protocol. http://www.walnet.org/csis/papers/doezema-choose.html (accessed 6 August 2004) [a later version of the paper is published in Gender and Development 19(1) (March)].

Downer, Alexander (Minister for Foreign Affairs, Australia). 2004. Speech to the Bali Process Senior Officials'Meeting (8 June). Queensland.

Eckstein, Susan. 1976. The irony of organization: resource and regulatory. British Joumal of Sociology 27(2) (June), 150-164.

Edwards, Michael and David Hulme. 1996. Introduction: NGO performance and accountability. Beyond the Magic Bulled: NGO Performance and Accountability in the Post-Cold War World, ed. Edwards and Hulme, 1-20. West Hartford, CT: Kumarian Press.

Evans, Catrin and Pankaja Bhatterai. 2001. What is trafficking? The Kathmandu Telegraph (07 March). http://www.mahilaweb.org/footer/publications/articles/trafficking_telegraph.htm (accessed 01 March 2003).

Fyvie, Claire and Alastair Ager. 1999. NGOs and innovation: Organizational characteristics and constraints in development assistance work in the Gambia. World Development 27(8), 1383-1395.

Geddes, Andrew J. 2000. Immigration and European Integration: Towards Fortress Europe? Manchester: Manchester U. Press.

Gesellschaft für Technische Zusammenarbeit (GTZ). 2004. Working Together with the Diaspora: A New Direction for International Development Cooperation? (GTZ Meeting of Experts 3 - 4 May). Berlin. www.gtz.de/migration-and-development/english/ (accessed 26 October 2004)

Global March Against Child Labour. 2000. Out of the Shadows: $A$ Worldwide Report on the Worst Forms of Child Labour 2000 New Delbi, India. www.globalmarch.org/worstformsreport/ (accessed 28 February 2004).

Goffman, Erving. 1974. Frame Analysis. New York: Harper and Row.

Gothard, Jan. 2001. Wives or workers? Single British female migration to colonial Australia. In Women, Gender and L abour Migration: Historical and Global Perspectives, ed. Pamela Sharpe, 145-162. London: Routledge.

Harzig, Christiane. 2001. Women migrants as global and local agents: New research strategies on gender and migration. In Women, Gender and Labour Migration: Historical and Global Perspectives, ed. Pamela Sharpe, 15-28. London: Routledge.

Henkes, Barbara. 2001. Maids on the move: Images of femininity and European women's labour migration during the interwar years. In Women, Gender and Labour Migration: Historical and Global Perspectives, ed. Pamela Sharpe, 224- . London: Routledge.

Heyzer, Noeleen. Toward new government-NGO relations for sustainable and peoplecentred development. In Government-NGO Relations in Asia: Prospects and Challenges for People Centred Development, eds. Noeleen Heyzer, James V. Riker and Antonio B. Quizon (Eds.), St Martin's Press, Inc., 1995, NY. 1-13. 
House of Commons International Development Committee (UK). 2004. Migration and Development: How to make migration work for poverty reduction (Sixth Report of Session 20032004, volume 1). London: The Stationery Office.

Hulme, David and Michael Edwards. 1997. NGOs, States \& Donors: An Overview. In NGOs, States and Donors, eds. Hulme and Edwards, 3-22. New York: St. Martin's Press.

Human Rights Caucus. 1999. Recommendations and commentary on the draft protocol to combat international trafficking in women and children supplementary to the draft convention on transnational organised crime. www.hrlawgroup.org/site/programs/traffic (accessed

Human Rights Watch (HRW). 2002. Bosnia and Herzegovina bopes betrayed: Trafficking of women and girls to post-conflict Bosnia and Herzegavina for forced prostitution 14(9D) (November). New York: HRW.

Human Rights Watch (HRW). 2004. Out of Sight, Out of Mind: Thai Policy Toward Burmese Refugees 16 (2C) (February). New York: HRW.

Igoe, Jim. Scaling up civil society: Donor money, NGOs and the pastoralist land rights movements in Tanzania. Development and Change 34(5), 863-885. Oxford UK: Blackwell Publishing.

International Labour Organization (ILO). 2003. Phase II [Project Document]. Bangkok: ILO.

ILO. 2002. Thailand TICW project overview (June). Bangkok: ILO.

ILO. 2002. Sharing Experience and Lessons Learned (SELL) Notes. Bangkok: ILO.

ILO. 2002. Summary Notes: Technical Intervention Areas (TLAs). Bangkok: ILO.

ILO. 2001. Labour and Trafficking within the Greater Mekong Subregion: Proceedings of Mekong subregional experts meeting and exploratory policy paper. Bangkok: ILO.

International Organisation of Migration (IOM). 2001. Trafficking in Migrants: Quarterly Bulletin (April). IOM.

Jenkins, J. Craig and Craig M. Eckert. 1986. Channeling black insurgency: Elite patronage and professional social movement organizations in the development of the black movement. American Sociological Review 51(6) (December), 812-829.

Joachim, Jutta. 2002. Comparing the influence of NGOs in transnational institutions: The UN, the $E U$ and the case of gender violence. Presented at the $43^{\text {rd }}$ Annual Convention of the International Studies Association. (March 24-27). New Orleans. http://wwwisanet.org/noarchive/Joachim.html (accessed 15 November 03)

Jordan, Ann D. 2002. The Annotated Guide to the Complete UN Trafficking Protocol. Washington DC: Human Rights Law Group.

Jordan, Ann D. 2001. Trafficking in human beings: The slavery that surrounds us. Global Issues 6(2) (August), 15-18. Washington DC: US Department of State. http://usinfo.state.gov/journals/itgic/0801/ijge/ijge0801.pdf (accessed 26 October 2004).

Keck, Margaret E. and Kathryn Sikkink. 1999. Transnational Advocacy Networks in International and Regional Politics. UNESCO. Oxford: Blackwell. 
Korten, David C. and Antonio B. Quizon. 1995. Government, NGO and international Agency cooperation: Whose agenda? In Government-NGO Relations in Asia: Prospects and Challenges for People Centred Development, eds. Noeleen Heyzer, James V. Riker and Antonio B. Quizon, 131-164. NY: St Martin's Press.

Laczko, Frank. 2002. Human trafficking: The need for better data. IOM.

Legros, Pierre. 2004. Re: Announcement from Oxfam GB, Hanoi, Viet Nam [twcclist 679] (06 January).

Levine, Arielle. 2002. Convergence or convenience? International conservation NGOs and development assistance in Tanzania. World Development 30(6), 1043-1055.

MAG. n.d. Project to Combat Trafficking [on-line] www.mirrorartgroup.org/web/projects/proj-traffic.html (accessed 14 August 2004).

Marshall, Phil. 2001. Globalization, migration and trafficking: Some thoughts from the South East Asia Region. Trafficking in Women and Children in the Mekong Sub-region. Bangkok: UN-IAP.

Marshall, Phil. 2001. The Trojan Horse and other worries. Step By Step Newsletter (Third Quarter). Bangkok: UN-IAP.

Maslyukivska, Olena P. 1999. Role of nongovernmental organizations in development cooperation. UNDP/Yale Collaborative Programme Researcb Clinic. New Haven. httip://www.undp.org/ppp/library/files/maslyu01.html (accessed 06 August 2004).

Matenga, Chrispin Radoka. 2001. The changing orientation and practice of northern NGOs: Implications for African development. Presented at the Southern African Universities Social Science Conference (SAUSSC) 22nd Biannual Conference: Debt Relief Initiatives and Poverty Alleviation: Lessons from Africa (1 - 5 December). Windhoek, Namibia.

McAdam, D., J. D. McCarthy, and M. N. Zald. 1996. Introduction: Opportunities, mobilizing structures, and framing processes: Toward a synthetic, comparative perspective on social movements. In Comparative Perspectives on Social Movements, eds. D. McAdam, J. D. McCarthy, and M. N. Zald, 1-20. Cambridge: Cambridge University Press.

Memorandum of Understanding Between the Government of the Kingdom of Thailand and the Government of the Kingdom of Cambodia on Cooperation in the Employment of Workers signed 31 May 2003. Ubon Ratchatani (Thailand) by the Ministers of Labour (Thai Ministry of Labour; Cambodian Ministry of Social Affairs, Labour, Vocational Training and Youth Rehabilitation (MOSALVY).

Memorandum of Understanding Between the Government of the Kingdom of Thailand and the Government of the Kingdom of Cambodia on Bilateral Cooperation for Eliminating Trafficking in Children and Women and Assisting Victims of Trafficking signed on 31 May 2003 in Siem Reap (Cambodia) (Thai Minister of Social Development and Human Security; Cambodian Minister of MOSALVY).

Meyer, Carrie A. 1995. Opportunism and NGOs: Entrepreneurship and green North-South transfers. World Development 23(8), 1277-1289. 
Miko, Francis T. 2004. Congressional Research Service (CRS) Report for Congress: Trafficking in Women and Children: The US and International Response (Order Code R130545). Washington DC: Library of Congress.

Mirror Art Group (MAG). n.d. Projects [on-line]. http://www.mirrorartgroup.org/web/projects/index.htm (accessed 14 August 2004).

Mohanty, Chandra Talpade. 1991. Under western eyes: Feminist scholarship and colonial discourses. In Third World Women and the Politics of Feminism, eds. Chandra Talpade Mohanty, Ann Russo and Lourdes Torres, 51-80. Indianapolis: Indiana U. Press.

Najam, Adil. 1996. NGO accountability: A conceptual framework. Development Policy Review 14(4) (December), 339-353.

Ness, Gayl D. and Steven R. Brechin. 1988. Bridging the gap: International organizations as organizations. International Organization 42(2) (Spring), 245-73.

Niessen, Jan. 2004. International migration and relations with third countries: The European Union. EU and US approaches to the management of immigration, eds. Jan Niessen, Yongmi Schibel and Raphaele Magoni. Brussels: Migration Policy Group. http://www.migpolgroup.com/publications (14 October 2004).

Niessen, Jan and Yongmi Schibel. 2003. EU and US approaches to the management of immigration: Comparative Perspectives. EU and US approaches to the management of immigration, eds. Jan Niessen, Yongmi Schibel and Raphaele Magoni. Brussels: Migration Policy Group. http://www.migpolgroup.com/publications (14 October 2004).

O'Briain, Maurieann. 2001. Anti-Trafficking Programs in South Asia: Appropriate Activities, indicators and Evaluation Methodologies: Summary Report of a Technical Consultative Meeting, comp. Dale Huntington. New Delhi: Population Council, 2001.

Organisation for Economic Co-operation and Development. 1993. Migration and International Co-operation: Challenges for OECD Countries (conference organised by the OECD, Canada and Spain; Madrid 29-31 March). Paris: OECD.

Organisation for Economic Co-operation and Development Development Co-operation Directorate (OECD-DAC). Development Co-operation Directorate (DAC) Home-page [online]. www.oecd.org (accessed 18 October 2004).

OECD-DAC. n.d. International Development Statistics (IDS) online: Databases on aid and other resources flows. www.oecd.org/dataoecd/50/17/5037721.htm (accessed 31 October 2004).

Patt, Martin. n.d. Human Trafficking and Modern-day Slavery. http://gvnet.com/humantrafficking/ (accessed 26 October 2004).

Pearce, Jenny. 2000. Introduction. Development, NGOs and Civil Society. Development in Practice Reader. Oxford: Oxfam Great Britain. www.developmentinpractice.org/readers/NGOs/intro.htm (accessed 22 October 2004).

Pearce, Jenny. 1997. Between co-option and irrelevance? Latin American NGOs in the 1990s. In NGOs, States and Donors, eds. Hulme and Edwards, 257-274. New York: St. Martin's Press. 
Pedersen, Peder J., Mariola Pytlikova and Nina Smith. 2004 Selection or Network Effects? Migration Flows into 27 OECD Countries, 1990-2000. IZA Discussion Paper No. 1104 (April). http://ssrn.com/abstract=527144 (accessed 22 October 2004).

Pheterson, Gail. 1996. The Prostitution Prism, 7- 26. Amsterdam: Amsterdam U Press.

Phongpaichit, Pasuk. 1999. Trafficking in People in Thailand. In Illegal Immigration and Commercial Sex: The New Slave Trade, ed. Phil Williams, 74-104. London: Frank Cass.

Piper, Nicola and Anders Uhlin. 2002. Transnational advocacy networks, female labor migration and trafficking in East and Southeast Asia: A gendered analysis of opportunities and obstacles. Asian and Pacific Migration Joumal 11(2), 171-95.

Piper, Nicola. 2003. Identification of the Obstacles to the Signing and Ratification of the UN Convention on the Protection or the Rights of All Migrant Workers 1990: The Asia Pacific Perspective. UNESCO. http:// www.metropolis2003.at/en/WS2.5Piper02.pdf (accessed 12 December 03).

Piper, Nicola and Robyn Iredale. 2002. Identification of the Obstacles to the Signing and Ratification of the UN Convention on the Protection of the Rights of All Migrant Workers and Members of their Families (Research project APMRN). UNESCO. http://www.unesco.org/most/apmrn.htm (accessed 26 October 2004).

Population Council. 2001. Anti-trafficking Programs in South Asia: Appropriate Actions, Indicators and Evaluation Methodologies: Summary report of Technical Consultative Meetings in Nepal. Nepal: Population Council.

Programme de Développement Cambodge - Canada (PDCC). Vocational Training Program for Women [on-line]. http://www.pdcc-ccdp.ca/anglais/html/liste.html (accessed 14 August 2004).

Ralph, Regan E. 2000. Background briefing: International Trafficking of Women and Children. Senate Commission on FR Sub-commission on Near East and S. Asian Affairs [testimony]. Human Rights Watch.

Ratha, Dilip. 2003. Workers' remittances: An important and stable source of external development finance (Chapter 7). In World Bank Group Global Development Finance: Striving for Stability in Development Finance World Bank, 157-175.

Raymond, Janice G. 2002. The new UN Trafficking Protocol. Women's Studies International Forum 25(5), 491-502.

Reale, Daniela. 2003. Mapping and Analysis of SC UK's Work on Trafficking. London: SC UK.

Ricker, Tom and Dale W. Wimberley. 2003. Global networking in the $21^{\text {st }}$ century: Labour rights movements and Nicaragua's maquilas 2000-2001. In Crises and Resistance in the $21^{\text {st }}$ Century World-System, ed. Wilma A. Dunaway. Westport, CT: Greenwood Press.

Riker, James V. 1995b. From cooptation to cooperation and collaboration in governmentNGO relations: Toward an enabling policy environment for people-centred development in Asia. In Government-NGO Relations in Asia: Prospects and Challenges for People Centred Development, eds. Noeleen Heyzer, James V. Riker and Antonio B. Quizon, 91-130. NY: St Martin's Press.

Riker, James V. 1995a. Contending perspectives for interpreting government-NGO relations in South and Southeast Asia: Constraints, challenges and the search for common ground in rural development. In Government-NGO Relations in Asia: Prospects and 
Challenges for People Centred Development, eds. Noeleen Heyzer, James V. Riker and Antonio B. Quizon, 14-55. NY: St Martin's Press.

Rowlands, Dane. 1998. International Migration and Development: Poverty and environmental degradation as root causes of international migration: a critical assessment. Presented to Technical Symposium on International Migration and Development (29 June - 3 July). Netherlands: The Hague.

Sabieszczyk, Teresa. 2000. Pathways abroad: Gender and international migration recruitment choices in northern Thailand. Asian and Pacific Migration Journal 9(4), 391-428.

Saith, Ashawani. Migration processes and policies: Some Asian perspectives. Asian and Pacific Migration Journal 8(3), 285-311.

Sanghera, Jyoti. 1998. Trafficking of Women and Children in South Asia: Taking Stock and Moving Ahead: A review of anti-trafficking initiatives in Nepal, Bangladesh and India (Draft). Published 1999 (November) UNICEF and Save the Children Alliance.

Sanghera, Jyoti. 2002. Trafficking of Children and Women in India: Thinking Through, Thinking Beyond: A Critical Framework of Analysis for Strategic Action (Draft for Discussion). India: UNICEF India.

Sarasúa, Carmen. 2001. Leaving home to help the family: Male and female temporary migrants in eighteenth and nineteenth-century Spain. In Women, Gender \& Labour Migration: Historical and Global Perspectives, ed. Pamela Sharpe, 29-59. London: Routledge.

Sassen, Saskia. 1999. Beyond sovereignty: De-facto transnationalism in immigration policy. European Journal of Migration and Law 1, 177-98. Netherlands: Kluwer Law International.

Save the Children Alliance (SCA). 2001. Comparative Study of the Legal Provisions of the 6 Countries in the Mekong Subregion with respect to Trafficking in Women and Children. Bangkok: SCA.

Save the Children UK (SC UK). 2001. Breaking Through the Clouds: A Participatory Action Research (PAR) Project with Migrant Children and Youth Along the Borders of Cambodia, Myanmar and Thailand. Bangkok: SC UK.

SC UK. 2002. Cross-border Community-based Initiatives Against Trafficking in Children in the Mekong Sub-Region. Bangkok: SC UK.

Scholdan, Bettina. 2000. Addressing the root causes: Relief and development assistance between peacebuilding and preventing refugee flows. The Journal of Humanitarian Assistance (June). Bradford UK: Department of Peace Studies, Bradford University. http://www.jha.ac (accessed 26 October 2004).

Shamim, Israt. 2003. Women and Children Trafficking: Myths and Realities. Paper delivered at Sixth Sustainable Development Conference of the Sustainable Development Policy Institute (11-13 December). Islamabad.

http://www.sdpi.org/sdc_2003/sdcMain.htm (accessed 26 October 2004).

Sharpe, Pamela. 2001. Introduction. In Women, Gender and Labour Migration: Historical and Global Perspectives, ed. in Pamela Sharpe, 1-14. London: Routledge. 
Skeldon, Ronald. 2001. Irregular migration in the Greater Mekong Sub-region: Policy dimensions of a growing issue (exploratory policy paper for ILO and UN-IAP). In Labour and Trafficking witbin the Greater Mekong Subregion: Proceedings of Mekong subregional experts meeting and exploratory policy paper, 35-75. Bangkok: ILO.

Snow and Benford. 2000. Clarifying the relationship between framing and ideology in the study of social movements: A comment on Oliver and Johnston.

http://www.ssc.wisc.edu/ oliver/PROTESTS/articlecopies/snowbenfordresponse.p df (accessed 15 November 03).

Snow, David A. and Robert D. Benford. 1988. Ideology, frame resonance, and participant mobilization. International Social Movement Researcb 1, 197-217.

Snow, David A., E. Burke Rochford, Jr., Steven K. Worden, Robert D. Benford. 1986. Frame alignment processes, Micromobilization, and movement participation. American Sociological Review 51(4) (August), 464-481.

Stahl, Charles W. 1995. Theories of international labor migration: An overview. Asian and Pacific Migration Journal 4(2/3), 211-32.

Stark, Oded. 1991. The Migration of Labour. Oxford: Blackwell.

Stasiulis, Daiva K. 1997. International migration, rights and the decline of 'actually existing liberal democracy.' New Community 23(2) (April), 197-214. London: Carfax Publishing Limited.

Stasiulis, Daiva K. and Abigail B. Bakan. 2003. Negotiating Citizenship: Migrant Women in Canada and the Global System. NY: Palgrove Macmillan.

Stern, Aaron. 1997. Quantitative international migration data for Thailand: An overview. Asian and Pacific Migration Journal 6(2), 229-54.

Stop Violence Against Women. n.d. Historical Overview of the UN Perspective on Trafficking. www.stopvaw.org (accessed 06 August 2004).

Sullivan, Barbara. 2003. Trafficking in women: Feminist and new international law. International Feminist Journal of Politics 5(1) (March), 67-91.

Tarrow, Sidney. n.d. Beyond globalization: Why creating transnational social movements is so hard and when is it most likely to happen. Global Solidarity Dialogue [on-line] http://www.antenna.nl/ waterman/tarrow.html (accessed 06 August 2004).

Themudo, Nuno. 2002. Managing the paradox: NGOs, resource dependence and political independencecase studies from Portugal and Mexico. Presented at the International Society for Third Sector Research (ISTR) Fifth International Conference Transforming Civil Society, Citizenship and Governance: The Third Sector in an Era of Global (Dis)Order. Cape Town, South Africa (July 7-10). www.jhu.edu/ istr/ (accessed 28 October 2004).

Todaro, Michael P. and Stephen C. Smith. 2003. Economic Development $8^{\text {th }}$ ed. Toronto: Addison-Wesley.

Tumlin, Karen C. 2000. Trafficking in children and women: A regional overview. From Asian Regional High-Level Meeting on Child Labour (Jakarta 8-10 March 2000). Thailand: Chulalongkorn University.

United Nations (UN). 1945. UN Charter. San Francisco: UN.

UN Convention on the Rights of the Child (CRC). 1989. http://www.unicef.org/crc/fulltext.htm (accessed 12 December 03). 
UN Development Fund for Women (UNIFEM). n.d. Trafficking in Persons: A Gender Rights Perspective (Briefing Kit). Bangkok: UNIFEM. http://www.unifemeseasia.org/resources/traffick2.html (accessed 18 December 2002).

UN Development Programme (UNDP) Civil Society Organizations and Participation Programme (CSOPP). 1998. Policies and Procedures: Procedure for Programme Executioning by an NGO. http://www.undp.org/csopp/CSO/NewFiles/policiesngo.html (accessed 22 October 2004).

UN Educational, Scientific and Cultural Organisation (UNESCO). n.d. Trafficking Project. www.unescoblkk.org/culture/trafficking/ (accessed 28 February 2004).

UN High Commissioner on Human Rights (UNHCHR). 2003. Convention on Protection of Rights of Migrant Workers to Enter into Force Next July [press release]. www.unhchr.ch (accessed 2004 August 28).

UN HCHR. International Convention on the Protection of the Rights of All Migrant Workers and Members of Their Families. www.ohchr.org/english/law/cmw.htm (accessed 28 August2004).

UN IFEM. 2001. Violence Against Women NGO Projects, Cambodia. UNIFEM East and South East Asia Regional Office. http://www.unifemeseasia.org/projects/evaw/vawngo/vamcam.htm (accessed 14 August 2004).

UN Inter Agency Project to Combat Human Trafficking (UN-IAP). n.d. [web site]. www.un.or.th/traffickingproject (accessed 20 August 2003).

UN Non-Governmental Liaison Service (NGLS). 1995. Cballenges for the 21st Century. 20th Anniversary Conference on The United Nations, NGOs and Global Governance. (30 October-1 November). Geneva.

UN Office of the High Commissioner for Human Rights (OHCHR). 1999. Informal note by the United Nations High Commissioner for Human Rights UN Doc. A/AC.254/16 (1 June 1999). http://www.unhchr.ch/Huridocda/Huridoca.nsf (accessed 18 October 2004).

UN OHCHR. 2001. Trafficking in Persons. UN OHCHR. http://www.unhchr.ch/women/focus-trafficking.html (accessed 18 October 2004).

UN Office on Drugs and Crime (UN ODC). 2004. Untitled [on-line]. http://www.unodc/org (accessed 14 August 2004).

UN ODC. 2000. Protocol Against the Smuggling of Migrants by Land, Sea and Air, Supplementing the United Nations Convention Against Transnational Organized Crime.

UN ODC. 2000. Protocol to Prevent Suppress and Punish Trafficking in Persons, Especially Women and Children, Supplementing the United Nations Convention Against Transnational Organized Crime. UN ODC.

UN ODC. n.d. Summary: The Protocol to Prevent, Suppress and Punish Trafficking in Persons. UN ODC. http://www.unodc.org/unodc/en/trafficking_protocol.html (accessed 31 October 2004). 
UN Secretary-General. 2001. Note of the Secretary-General to the $57^{\text {th }}$ Session of the Commission on Human Rights, Smuggling and Trafficking in Persons and the protection of their Human Rights UN Doc. E/CN.4/Sub.2/2001/26. http://www.unhchr.ch (accessed 14 August 2004).

UN Special Rapporteur on Violence Against Women, its causes and consequences, Radhika Commaraswamy. 2000. Integration of the Human Rights of Women and the Gender Perspective: Violence Against Women: Report of the Special Rapporteur on violence against women, its causes and consequences, Ms. Radbika Commaraswamy, on trafficking in women, women's migration and violence against women, submitted in accordance with Commission on Human Rights resolution 1977/44, (E/CN.4/2000/68) (29 February). ECOSOC Commission on Human Rights.

UN Special Rapportuer on the Sale of Children, child prostitution and child pornography, Ofelia Calcetas-Santos. 1998. Right of the Child: Report of the, Ms. Ofelia Calcetas-Santos Addendum: Mission of the Special Rapporteur to the Lao PDR on the issue of trafficking of children (September). ECOSOC.

UN Working Group on Contemporary Forms of Slavery. 2000. Contemporary Forms of Slavery: Report of the Working Group on Contemporary Forms of Slavery on its twenty-fifth session. (E/CN.4/Sub.2/2000/23) (21 July). Commission on Human Rights.

United States (US) Department of Health and Human Services. 2004. Fact Sheet: Human Trafficking. www.acf.hhs.gov/trafficking/about/fact_human.html (accessed 26 October 2004).

United States (US) Department of State. 2003. Bush signs national security directive against human trafficking. (25 February). http://usinfo.state.gov/gi/Archive/2003/Jun/10239581.html (accessed 28 February 2004).

US Department of State. 2004. Trafficking in Persons Report 2004. www.state.gov/g/tip/rls/tiprpt/2004/ (accessed 10 September 2004)

US Department of State. 2003. Trafficking in Persons Report 2003. www.state.gov/g/tip/rls/tiprpt/2003/ (accessed 10 August 2004)

US Embassy in Thailand. 2004. Supporting Human Rights and Democracy: The U.S. Record 2003 - 2004 Thailand (issued May 17). http://bangkok.usembassy.gov/services/docs/reports/supporthr0304.htm (accessed 12 August 2004).

Vakil, Anna C. 1997. Confronting the classification problem: Toward a taxonomy of NGOs. World Development 25(12), 2057-2070.

van Impe, Kristof. 2000. People for sale: The need for a multidisiciplinary approach towards human trafficking. International Migration (Special Issue 2000/2001), 113-131. IOM.

Welch, David A. 1992. The organizational process and bureaucratic politics paradigms: Retrospect and prospect. International Security 17(2) (Autumn), 112-146.

Widgren, Jonas and Philip Martin. 2002. Managing Migration: The Role of Economic Instruments. Expert Working Paper prepared for the Centre for Development Research study: Migration-Development Links: Evidence and Policy Options. Copenhagen: Centre for Development Research.

http://www.cdr.dk/migdevwall/papers/ManagingMigration.doc\#_Toc4486125 (accessed 01 November 2004). 
Williams, Phil. 1999. Human commodity trafficking: An Overview. In Illegal Immigration and Commerial Sex: The New Slave Trade, ed. Phil Williams, 1-10. London: Frank Cass Publishers.

Wong Sak Hoi, Geraldine. 2004. Of Golden Ventures: The quest for a comprehensive approach to addressing global smuggling in migrants and trafficking in persons. Ottawa: Carleton U.

World Bank Group (WB). The World Bank staff's grassroots communities experience: Learning from grassroots communities to enbance corporate social responsibility, learn lessons from the poor. n.d. www.worldbank.or.th/wbsite/external/countries/eastasiapacificext/thailandextn (accessed 12 August 2004).

WB. 2003. Social Capital Home Page. : www.worldbank.org/poverty/scapital (accessed 12 December 2003).

WB Operation Policies and Country Services (OPCS). n.d. LogFrame. http://opcs.worldbank.org/me/bank_operations/logframe.html (accessed 12 December 2003).

WB. 2003. Social Capital Home Page. http://www.worldbank.org/poverty/scapital (accessed 12 December 2003). 